\title{
Mongolia: Report on the Observance of Standards and Codes- Data Module, Response by the Authorities, and Detailed Assessment Using the Data Quality Assessment Framework (DQAF)
}

This Report on the Observance of Standards and Codes on Data Module for Mongolia was prepared by a staff team of the International Monetary Fund as background documentation for the periodic consultation with the member country. It is based on the information available at the time it was completed on March 27, 2008. The views expressed in this document are those of the staff team and do not necessarily reflect the views of the government of Mongolia or the Executive Board of the IMF.

The Response by the Authorities to this report, and the Detailed Assessments Using the Data Quality Assessment Framework (DQAF) are also included.

The policy of publication of staff reports and other documents by the IMF allows for the deletion of market-sensitive information.

Copies of this report are available to the public from

International Monetary Fund $\bullet$ Publication Services

700 19th Street, N.W. • Washington, D.C. 20431

Telephone: (202) 6237430 • Telefax: (202) 6237201

E-mail: publications@imf.org • Internet: http://www.imf.org

Price: $\$ 18.00$ a copy

\section{International Monetary Fund Washington, D.C.}



INTERNATIONAL MONETARY FUND

MONGOLIA

\section{Report on the Observance of Standards and Codes (ROSC)_Data Module}

\section{Volume I}

Prepared by the Statistics Department

Approved by Robert W. Edwards and David Burton

March 27, 2008

The Report on the Observance of Standards and Codes (ROSC)—Data Module provides an assessment of Mongolia's macroeconomic statistics against the General Data Dissemination System $(G D D S)$ complemented by an assessment of data quality based on the IMF's Data Quality Assessment Framework (DQAF) July 2003. The DQAF lays out internationally accepted practices in statistics, ranging from good governance in data-producing agencies to practices specific to datasets.

The datasets covered in this report are national accounts, consumer price index, government finance, monetary, and balance of payments statistics. The agencies that compile the datasets assessed in this report are the National Statistical Office (NSO), the Ministry of Finance (MOF), and the Bank of Mongolia (BOM). The NSO compiles the national accounts and price statistics, the MOF compiles the government finance statistics, and the BOM compiles the monetary and balance of payment statistics.

The datasets to which this report pertains can be accessed in print and on the Internet:

NSO: http://www.nso.mn/eng/index.php

MOF: http://www.mof.pmis.gov.mn

BOM: www.mongolbank.mn

This report is based on information provided prior to and during a staff mission from September 17-28, 2007 and publicly available information. The mission team comprised S. Rajcoomar (Head), Thomas Alexander, Ulhas Gunjal, Alberto Jimenez de Lucio, Robert Dippelsman, Shelley Winston, and Sonia Bright (all STA). 
Contents Page

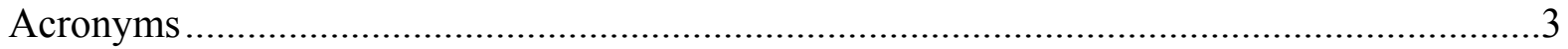

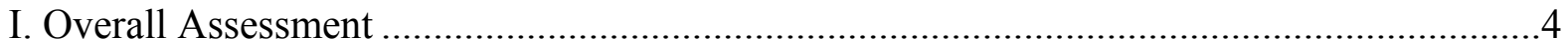

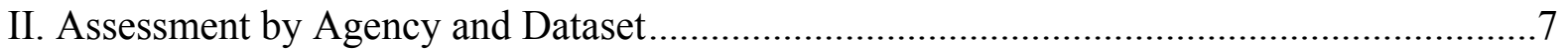

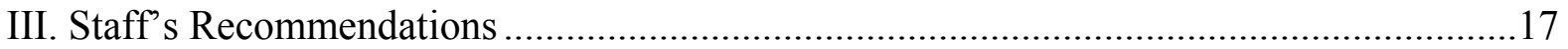

Tables

1. Data Quality Assessment Framework July 2003-Summary Results.............................8

2a. Assessment of Data Quality_Dimensions 0 and 1-National Statistical Office ..............9

2b. Assessment of Data Quality_-Dimensions 0 and 1-Ministry of Finance ......................10

2c. Assessment of Data Quality_Dimensions 0 and 1-Bank of Mongolia.........................11

3a. Assessment of Data Quality_Dimensions 2 to 5-National Accounts ...........................12

3b. Assessment of Data Quality_Dimensions 2 to 5-Consumer Price Index ......................13

3c. Assessment of Data Quality_-Dimensions 2 to 5-Government Finance Statistics......... 14

3d. Assessment of Data Quality-Dimensions 2 to 5-Monetary Statistics..........................15

3e. Assessment of Data Quality_Dimensions 2 to 5-Balance of Payments Statistics.........16

Appendix Table

Appendix Table 4. Practices Compared to the GDDS Coverage, Periodicity, and Timeliness of Data 


\section{ACRONYMS}

1993 SNA

BOM

BPM5

CPI

DQAF July 2003

DSBB

GDDS

GDP

GFMIS

GFS

GFSY

GFSM 1986

GFSM 2001

HIES

IMF

ITRS

MFSM

$\mathrm{MOF}$

NSO

ODC

ROSC

SDDS

STA
System of National Accounts 1993

Bank of Mongolia

Balance of Payments Manual, fifth edition

Consumer Price Index

Data Quality Assessment Framework, July 2003 version

Dissemination Standards Bulletin Board

General Data Dissemination System

Gross Domestic Product

Government Financial Management Information System

Government Finance Statistics

Government Finance Statistics Yearbook

A Manual on Government Finance Statistics, 1986

Government Finance Statistics Manual 2001

Household Income and Expenditure Survey

International Monetary Fund

International Transactions Reporting System

Monetary and Financial Statistics Manual

Ministry of Finance

National Statistical Office

Other Depository Corporations

Report on the Observance of Standards and Codes

Special Data Dissemination Standard

IMF Statistics Department 


\section{Overall ASSESSMent}

1. Mongolia was one of the earliest participants in the General Data Dissemination System (GDDS), posting its metadata on the Dissemination Standards Bulletin Board (DSBB) on August 7, 2000. Mongolia meets many of the GDDS recommendations for coverage, periodicity, and timeliness. The major exceptions include: the incomplete coverage of the international investment position; and the nonavailability of a primary commodity, agricultural, or other relevant production index; the producer price index; wages and earnings; and non-guaranteed private external debt; as well as the nondissemination of data on central government debt and government-guaranteed debt; public and publicly guaranteed external debt and debt service schedule; gross official reserves; and reserve-related liabilities. In some data categories, the coverage, periodicity, and timeliness meet the requirements of the Special Data Dissemination Standard (SDDS). However, the SDDS coverage requirements are not met with respect to wages and earnings, the producer price index, the international investment position, and central government and external debt statistics; in addition, the SDDS periodicity and timeliness requirements are not met with respect to the national accounts, interest rates, the stock market share price index, and international reserves and foreign currency liquidity. Appendix I provides an overview of Mongolia's dissemination practices compared to the GDDS.

2. Mongolia was also one of the earliest countries to participate in a data module assessment for the Report on the Observance of Standards and Codes (ROSC) - the assessment took place in May 2000 and the report was posted on the IMF web site in May 2001. The current ROSC is a reassessment based on the subsequently developed Data Quality Assessment Framework (DQAF), dating from July 2003, which is the IMF's instrument for assessing national statistical systems. The reassessment concludes that Mongolia's statistical system has made important progress in adopting internationally accepted statistical standards despite significant resource constraints that are compounded by rapid staff turnover and limitations on absorptive capacity. The statistical agencies covered in this report - the National Statistical Office (NSO), the Ministry of Finance (MOF), and the Bank of Mongolia (BOM) - have benefited from substantial technical assistance and staff training provided by numerous donors, including the IMF. Mongolia's statistical agencies demonstrate strong commitment to pursuing plans and programs to further upgrade statistics in response to the growing challenges posed by a rapidly evolving economy and in pursuit of the authorities' stated objective of subscribing to the SDDS over the medium term. Mongolia's macroeconomic statistics are generally adequate for conducting effective surveillance. However, the production and dissemination of official statistics is aimed primarily at serving the needs of the state and international organizations, and would need to be refocused to underpin, service, and support the data needs of private economic agents and the public at large.

3. The remainder of this section presents the mission's main conclusions by using the structure of the IMF's DQAF. The presentation is done at the level of the DQAF's quality dimensions, by agency for the first two dimensions and across datasets for the remaining four. Section II provides summary assessment tables of data quality by agency and dataset. This is followed by staff recommendations in Section III. 
4. Prerequisites of quality and assurances of integrity. All three agencies compiling and disseminating macroeconomic statistics operate within a supportive legal and institutional environment and demonstrate high levels of professionalism and ethical standards.

- $\quad$ The National Statistical Office operates within a legal framework that clearly defines its authority for compiling and disseminating national accounts and price statistics and allows it to perform an effective coordinating role in the field of macroeconomic and social statistics. Legal provisions are adequate for safeguarding the confidentiality of individual records and statistical reporting. However, resources for compiling national accounts and price statistics are not sufficient both in terms of personnel and physical facilities. The relevance of data is promoted through advisory groups and bilateral meetings although consultations with users are not undertaken in a systematic manner. Statistics are compiled on an impartial basis. The choices of sources and statistical techniques are influenced solely by statistical considerations. The NSO's statistical policy and practices are broadly transparent although no advance notice of changes in methodology, source data, and statistical techniques is provided. Staff conduct is guided by civil service rules and regulations.

- $\quad$ The Ministry of Finance operates within a legal and institutional environment that supports its responsibility for compiling and disseminating fiscal statistics. The laws allow the MOF to require the provision of information necessary to perform its functions, and mandates respondents to comply with its requests. While the GFS statistical work program is completed with existing resources, any new tasks, such as adoption of the methodology of the Government Finance Statistics Manual 2001 (GFSM 2001), will require additional resources. The needs of official users and international organizations are met, but the general public is given relatively low priority. Data quality is an integral part of MOF operations. The laws and regulations, together with the culture in the MOF, promote professionalism. The MOF's statistical policy and practices are generally transparent and staff conduct is guided by civil service rules and regulations.

- $\quad$ The Bank of Mongolia operates in a legal framework that provides a clear responsibility for producing and disseminating monetary statistics and implicitly for balance of payments statistics. Legal provisions ensure compliance with statistical reporting requirements and confidentiality of individual records. Formal arrangements exist to promote data sharing and coordination with other data producing agencies. Resources are adequate to undertake only the current statistical work program, but not for important developmental projects. The mechanisms to monitor and enhance the relevance of balance of payments statistics are sufficient. However, for monetary statistics, although an established process of regular consultation with users exists, the feedback so far has been modest. Adequate procedures are in place that focus on quality of data which are compiled with professional integrity. The BOM's statistical policy and practices are generally transparent, although no advance notice on major changes in methodology, source data, and techniques is provided. Staff conduct is guided by appropriate regulations and ethical standards. 
5. In general, concepts and definitions are methodologically sound, and in conformity with internationally accepted standards and practices. No formal decision has yet been taken by the authorities on adopting a migration path to the GFSM 2001 methodology. The scope of macroeconomic statistics suffers due to the non-coverage of several accounts and tables necessary for implementation of the System of National Accounts 1993 (1993 SNA), the compilation of a single consumer price index (CPI) with national coverage, and nonavailability of data on central government debt. All datasets follow international classification and sectorization guidelines, except that banking system net credit in government finance statistics is calculated as a residual and certain key accounting data in monetary statistics are misclassified. The basis for recording in all statistical areas is broadly appropriate and conforms with internationally accepted methodologies.

6. The accuracy and reliability of macroeconomic statistics is generally sound. Deficiencies in source data relate to the exclusion of small retail outlets from price collection as well as the implicit rent for owner-occupants in the CPI, the absence of data for extrabudgetary units for GFS compilation, and inadequacies in the enterprise survey undertaken for various balance of payments items. Suitable processes are used for assessment of source data and validation of intermediate and final statistical outputs, although the tight compilation schedule for the national accounts limits the comprehensiveness of the assessment exercise. The statistical techniques used to derive volume estimates for the national accounts are relatively weak and appropriate quality adjustment techniques are not applied to the CPI. With respect to balance of payments statistics, coverage of some important components is lacking and techniques to adjust for nonresponse to surveys are inadequate. Revision studies and analyses are generally not conducted for the national accounts, GFS, and monetary statistics.

7. Serviceability of macroeconomic statistics is adequate. The periodicity and timeliness of disseminated data exceed GDDS recommendations and in certain cases meet SDDS requirements. All statistics fulfill adequately the consistency parameters within each dataset, over time, and with other major datasets, except for important differences in financing data from the monetary and fiscal accounts that are not reconciled on a regular basis, and discrepancies in interbank positions between the central bank and other depository corporations. A number of deficiencies exist across all datasets with respect to revision policy, notably lack of dissemination of existing policies to the public, the absence of regular and transparent revision cycles, and the inappropriateness of the length of the cycle in the case of the national accounts.

8. Accessibility, for the most part, is satisfactory. While nonconfidential data (as defined by current legislation) are generally available to all users at the same time, no advance release calendar is posted with respect to dissemination of national accounts, CPI, and government finance statistics. The MOF publishes on its website the GDDS metadata posted on the IMF's DSBB. Comprehensive metadata for GFS are not currently disseminated. Assistance to users is adequate, except that the MOF does not indicate a contact point for fiscal statistics and neither the MOF nor the BOM provides a catalog of their publications. 


\section{Assessment by Agency And Dataset}

The assessment of the quality of five macroeconomic datasets - national accounts, consumer price index, government finance, monetary, and balance of payments statistics - was conducted using the Data Quality Assessment Framework (DQAF July 2003). In this section, the results are presented at the level of the DQAF elements and using a four-point rating scale (Table 1). Assessments of the prerequisites of data quality and the assurances of integrity (Dimensions " 0 " and " 1 " of the DQAF) are presented in Tables $2 \mathrm{a}-\mathrm{c}$. For each dataset, the assessment of methodological soundness, accuracy and reliability, serviceability, and accessibility (Dimensions "2" to " 5 " of the DQAF) are shown in Tables 3a-e. 
Table 1. Mongolia: Data Quality Assessment Framework July 2003—Summary Results

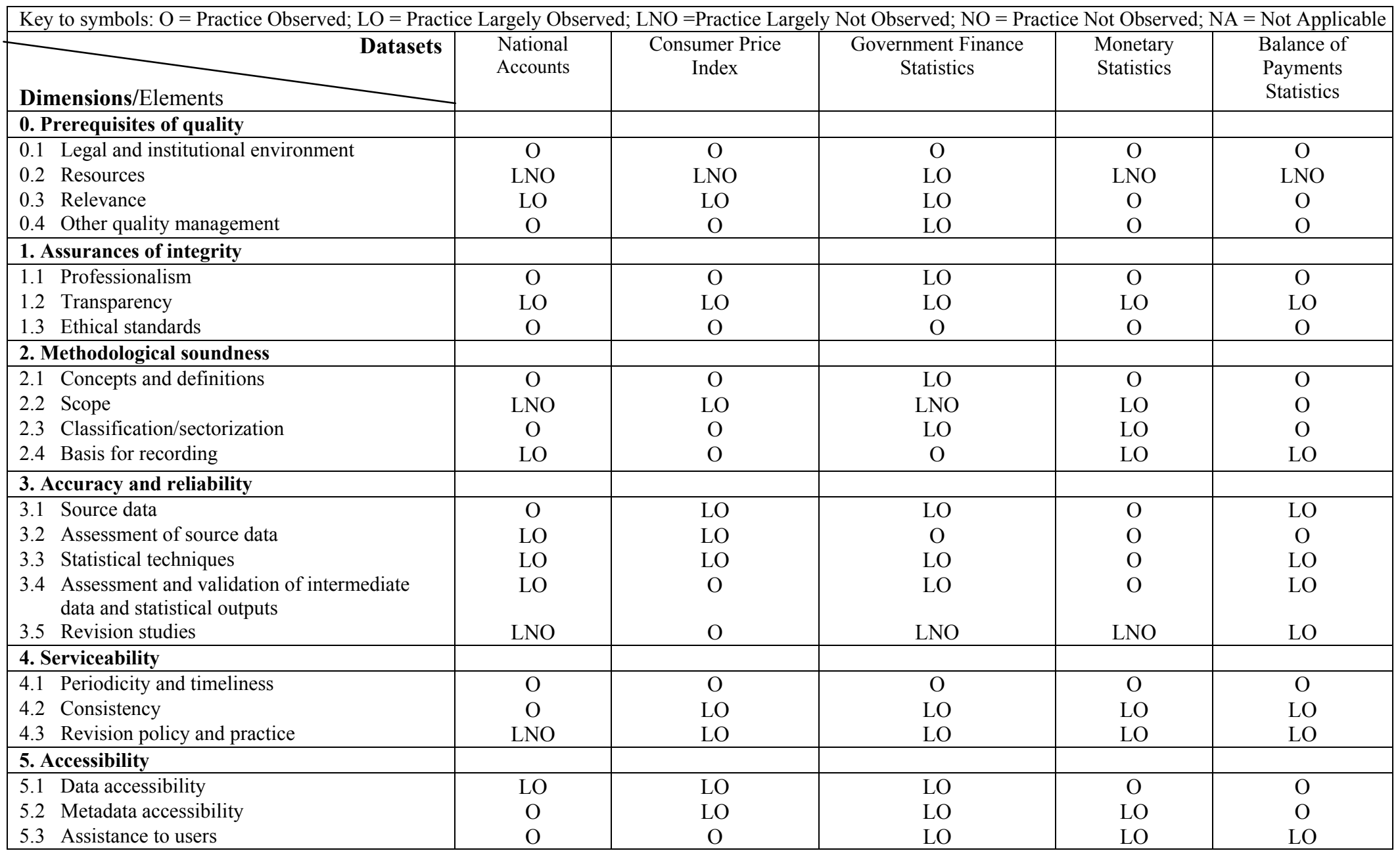

Practice observed: current practices generally in observance meet or achieve the objectives of DQAF internationally accepted statistical practices without any significant deficiencies. Practice largely observed: some departures, but these are not seen as sufficient to raise doubts about the authorities' ability to observe the DQAF practices. Practice largely not observed: significant departures and the authorities will need to take significant action to achieve observance. Practice not observed: most DQAF practices are not met. Not applicable: used only exceptionally when statistical practices do not apply to a country's circumstances. 


\section{Prerequisites of quality}

\section{Legal and institutional environment}

The legal and institutional environment for compiling the statistics is sound. The Law on Statistics of 1997 (amended 2004) gives the NSO the responsibility to compile and disseminate the national accounts and price statistics. The Law also gives the NSO the authority to coordinate the compilation of all official statistics. To fulfill this mandate, the agency has established working groups and signed memoranda of understanding on data sharing and cooperation with various other government agencies. It conducts regular meetings with these agencies. The Law provides respondents with assurances of confidentiality, and the NSO has established the necessary safeguards to ensure that the information on individual respondents is not divulged during data transmission, processing, or dissemination. The Law authorizes the NSO to collect all information from domestic units that it deems necessary to compile official statistics. The Law allows the NSO to penalize nonrespondents. However, efforts to encourage response have been relatively successful and the NSO has been able to record high survey response rates.

\section{Resources}

The staff resources for compiling the national accounts and price statistics are barely adequate to undertake the current work programs. The budget allocation from the central government constrains the ability of the NSO to recruit additional staff. Moreover, the physical facilities would not be able to accommodate any additional employees.

\section{Relevance}

The NSO consults regularly with users in the public sector through working group and bilateral meetings arranged in accordance with the respective memoranda of understanding. However, consultations with users in the private sector are not undertaken in a systematic manner.

\section{Other quality management}

The NSO has established a Methodology and Research Department to assist the management in monitoring the quality of the agency's output. The mission statement and medium-term program objectives stress the importance of quality.

\section{Assurances of integrity}

\section{Professionalism}

The NSO is an independent agency, and the chairman reports directly to the Parliament of Mongolia. The chairman is appointed to a fixed, but renewable, six-year term and his services may be terminated involuntarily if his performance is deemed unsatisfactory or if he is convicted of a criminal offence. The Law provides the chairman with sole authority for approving and adopting decisions relating to the management and organization of official statistics.

The choices of sources and statistical techniques are influenced solely by statistical considerations. Staff, with the occasional assistance of external experts, decide on the statistical techniques, methodology, and data sources to be employed based solely on the need to implement international statistical recommendations.

\section{Transparency}

The Law on Statistics is available on the web site of the NSO in Mongolian. In addition, the data collection instruments refer to the Law and advise respondents about their rights and responsibilities under the Law.

There is no internal access to statistics prior to their release. The products of the NSO are clearly identified by name and with the agency's logo.

When the NSO conducts exercises with other government agencies, the NSO is clearly identified as a contributor.

Apart from occasional announcements of the agency's work plans, the NSO provides no advance notice of changes in methodology, source data, and statistical techniques.

\section{Ethical standards}

Staff are subject to the internal rules of the NSO as well as the rules and regulations of the public service. They receive a copy of the rules and regulations upon recruitment and must take an oath of secrecy before they can have access to any information collected by the NSO. 


\section{Prerequisites of quality}

\section{Legal and institutional environment}

The responsibility for collecting, processing, and disseminating fiscal statistics is clearly assigned to the Ministry of Finance by the Budget Law and the Public Sector Management and Finance Law. The Law on Statistics explicitly refers to wide dissemination as one of the principles of statistical activities. However, Article 22 also states that the dissemination of information classified by the appropriate authorities as confidential is illegal.

The Financing, Accounting, and Reporting Division and the Debt Management Division of the MOF's Treasury Department are responsible for compiling the statistics on central and general government operations, and central government debt.

The confidentiality of data reported by individual persons and entities is protected by Article 9 of the Law on Statistics. Penalties are applied to individuals who infringe the law.

\section{Resources}

Additional staff will be required to perform new tasks, such as adoption of the methodology of the GFSM 2001, or to further improve the quality of the statistics currently compiled. A high priority is staff training in international methodologies. Sufficient resources are currently allocated to computing technology. A comprehensive performance evaluation system has been introduced for civil servants.

\section{Relevance}

Current fiscal statistics are mainly geared towards compliance with existing legislation. The needs of official users and international organizations are met, but the needs of the general public are not given high priority.

The subannual and annual fiscal statistics compiled are an integral part of the budget process, and are used to assess fiscal policy.

\section{Other quality management}

Management recognizes the importance of quality statistics, as evidenced by the introduction of the Treasury Single Accounts and the Government Finance Management Information System. Increased recognition needs to be given to incorporating international best practice, such as GFSM 2001, into the statistical program.

\section{Assurances of integrity}

\section{Professionalism}

The Law on Statistics states that one of the main principles guiding statistical activities is independence. A culture of professionalism is observed and no outside interference with statistical results is permitted. Recruitment is conducted through a competitive process based on candidates' qualifications for the position being filled. Processes and activities in the workplace that promote a culture of professionalism are also in place.

The choice of source data and statistical techniques is based exclusively on data and processing requirements. Decisions about the timing and other aspects of dissemination are based on statistical considerations and the timetable established by current legislation. However, the authorities may determine that certain specific data are confidential and dissemination may be deemed illegal. The MOF is entitled to comment on misinterpretation or misuse of statistics.

\section{Transparency}

The legislation that established the terms and conditions under which statistics are compiled and disseminated is publicly available on the web site of the Ministry of Justice. The fiscal statistics compiled by the MOF are available to senior officials prior to their general dissemination. This internal access is made public.

The identity of the agency responsible for compiling the data released to the public is clearly identified. The MOF is the only data producing agency that compiles fiscal statistics, and therefore is the only source of these statistics.

No advance notice of major changes in methodology and source data is provided. Rather, these changes are usually contained in legislation or are announced when the changes are introduced.

\section{Ethical standards}

The Civil Service Law includes provisions on the proper behavior of civil servants. These provisions are incorporated into the contract civil servants sign upon joining the service. In addition, civil servants must take an oath that includes a clause on correct behavior. Staff are reminded periodically of the ethical standards. 
Table 2c. Mongolia: Assessment of Data Quality_Dimensions 0 and 1- Bank of Mongolia

\section{Prerequisites of quality}

\section{Legal and institutional environment}

The BOM collects, compiles, and disseminates monetary and balance of payments statistics. The Law of Mongolia on Central Bank invests the BOM with the authority to collect source data for monetary and balance of payments statistics, to disseminate information on the state of monetary developments and financial markets, and to publish a monthly bulletin on monetary statistics. Monetary and balance of payments statistics compilers maintain adequate coordination with the other work units within the BOM from which source data are drawn. A working group on balance of payments includes data suppliers and BOM staff to coordinate data collection issues. The Law of Mongolia on Central Bank prohibits BOM staff from disclosing financial data collected from banks and other data suppliers.

\section{Resources}

Staff resources are adequate only to compile the Monetary Survey based on limited institutional coverage, but not for undertaking developmental projects, such as a Depository Corporations Survey with a broader institutional coverage. Staff resources for balance of payments statistics are not adequate to implement identified plans for improvement or to capture new developments in balance of payments statistics. Computing facilities are not adequate for largescale data processing required for balance of payments statistics or for automated data collection.

\section{Relevance}

The BOM monitors the relevance of monetary and balance of payments statistics. It encourages users to provide feedback on its monetary statistics by publicizing its contact list. However, relatively few users have provided any feedback on monetary statistics, while some changes have been made to the balance of payments publication in response to feedback.

\section{Assurances of integrity}

\section{Professionalism}

Staff at the BOM maintain a high degree of professionalism. The Law of Mongolia on Central Bank seeks to establish the independence of the BOM's top management from external intervention by identifying specific circumstances in which the Governor, First Deputy Governor, or Deputy Governor could be discharged from their posts.

Professionalism is supported within the BOM through a number of channels - for example, the process of recruiting and promoting staff, which takes into account a candidate's professional and educational qualifications, is primarily merit-based.

\section{Transparency}

The BOM's web site posts The Law of Mongolia on Central Bank, which presents the terms and conditions under which the BOM compiles monetary and balance of payments statistics. There is no internal governmental access to monetary and balance of payments statistics prior to release. The BOM's statistical publications clearly identify monetary and balance of payments statistics as the products of the BOM. The BOM does not give users an advance notice on major changes in methodology.

\section{Ethical standards}

The Law of Mongolia on Central Bank establishes the ethical standards for staff behavior.

\section{Other quality management}

The BOM reviews the quality of data prior to release. 
Table 3a. Mongolia: Assessment of Data Quality_Dimensions 2 to 5-National Accounts

\begin{tabular}{|c|c|c|c|}
\hline 2. Methodological soundness & 3. Accuracy and reliability & 4. Serviceability & 5. Accessibility \\
\hline $\begin{array}{l}\text { Scope } \\
\text { The scope of the national accounts does } \\
\text { not cover several accounts and tables } \\
\text { recommended by the Inter-Secretariat } \\
\text { Working Group on National Accounts } \\
\text { as being necessary to implement the } \\
1993 S N A \text {. The NSO disseminates } \\
\text { annual GDP by activity at current and } \\
\text { constant prices and expenditure on } \\
\text { GDP at current prices. However, the } \\
\text { sequence of accounts from the income } \\
\text { accounts, quarterly GDP, and annual } \\
\text { supply and use tables are not } \\
\text { disseminated. } \\
\text { Classification/sectorization } \\
\text { The classifications used to compile and } \\
\text { disseminate the estimates are consistent } \\
\text { with international standards. } \\
\text { Basis for recording } \\
\text { The recording of transactions and flows } \\
\text { is generally in line with international } \\
\text { best practice. Market prices are used to } \\
\text { value flows and stocks. All transactions } \\
\text { and flows, with the exception of } \\
\text { government transactions, are recorded } \\
\text { on an accrual basis. Transactions } \\
\text { between establishments in the same } \\
\text { enterprise are recorded net rather than } \\
\text { gross as recommended by the } \\
1993 S N A \text {. }\end{array}$ & $\begin{array}{l}\text { Source data } \\
\text { The source data are collected from a } \\
\text { comprehensive program that includes an } \\
\text { annual enterprise survey, a continuous } \\
\text { Household Income and Expenditure Survey } \\
\text { (HIES), and administrative data sources. } \\
\text { The data are timely. } \\
\text { Assessment of source data } \\
\text { The NSO assesses the source data for } \\
\text { coverage, consistency, and nonresponse, and } \\
\text { undertakes a scientific measurement of } \\
\text { possible sampling and nonsampling errors. } \\
\text { However, the tight national accounts } \\
\text { compilation schedule limits the } \\
\text { comprehensiveness of the assessment } \\
\text { exercise. } \\
\text { Statistical techniques } \\
\text { Statistical techniques are relatively sound. } \\
\text { International guidelines are followed to derive } \\
\text { current price estimates and the base year is } \\
\text { updated with adequate frequency. However, } \\
\text { some of the techniques and indicators used to } \\
\text { derive the volume estimates are weak. } \\
\text { Assessment and validation of intermediate } \\
\text { data and statistical outputs } \\
\text { While intermediate data are assessed, final } \\
\text { outputs are not routinely assessed against } \\
\text { supply and use tables. } \\
\text { Revision studies } \\
\text { Revision studies and analyses are not } \\
\text { routinely conducted. }\end{array}$ & $\begin{array}{l}\text { Periodicity and timeliness } \\
\text { The periodicity and timeliness } \\
\text { of the GDP estimates are in } \\
\text { line with the GDDS } \\
\text { recommendations. The NSO } \\
\text { disseminates preliminary } \\
\text { annual GDP estimates three } \\
\text { months following the end of } \\
\text { the reference year. Revised } \\
\text { estimates are disseminated } \\
\text { six months after the end of the } \\
\text { period. } \\
\text { Consistency } \\
\text { The statistics are internally } \\
\text { consistent and the statistical } \\
\text { discrepancy is only about one } \\
\text { percent. A consistent series, } \\
\text { based on the new revised } \\
\text { methodology, is available from } \\
\text { 2000 and the NSO plans to } \\
\text { revise the series backwards to } \\
1990 \text {. } \\
\text { Revision policy and practice } \\
\text { The revision policy is not made } \\
\text { known to the public. The } \\
\text { revision cycle is inadequate as } \\
\text { the data are revised only once, } \\
\text { six months following the end } \\
\text { of the period. While } \\
\text { preliminary data are clearly } \\
\text { identified, revised estimates are } \\
\text { not annotated. }\end{array}$ & $\begin{array}{l}\text { Data accessibility } \\
\text { Data are disseminated in varying } \\
\text { levels of detail on the NSO web } \\
\text { site, in the Statistical Yearbook of } \\
\text { Mongolia, and in the monthly } \\
\text { bulletins. The chairman may also } \\
\text { announce the release of the } \\
\text { estimates during his monthly news } \\
\text { conference. The estimates are not } \\
\text { released according to a } \\
\text { preannounced schedule although } \\
\text { regular users may be aware of the } \\
\text { general timing of dissemination. } \\
\text { The national accounts are released } \\
\text { to all users at the same time and the } \\
\text { agency makes detailed, } \\
\text { unpublished, but nonconfidential } \\
\text { data available on request. } \\
\text { Metadata accessibility } \\
\text { Brief notes on compilation } \\
\text { procedures are presented in the } \\
\text { regular publications. Detailed } \\
\text { metadata are available in the NSO } \\
\text { Handbook on Sources and } \\
\text { Methods. Updated metadata are } \\
\text { also presented on the GDDS web } \\
\text { site. } \\
\text { Assistance to users } \\
\text { The hardcopy publications and the } \\
\text { NSO web site present } \\
\text { comprehensive information on how } \\
\text { users may contact the NSO. }\end{array}$ \\
\hline
\end{tabular}


Table 3b. Mongolia: Assessment of Data Quality-Dimensions 2 to 5-Consumer Price Index

\begin{tabular}{|c|c|c|c|}
\hline 2. Methodological soundness & 3. Accuracy and reliability & 4. Serviceability & 5. Accessibility \\
\hline $\begin{array}{l}\text { Concepts and definitions } \\
\text { Concepts and definitions are broadly } \\
\text { in line with international standards, } \\
\text { guidelines, or good practices. } \\
\text { Household expenditure estimates } \\
\text { from the HIES are used for the } \\
\text { weights of market expenditure on } \\
\text { goods and services. } \\
\text { Scope } \\
\text { The NSO does not compile a } \\
\text { national CPI. Though the geographic } \\
\text { coverage of expenditure includes } \\
\text { both urban and rural areas, national } \\
\text { weights are not estimated to } \\
\text { determine a national CPI. } \\
\text { Classification/sectorization } \\
\text { The CPI covers noninstitutionalized } \\
\text { Mongolian households, consistent } \\
\text { with the } 1993 \text { SNA household sector. } \\
\text { The Ulaanbaatar and regional CPI } \\
\text { are classified according to the } \\
\text { Classification of Individual } \\
\text { Consumption by Purpose } \\
\text { (COICOP), which conforms to the } \\
\text { guidelines of the } 1993 \text { SNA and the } \\
\text { Consumer Price Index } \\
\text { Manual, } 2004 \text { (CPI Manual). } \\
\text { Basis for recording } \\
\text { The prices reflect those that a } \\
\text { consumer would pay on the day of } \\
\text { the survey, including value added, } \\
\text { excise taxes, trade and transportation } \\
\text { margins. }\end{array}$ & $\begin{array}{l}\text { Source data } \\
\text { The source data for the weights is the HIES, with } \\
\text { current CPI weights based on the } 2004 \text { HIES. } \\
\text { The price reference period is December } 2005 \text {. } \\
\text { The weights are not updated for price changes to } \\
\text { be aligned with the price base period. Very small } \\
\text { outlets are excluded from price collection. } \\
\text { Moreover, there are no imputations for owner- } \\
\text { occupied dwellings. } \\
\text { Assessment of source data } \\
\text { Analysis of sampling errors for the HIES is not } \\
\text { undertaken. Consumption expenditure on alcohol } \\
\text { and tobacco is not routinely crosschecked with } \\
\text { supply data such as imports and retail trade. } \\
\text { Statistical techniques } \\
\text { Prices for temporarily missing and seasonal } \\
\text { products for the new CPI are estimated by carrying } \\
\text { forward and imputing the price. However, implicit } \\
\text { and/or explicit quality adjustment techniques } \\
\text { should be applied for items that have replaced } \\
\text { permanently unavailable products. } \\
\text { Assessment and validation of intermediate data } \\
\text { and statistical output } \\
\text { The CPI results are assessed and validated using } \\
\text { other independent data sources, including data on } \\
\text { money supply. } \\
\text { carried out when there is a new HIES, and are used } \\
\text { internally to improve statistical processes. }\end{array}$ & $\begin{array}{l}\text { Periodicity and timeliness } \\
\text { The CPI is a monthly index and it } \\
\text { is disseminated one week after the } \\
\text { reference month, thereby meeting } \\
\text { the GDDS recommendation. } \\
\text { Consistency } \\
\text { The CPI elementary and higher } \\
\text { level aggregates are consistent. } \\
\text { Time series data are available for } \\
\text { at least five years. Aggregated } \\
\text { historical time series data are } \\
\text { available back to } 1991 \text {. When the } \\
\text { weights and baskets are updated, } \\
\text { the long term time series are } \\
\text { carried back to } 2000 \text { to revise the } \\
\text { series. } \\
\text { Revision policy and practice } \\
\text { The CPI series are final when first } \\
\text { released and are not subject to } \\
\text { revisions. However, studies on the } \\
\text { impact of weight updating are not } \\
\text { disseminated in official statistical } \\
\text { publications. }\end{array}$ & $\begin{array}{l}\text { Data accessibility } \\
\text { Data for the CPI are generally } \\
\text { accessible. The CPI data are } \\
\text { disseminated on the NSO's web site, } \\
\text { Www.nso.mn/eng/index.php. But } \\
\text { there is no advance release calendar } \\
\text { posted on the website. } \\
\text { The CPI data are made available to } \\
\text { all users at the same time. In certain } \\
\text { publications, charts and tables are } \\
\text { also disseminated with the data to } \\
\text { facilitate analysis. Datasets are } \\
\text { published in consolidated format, by } \\
\text { food, nonfood, and services. Data for } \\
\text { each category are further broken } \\
\text { down by type, by group, and by } \\
\text { aimags. } \\
\text { Metadata accessibility } \\
\text { Short documentation on concepts, } \\
\text { scope, classification, data sources, } \\
\text { and methods of the CPI is available } \\
\text { on the IMF's DSBB. In addition, CPI } \\
\text { methodological notes are posted on } \\
\text { the NSO's web site, which is linked } \\
\text { to the DSBB. However, no } \\
\text { brochures, pamphlets, or newsletters } \\
\text { about the CPI are available to the } \\
\text { public. } \\
\text { Assistance to users } \\
\text { Contact points for the CPI are } \\
\text { publicized in official publications. }\end{array}$ \\
\hline
\end{tabular}


Table 3c. Mongolia: Assessment of Data Quality-Dimensions 2 to 5-Government Finance Statistics

\begin{tabular}{|c|c|c|c|}
\hline 2. Methodological soundness & 3. Accuracy and reliability & 4. Serviceability & 5. Accessibility \\
\hline $\begin{array}{l}\text { Concepts and definitions } \\
\text { The concepts and definitions used to } \\
\text { compile fiscal statistics generally follow } \\
\text { the guidelines of the GFSM } 1986 \text {. No } \\
\text { formal decision has yet been taken on } \\
\text { adopting a "migration path" to the } \\
\text { GFSM } 2001 \text { methodology, although the } \\
\text { new framework is planned to be used } \\
\text { for compiling fiscal statistics. } \\
\text { Scope } \\
\text { The institutional scope of the monthly } \\
\text { and annual fiscal statistics for the } \\
\text { general government sector and its } \\
\text { subsectors (except for extrabudgetary } \\
\text { units) generally follows international } \\
\text { guidelines. However, no data for central } \\
\text { government debt are disseminated. } \\
\text { The transaction coverage is generally } \\
\text { consistent with the GFSM } 1986 \text { tables. } \\
\text { Classification/sectorization } \\
\text { The classifications used for sub-annual } \\
\text { and annual fiscal statistics follow } \\
\text { broadly the classifications of the } G F S M \\
1986 \text {, but with some differences for } \\
\text { financing. } \\
\text { A major classification issue concerns } \\
\text { financing. The item banking system net } \\
\text { credit is calculated as a residual and the } \\
\text { change in cash balances for the period is } \\
\text { not identified separately. } \\
\text { the GFSM } 1986 \text {. }\end{array}$ & $\begin{array}{l}\text { Source data } \\
\text { Data sources are complete to allow the } \\
\text { compilation and consolidation of fiscal } \\
\text { statistics (except for extrabudgetary units). } \\
\text { There is no comprehensive register of } \\
\text { individual public sector units. } \\
\text { Assessment of source data } \\
\text { The monthly reports submitted by } \\
\text { budgetary agencies and the provinces are } \\
\text { cross-checked against data in the GFMIS. } \\
\text { Data inconsistencies are confirmed with } \\
\text { reporting units. } \\
\text { Statistical techniques } \\
\text { Compilation procedures are in place to } \\
\text { minimize processing errors. Monthly data } \\
\text { are preliminary when first disseminated, } \\
\text { but are not replaced by final data. } \\
\text { Compilation procedures are not } \\
\text { documented. Discrepancies between sub- } \\
\text { annual and annual data are not removed, } \\
\text { although these have been small in the last } \\
\text { two years. }\end{array}$ & $\begin{array}{l}\text { Periodicity and timeliness } \\
\text { The periodicity and timeliness of } \\
\text { fiscal statistics meets the GDDS } \\
\text { recommendation for central } \\
\text { government budgetary operations, } \\
\text { but not for central government debt } \\
\text { (not disseminated). However, } \\
\text { information is available to compile } \\
\text { and disseminate central government } \\
\text { debt that would easily meet the } \\
\text { GDDS recommendation. } \\
\text { Consistency } \\
\text { The concepts, definitions, and } \\
\text { classifications for producing sub- } \\
\text { annual and annual fiscal statistics by } \\
\text { the MOF are the same. Sub-annual } \\
\text { and annual fiscal statistics have been } \\
\text { consistent the last two years, though } \\
\text { this was not the case in earlier years. } \\
\text { Consistent time series for annual } \\
\text { fiscal statistics are available for an } \\
\text { adequate period of time. } \\
\text { Differences exist with the financing } \\
\text { data from the monetary accounts, } \\
\text { which are not reconciled on a regular } \\
\text { basis. } \\
\text { Revision policy and practice } \\
\text { There is no revision policy. When } \\
\text { revisions to fiscal statistics do occur } \\
\text { they are not made known to the } \\
\text { public. } \\
\text { At the time of data dissemination } \\
\text { users are not informed whether data } \\
\text { are preliminary or final. }\end{array}$ & $\begin{array}{l}\text { Data accessibility } \\
\text { Fiscal statistics are disseminated } \\
\text { generally according to the standard } \\
\text { recommended by the GFSM } 1986 \text { for } \\
\text { revenues and expenditures, but not for } \\
\text { financing. } \\
\text { There is no advance release schedule } \\
\text { communicated to the public. However, } \\
\text { fiscal statistics are in practice released } \\
\text { punctually on a regular schedule, } \\
\text { which the public knows. } \\
\text { Fiscal statistics are made available to } \\
\text { all users simultaneously and with no } \\
\text { preferential treatment. } \\
\text { The procedures for obtaining } \\
\text { additional statistics or their availability } \\
\text { are not made known. } \\
\text { Metadata accessibility } \\
\text { The MOF publishes on its web site the } \\
\text { GDDS metadata posted on the IMF's } \\
\text { DSBB. There are no other metadata } \\
\text { with levels of detail adapted to users. } \\
\text { Assistance to users } \\
\text { No contact point for fiscal statistics is } \\
\text { identified in MOF publications. In } \\
\text { general, limited assistance is provided } \\
\text { to general public users of fiscal } \\
\text { statistics. } \\
\text { The MOF does not have a catalog of } \\
\text { publications. The NSO provides on its } \\
\text { web site a list of its publications and } \\
\text { their prices in electronic and hardcopy } \\
\text { format. }\end{array}$ \\
\hline
\end{tabular}


Table 3d. Mongolia: Assessment of Data Quality_Dimensions 2 to 5-Monetary Statistics

\begin{tabular}{|c|c|c|c|}
\hline 2. Methodological soundness & 3. Accuracy and reliability & 4. Serviceability & 5. Accessibility \\
\hline $\begin{array}{l}\text { Concepts and definitions } \\
\text { The concepts and definitions broadly } \\
\text { conform to the methodology of the } \\
\text { Monetary and Financial Statistics } \\
\text { Manual (MFSM). } \\
\text { Scope } \\
\text { The coverage of the BOM's Monetary } \\
\text { Survey comprises the BOM and resident } \\
\text { commercial banks, but excludes savings } \\
\text { and credit unions, which are collecting an } \\
\text { increasing share of deposits. } \\
\text { Classification/sectorization } \\
\text { The definition of residency used for the } \\
\text { Monetary Survey follows the BPM5 and } \\
\text { MFSM. The sectorization scheme used is } \\
\text { broadly as required by the MFSM. The } \\
\text { classification of certain accounting data is } \\
\text { erroneous. } \\
\text { Basis for recording } \\
\text { As recommended by the } M F S M \\
\text { methodology, the BOM uses market } \\
\text { prices for valuation of most assets and } \\
\text { liabilities and book values for valuation } \\
\text { of loans. It relies on accrual accounting. } \\
\text { Its grossing and netting operations are } \\
\text { correct with one exception: it treats } \\
\text { financial derivatives with the nonresident } \\
\text { sector on a net basis in the central bank's } \\
\text { survey. It treats repurchase agreements, } \\
\text { correctly, as collateralized loans. }\end{array}$ & $\begin{array}{l}\text { Source data } \\
\text { The source data on commercial } \\
\text { banks provide broadly sufficient } \\
\text { detail to sectorize institutional units } \\
\text { and classify financial instruments in } \\
\text { line with the MFSM methodology. } \\
\text { Assessment of source data } \\
\text { The assessment of source data is } \\
\text { generally sound. The BOM staff } \\
\text { scrutinize data submitted by the } \\
\text { banks. For out-of-trend changes or } \\
\text { high-value transactions, banks are } \\
\text { contacted for verification. } \\
\text { Statistical techniques } \\
\text { As monetary statistics are based on } \\
\text { the actual accounting records of } \\
\text { financial institutions covered, no } \\
\text { statistical techniques are used. } \\
\text { Assessment and validation of } \\
\text { intermediate data and statistical } \\
\text { outputs } \\
\text { The BOM assesses and validates } \\
\text { intermediate data and statistical } \\
\text { outputs against data available from } \\
\text { other sources. } \\
\text { Revision studies } \\
\text { Revision studies are not routinely } \\
\text { prepared. }\end{array}$ & $\begin{array}{l}\text { Periodicity and timeliness } \\
\text { The periodicity (monthly) and } \\
\text { the timeliness (three weeks after } \\
\text { the end of the reference month) } \\
\text { of the central bank's survey and } \\
\text { other depository corporations' } \\
\text { survey meet the GDDS } \\
\text { recommendations. } \\
\text { Consistency } \\
\text { Monetary statistics are not } \\
\text { consistent within the dataset as } \\
\text { interbank positions between the } \\
\text { central bank and other } \\
\text { depository corporations show } \\
\text { discrepancies. Monetary } \\
\text { statistics and government budget } \\
\text { data show large discrepancies on } \\
\text { bank financing of the central } \\
\text { government budget. Monetary } \\
\text { and balance of payments } \\
\text { statistics have differences in } \\
\text { foreign assets and liabilities that } \\
\text { are reconcilable as these are due } \\
\text { to the use of different exchange } \\
\text { rates. } \\
\text { Revision policy and practice } \\
\text { Revisions do not follow a } \\
\text { regular and transparent cycle. }\end{array}$ & $\begin{array}{l}\text { Data accessibility } \\
\text { The BOM disseminates monetary } \\
\text { statistics through the Monthly } \\
\text { Statistical Bulletin, which is posted } \\
\text { on the BOM's web site. The BOM } \\
\text { has recently begun to post on its web } \\
\text { site a preannounced schedule for data } \\
\text { release. Monetary data are made } \\
\text { available to all users simultaneously. } \\
\text { Metadata accessibility } \\
\text { The metadata are posted on the } \\
\text { IMF's DSBB as part of Mongolia's } \\
\text { GDDS participation and a link exists } \\
\text { on the NSO's web site. There are no } \\
\text { alternative metadata with levels of } \\
\text { detail adapted to the needs of the } \\
\text { audience. } \\
\text { Assistance to users } \\
\text { The BOM provides assistance to } \\
\text { users, primarily by providing contact } \\
\text { points in its publications and web } \\
\text { site. However, no catalog of } \\
\text { publications and other services is } \\
\text { made available to users. }\end{array}$ \\
\hline
\end{tabular}


Table 3e. Mongolia: Assessment of Data Quality-Dimensions 2 to 5-Balance of Payments Statistics

\begin{tabular}{|c|c|c|c|}
\hline $\begin{array}{l}\text { 2. Methodological } \\
\text { soundness }\end{array}$ & 3. Accuracy and reliability & 4. Serviceability & 5. Accessibility \\
\hline $\begin{array}{l}\text { Concepts and definitions } \\
\text { The concepts and definitions } \\
\text { broadly conform to the } \\
\text { methodology of the fifth edition of } \\
\text { the Balance of Payments Manual } \\
\text { (BPM5). } \\
\text { Scope } \\
\text { The scope of the balance of } \\
\text { payments statistics is broadly } \\
\text { consistent with guidelines outlined } \\
\text { in BPM5. } \\
\text { Classification/sectorization } \\
\text { Classification and sectorization } \\
\text { systems are consistent with } \\
\text { BPM5. } \\
\text { Basis for recording } \\
\text { Generally, the recording basis is } \\
\text { consistent with BPM5. } \\
\text { Transactions are valued at market } \\
\text { prices. The timing of data is based } \\
\text { on customs processing (goods) } \\
\text { and payments (otherwise). } \\
\text { However, many items are not } \\
\text { adjusted to an accrual basis. }\end{array}$ & $\begin{array}{l}\text { Source data } \\
\text { The major data sources are customs statistics } \\
\text { (merchandise trade), international transactions } \\
\text { reporting system, direct reporting from major } \\
\text { enterprises and government agencies, and a range of } \\
\text { special-purpose surveys. These sources are generally } \\
\text { adequate and timely. However, the enterprise survey } \\
\text { has problems of an outdated register, incomplete } \\
\text { survey response, and lack of estimation for missing } \\
\text { enterprises. Gaps exist in the coverage of small-scale } \\
\text { transactions, such as informal trade, remittances } \\
\text { outside the banking system, and transactions through } \\
\text { foreign exchange bureaus. Large values of quarterly } \\
\text { net errors and omissions indicate timing problems. } \\
\text { Assessment of source data } \\
\text { Appropriate procedures are followed to assess source } \\
\text { data. } \\
\text { Statistical techniques } \\
\text { Compilation techniques are appropriate. Valid } \\
\text { techniques are used for adjustments, except for } \\
\text { nonresponse to surveys. } \\
\text { Assessment and validation of intermediate data } \\
\text { and statistical outputs } \\
\text { Routine validation and cross-checking with } \\
\text { alternative data and results are undertaken at all } \\
\text { stages. Statistical discrepancies are investigated and } \\
\text { taken into account in improving sources and } \\
\text { compilation procedures, although there is insufficient } \\
\text { cross-checking with position data. } \\
\text { checked. No long-term revision studies are prepared. }\end{array}$ & $\begin{array}{l}\text { Periodicity and timeliness } \\
\text { Balance of payments statistics } \\
\text { are available quarterly, usually } \\
\text { within six weeks after the end of } \\
\text { the reference quarter. These } \\
\text { practices are considerably better } \\
\text { than GDDS recommendations. } \\
\text { Consistency } \\
\text { Balance of payments data are } \\
\text { published on a consistent basis } \\
\text { from } 1989 \text { (annually) and } \\
\text { 2002 (quarterly). Balance of } \\
\text { payments data are consistent } \\
\text { with the national accounts. } \\
\text { Monetary and balance of } \\
\text { payments statistics can be } \\
\text { reconciled, while there are } \\
\text { unreconciled differences with } \\
\text { government finance statistics. } \\
\text { Revision policy and practice } \\
\text { Data revisions are made } \\
\text { according to schedule and to } \\
\text { correct errors. Preliminary data } \\
\text { are identified. However, there is } \\
\text { no published statement of } \\
\text { revision policy. }\end{array}$ & $\begin{array}{l}\text { Data accessibility } \\
\text { BOM disseminates balance of } \\
\text { payments statistics with tables, } \\
\text { graphs, and commentary in its } \\
\text { quarterly and annual bulletins. } \\
\text { Publications are available in } \\
\text { hard copy and are posted on the } \\
\text { BOM's web site } \\
\text { (www.mongolbank.mn). There } \\
\text { is a preannounced schedule for } \\
\text { data release on the web site. } \\
\text { The BOM makes balance of } \\
\text { payments data available to all } \\
\text { users simultaneously. } \\
\text { Metadata accessibility } \\
\text { Metadata are published in } \\
\text { various formats and degrees of } \\
\text { detail in notes to the BOM } \\
\text { publications, the BOM } \\
\text { contribution to the GDDS } \\
\text { metadata, and in a detailed } \\
\text { manual. The NSO's web site } \\
\text { contains a link to the DSBB. } \\
\text { Assistance to users } \\
\text { The BOM provides assistance } \\
\text { to users, primarily by providing } \\
\text { contact points in its } \\
\text { publications and web site. } \\
\text { However, no catalog of } \\
\text { publications and other services } \\
\text { is made available to users. }\end{array}$ \\
\hline
\end{tabular}




\section{STAFF's RECOMMENDATIONS}

9. Based on the review of Mongolia's statistical practices, discussions with the data producing agencies, and responses from data users (see Appendix III of the Detailed Assessments volume), the mission has developed a set of recommendations. They are designed to increase further Mongolia's adherence to internationally accepted statistical practices and would, in the mission's view, enhance the analytical usefulness of Mongolia's statistics. Some additional technical suggestions are included in the Detailed Assessments volume.

\section{Cross-cutting Recommendations}

- $\quad$ Allocate additional resources for the current and planned macroeconomic statistics compilation and dissemination programs, including for information technology support.

- $\quad$ Maintain a stable complement of trained professional staff to maximize benefits from external training and manage turnovers more efficiently. Upgrade office facilities in dataproducing agencies to address effectively new data demands and priorities, in particular at the NSO.

- Implement an electronic (online) reporting system for banks and other financial institutions to enhance the efficiency of monetary and balance of payments statistics compilation process. Introduce a database-driven compilation system for monetary and balance of payments statistics.

- $\quad$ Establish and disseminate revision policies and carry out revision studies across datasets.

- $\quad$ Develop and implement a policy to inform users of upcoming changes in definitions and compilation process and the effects on disseminated data.

- Give increased attention to meeting the needs of data users other than those from the government and international organizations.

- Harmonize monetary and government finance statistics data on bank credit to the government sector on a regular cycle.

- $\quad$ Reconcile differences between government finance statistics and balance of payments statistics.

\section{National Accounts}

- Review statistical techniques used to derive the volume estimates and avoid direct deflation of value added.

- Increase the number of revisions to the estimates and lengthen the revision cycle.

- $\quad$ Identify the revised data with clear notations and explanations. 


\section{Consumer Price Index}

- $\quad$ Provide to data users and the public advance notice of major changes in methodology, source data, and statistical techniques.

- Include the imputation of rents for owner-occupied housing in the CPI.

- $\quad$ Expand the scope of the CPI to a national CPI.

- Apply implicit and/or explicit quality adjustment techniques for items that have replaced permanently unavailable products.

\section{Government Finance Statistics}

- $\quad$ Review the decision to classify data on central government debt as confidential and disseminate these data in MOF, BOM, and NSO publications.

- Identify data sources for extrabudgetary units and begin compiling fiscal statistics for these units. Incorporate and consolidate these statistics with those for the central and general government sectors.

- $\quad$ Take formal decision to adopt the GFSM 2001 methodology, and develop the associated migration path. Implement recommendations of technical assistance missions according to an explicit timetable.

- $\quad$ Reconcile on a regular (i.e., monthly or quarterly) basis fiscal data discrepancies visà-vis other datasets, particularly monetary data.

\section{Monetary Statistics}

- Develop a Depository Corporations Survey by expanding the coverage of the Monetary Survey to include savings and credit unions and allocating additional resources.

- $\quad$ Harmonize interbank positions within monetary statistics.

- $\quad$ Adopt the Standardized Report Forms (SRFs) as the vehicle for reporting monetary data both within the financial system and with the IMF.

\section{Balance of Payments Statistics}

- $\quad$ Develop a computing system appropriate to a modern, large-scale statistical system. The system should include the capacity for on-line reporting and a database for statistical processing of balance of payments data.

- Use the enterprise survey results, after follow-up and appropriate adjustments for nonresponse, to improve balance of payments statistics and complete the compilation of the international investment position. 
- Investigate and resolve emerging issues in balance of payments methodology, including treatment of free trade zones, short-term construction workers, reinvested earnings, bond issues, share market purchases by nonresidents, intercompany debt, and financial derivative holdings. 


\section{Appendix Table 1. Mongolia: Practices Compared to the GDDS Coverage, Periodicity, and Timeliness of Data}

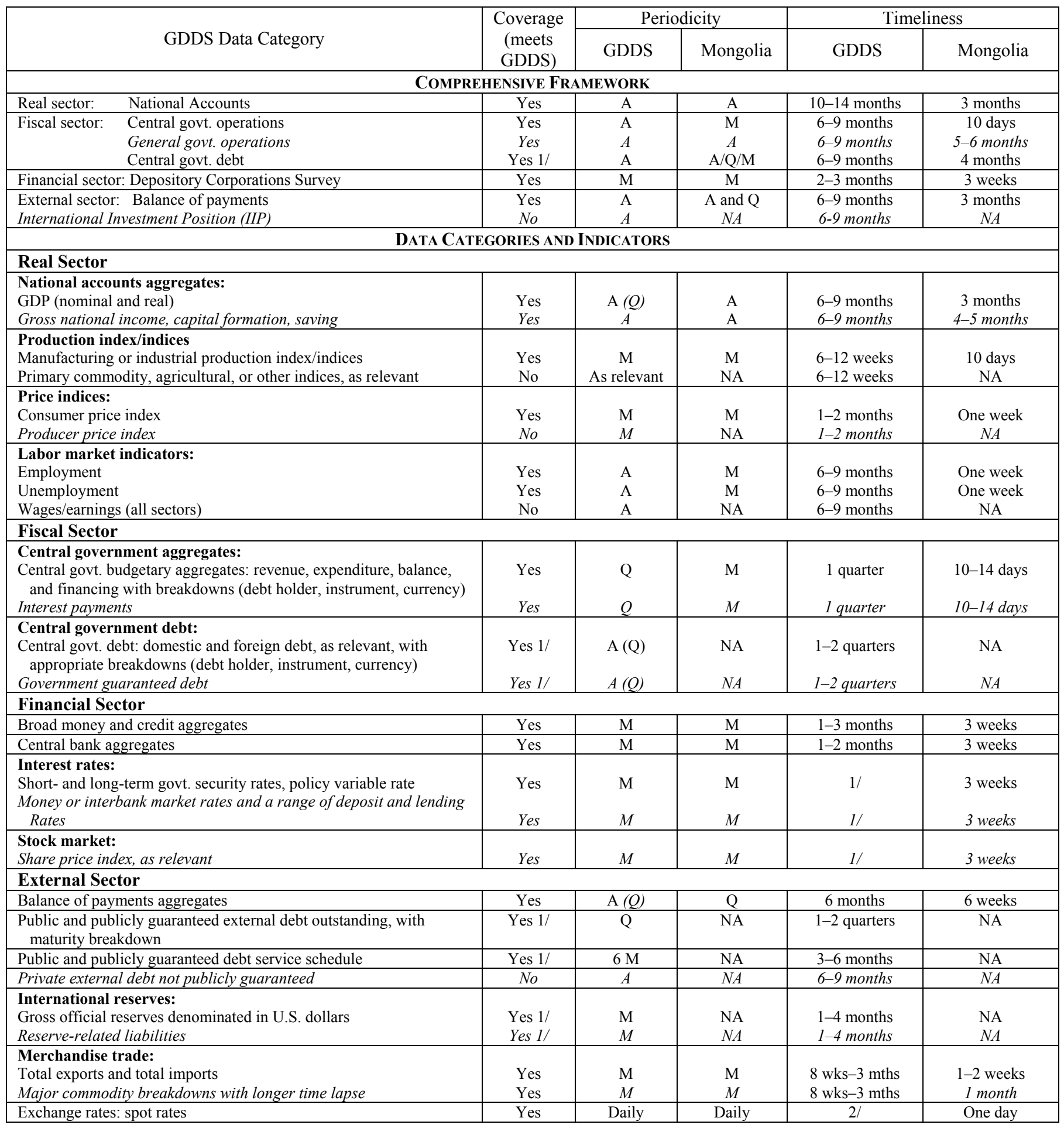

Italics indicate encouraged categories.

1/ Compiled but not publicly disseminated.

2/ Dissemination as part of a high-frequency (e.g., monthly) publication. 


\section{INTERNATIONAL MONETARY FUND}

MONGOLIA

\section{Report on the Observance of Standards and Codes (ROSC)—Data Module}

\section{Volume II}

\section{Response by the Authorities}

March 27, 2008

Contents

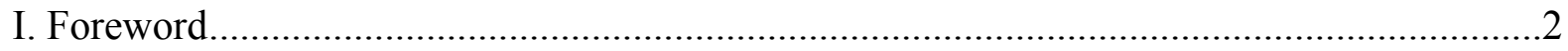

II. Response from the Mongolian National Statistics Office (NSO) ...................................

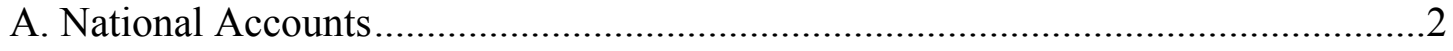

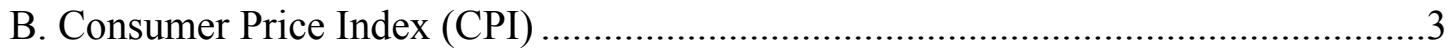

III. Response for the IMF recommendations from the Ministry of Finance............................5

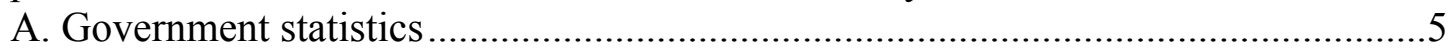

IV. Response by the Bank of Mongolia (BOM) ...........................................................

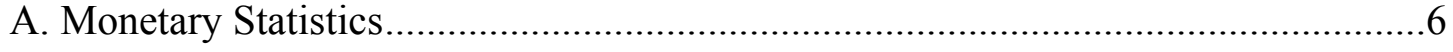

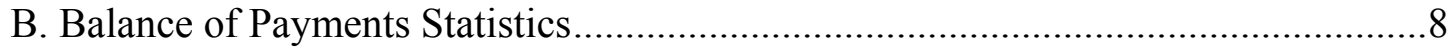




\section{FOREWORD}

The mission from IMF Statistics Department visited Ulaanbaatar from September 17-28, 2007 to prepare the data module for the Report on Observance of Standards and Codes (ROSC), which assessed the macroeconomic statistics in Mongolia using Data Quality Assessment Framework.

The assessment which has an important contribution for further development of statistical activities in our country has been made mainly on data accuracy and integrity, legal environment, ethic standards, methodology, data transparency and reliability. Regarding the conclusion and recommendation which has been provided by the IMF experts, we would like to submit following comments and proposals.

We would like to extend our deepest appreciation for the hard work, dedication, and interest of all the assessment team members in their tasks of assessing four macroeconomic datasetsnational accounts, government finance, monetary, and balance of payments statistics. We would like to also express our gratitude for receiving the close cooperation and constructive advice prior to and throughout the actual assessment. Mongolian authorities agree with the recommendations that there is still room for further improvement in certain areas.

\section{Response from the Mongolian National Statistics OfFice (NSO)}

\section{A. National Accounts}

1. Professionalized staff on national accounts and price statistics are not sufficient. Due to limited budget allocation from the government, it has restricted to hire additional staff on national account and price statistics. Furthermore, institutional capacity is not sufficient to hire new staff.

The recommendation has been considered by the NSO of Mongolia. The NSO has submitted its official request to the government to expand its building, to hire one more staff on estimation of housing price indices, three more staff on national accounts, from 2008.

2. The scope of the national accounts does not cover several accounts and tables recommended by Inter-Secretariat Working Group on National Accounts.

The NSO has compiled experimental accounts by residential institutional sector for all resident sectors for 2000-2005. The accounts cover production accounts, generation of income accounts, allocation of primary income accounts, secondary distribution of income accounts, use of income accounts, and capital accounts. It is planned to disseminate them to the users from 2008. In this connection, above mentioned conclusion/recommendation is not very acceptable from the NSO side and an official letter has been submitted to the task team leader. 
3. In order to improve data accuracy and reliability, clarification, finalize estimation and its dissemination, it has recommended to updating rules and guidelines.

It is proposed to have IMF technical assistance in developing the rules on conformity with international standards.

4. International guidelines are followed to deprive current price estimates and the base year is updated with adequate frequency. However, some of the techniques and indicators used to deprive the volume estimates are weak.

The IMF staff concluded that it would not be suitable to use CPI for the commercial sector when converting value added into constant price. Having undertaken a research to calculate retail trade price index for the commercial sector, the NSO has developed a methodology for it. It is expected to further study the possibilities of employing retail trade price index in the GDP at constant price and realize it.

5. While intermediate data are assessed, final outputs are not routinely assessed against supply and use tables.

Supply and Use Table has been compiled for 2005. Based on the results of the balance, the issue of revising GDP estimates will further be considered in the preparation of "the rules for validating accuracy of data and revising, updating and disseminating data."

6. The revision policy is not made known to the public. The revision cycle is inadequate as the data are revised only once. While preliminary data are clearly identified, revised estimates are not annotated.

It is proposed to have IMF technical assistance in developing the rules on conformity with international standards.

\section{B. Consumer Price Index (CPI)}

7. The NSO does not compile a national CPI. Though the geographic coverage of expenditure includes both urban and rural areas, national weights are not estimated to determine a national CPI.

The NSO plans to finish making preparations for a national CPI calculation within the fourth quarter of this year and to make it known to the public from January 2008. In the framework of the preparations for the national CPI calculation, it is aimed to develop a methodology for CPI compilation and have it approve, to revise every weight of goods and services in the consumption basket for 21 aimags and Ulaanbaatar city by 2005 HIES expenditure aggregates; to develop a data processing instruction and software for the national CPI calculation; and to compile the index on an experimental basis. 
8. Consumption expenditure on alcohol and tobacco is not routinely crosschecked with supply data such as imports and retail trade.

When re-updating consumption expenditure weights from 2010, the NSO consumption expenditure weights on alcohol beverages and tobacco of HIES will crosscheck with other related information.

9. Prices temporarily missing and seasonal products for the new CPI are estimated by carrying forward and imputing the price, but quality adjustment techniques should be applied.

The staff should be trained and re-trained on methodological areas on implicit and explicit quality adjustment techniques.

10. The CPI series are final when first released and are not subject to revisions. However, studies on the impact of weight updating are not disseminated in official statistical publications.

The NSO makes available to all users any changes related to the CPI at the same time through statistical publications and tables. We should explore and accomplish issue on publishing notes about comparison with updated weights and previous weights in monthly statistical bulletin.

11. CPI data are disseminated on the NSO's website, but there is no advance release calendar posted on the website.

Information about release of statistical information is posted on the NSO's website. We should be take a further consideration on posting detailed release calendar on the the NSO's website.

\section{Should be imputations for owner-occupied dwellings}

We could not able to accept this recommendation. Because of we understand that goods and services, which their prices can be directly measured, should be taken in consumer basket. We have taken actual rent of owner occupied dwellings in consumer basket.

13. Within the frame of IMF recommendations, we have requested to receive supports and technical assistances for the IMF on following areas:

a. Receive technical assistance on development of the "rule" to follow for checking data reliability and accuracy, update data and disseminate data;

b. Provide software of CPI estimation from the IMF and NSO staff attend the related training; and

c. Take actions to further involve NSO staff in long and short-term trainings on national accounts and price statistics. 


\section{RESPONSE FOR THE IMF RECOMMENDATIONS FROM THE MINISTRY OF FINANCE}

\section{A. Government Statistics}

1. The fiscal statistics are not published from Ministry of Finance.

The annual budget planning is published and posted on www.iltod.gov.mn website for comments and feedbacks from the public right after its submission to the parliament. Moreover, after its approval from the parliament it is published as booklet and disseminated to the public. The budget execution is also published as a booklet and is disseminated to the public.

2. Fiscal statistics are disseminated generally according to the standard recommended by the GFSM 1985 for revenues and expenditures, but not for financing.

Treasury Department and Fiscal Policy Coordination Department of Ministry of Finance is working in cooperation with country representative office of IMF to improve the accuracy and comprehensiveness.

3. There is no consolidated catolague for publications from the Ministry of Finance.

We agree that there is no consolidated catalogue therefore, in the future, the Ministry of Finance is working on to develop the consolidated catalogue of publications' section on the www.mof.pmis.gov.mn website of Ministry of Finance.

\section{Shifting government statistics to GFSM 2001 methodology.}

The framework of compilation of government statistics on accrual basis has been started and the Ministry of Finance is working on introducing a new program for budget planning. The technical description of this program has been developed and the Ministry of Finance would like to request an advisor to work on government statistics. We would also like to request from IMF to organize a training workshop on government statistics.

5. To start reflecting the extrabudgetary units on both national and consolidated budget.

The financial reports from State property and non government organizations are compiled at Accounting Policy Department and reflected on government finance statistics. In the future, the Ministry of Finance will study the best alternative of whether to reflect the reports from such organizations on budget.

Scheme

1. To obtain technical assistance on the implementation of GFSM 2001 methodology of the IMF.

2. To organize short and long term trainings courses on the methodologies of public accounting and government statistics. 


\section{RESPONSE BY THE BANK OF MONGOLIA (BOM)}

\section{A. Monetary Statistics}

\section{Improve resources}

1.1. Increase the staff of the Statistics Unit by two positions: Economist responsible for data quality issues and Economist responsible for data compilation from other financial institutions except banks.

A new position of an economist responsible for data quality issues was established in December 2007. According to the approved Plan on Measures to Improve the Monetary Statistics, a new position of an economist responsible for data compilation from other financial institutions except banks will be established in 2008 .

\subsection{Acquire software for collection and compilation of monetary statistics}

We will take measures to acquire or create software for collecting and compiling the information from banks.

\section{Enhance the transparency}

The Monetary Policy and Research Department will prepare paper on changes in methodology of data compilation and sources; inform the users in advance via the web site of the Bank of Mongolia.

\section{Improve the methodological soundness}

\subsection{Expand the scope}

The BOM will receive the consolidated data on savings and credit cooperatives from the Financial Regulatory Commission when the Commission starts to compile these data. The consolidated balance sheets of savings and credit cooperatives will be used for expanding the monetary survey.

\subsection{Reclassify certain accounting data}

In December 2007, we excluded Government Lending Funds (KFW, ADB, UNDP loan resources) from Other Items (net) and showed them as a separate item in the Central Bank Monetary Survey. The previous data are also modified since January 2005. In the Other Depository Corporations (Banks) survey, we will reclassify Accrued interest receivable/payable to incorporate them into the outstanding amount of the financial asset or liability in 2008. For this purpose, the Monetary Policy and Research Department will use the supplementary data from banks, which we started to receive since January 2006. 


\subsection{Change the basis for recording}

Assets and liabilities in financial derivatives in the Central Bank balance sheet and monetary survey will be shown on a gross basis starting January 1, 2008.

\section{Improve the accuracy and reliability}

In each case of revision, we will conduct revision studies comparing the initial and revised data, studying the reason of discrepancy and drawing a pattern.

\section{Improve the serviceability}

\subsection{Maintain data consistency}

We will take measures to reduce the discrepancies in interbank positions between the BOM and other banks (loans from the BOM, CBBs holdings, and banks' deposits with the BOM). Also, we will address these issues during meetings with the relevant staff from banks to avoid such discrepancies in future.

The BOM will collaborate with the MoF to estimate the discrepancy between monetary statistics (net claims on the government) and government finance statistics (domestic financing from the banking sector in the general government budget), find out the reasons for such inconsistency and take measures to eliminate them. We will request the MoF to provide report on Treasury bills trading and data on Government deposits with banks on a regular basis in order to reconcile these data with banks' balance sheets. In cases, when banks misreported Government deposits, we will verify with banks and rectify.

\subsection{Revision policy and practice}

The Monetary Policy and Research Department will prepare a revision policy paper and post on the web site of the BOM. The revision policy paper will comprise issues concerning modifications, for example, when and how data will be revised, how these changes will be studied and announced, and rationale for adjustment.

\section{Enhance the accessibility}

\subsection{Metadata accessibility}

We will prepare metadata with levels of detail adapted to needs of the general public and post on the web site of the BOM. This metadata will be based on metadata prepared within the GDDS framework and posted on Dissemination Standards Bulletin Board (DSBB) of the IMF. However, metadata will be adjusted to meet needs of domestic legal entities and individuals. 


\subsection{Assistance to users}

The home page of the BOM lists all publications and statistical data in two menus:

Publications and Statistics, and provides links to these sources. The issue to combine these two menus is questionable. However, we will study the appropriate information on other central banks' web site and define the desired structure.

\section{B. Balance of Payments Statistics}

1. Fill vacant staff positions. Consider creating one or two statistical officer grade positions to specialize in surveys and data processing. Link future improvements to availability of additional staff. Provide specialized computer support suitable for use in large-scale statistical collection systems, such as on-line reporting and a data processing system built on a database.

A new senior economist is appointed and another staff was employed to work in Balance of Payments and Research unit. Still have one economist's vacant position. Quarterly training course on the ITRS is organized. It needs more specialized computer software for collecting, processing and analyzing large-scale information. A new software and more advanced computer technology will be introduced in compilation of Balance of payments. The Bank of Mongolia (BOM) is planning to introduce this new system on the collection of ITRS data and enterprise reports. To create a new computer based statistical collection system the International department will need to send the BOP staff to Central banks of other countries to learn about their experience on software use.

2. Adopt policy of advance notification of major changes in methods by notification in a regular quarterly publication or by ad hoc release.

Advance notification of major changes in methods will be done in further quarterly publications. Notes regarding enterprise survey and International investment position (IIP) will be done.

3. Seek to identify any variations in timing for major transactions (such as major sales or purchases of equipment) and make adjustments where necessary.

In order to identify timing for major transactions the BOP compilers contacted the direct reporters of main enterprises to clarify the transactions and crosscheck it with the ITRS.

4. Update the register for the enterprise survey on an annual basis. Conduct intensive followup of nonresponse and develop suitable estimation procedures for nonresponse for the enterprise survey.

Update of the registration of enterprise survey is done when the enterprise survey was conducted. BOP compilers are still keeping contact with the enterprises that had no response to obtain available information and also received more information from different source and 
compared their activities with similar enterprises. We are working on the estimation for nonresponse of the enterprise survey.

5. Review gaps and problems on a continuing basis to see if they become more significant. Monitor new economic developments, such as free trade zones and commercial bond issues, to see if they require additional sources of data to be identified. Conduct a further survey of remittance recipients to ask them the channels used for sending remittances, and incorporate adjustment ratios to account for the proportion of remittances outside the ITRS. Use the incomplete data of the enterprise survey to identify the scope of omitted reinvested earnings, dividends in kind, and intercompany lending for direct investment in Mongolia. Consult with the Financial Regulatory Commission to allow measurement of transactions made through foreign exchange bureaus. Attempt to exclude holding gains and losses from reserves transactions, by direct reporting from the Accounting and Information Technology Department or making calculations separately for each major currency and gold.

The BOM will continue to review the problematic issues and consult it with experts from IMF and others. BOP compilers are monitoring new economic developments very carefully. BOM already contacted the Mongolian Stock Exchange and other big commercial banks who is involved in the issuing bonds and securities. As for the survey of remittance recipients, in the first half of 2007, BOM already conducted the remittance consumption survey among the recipients including questions on channels used for sending remittances, their preference, remitting fee, how they spend received remittances, and we are planning to conduct this survey on annual basis and collect more information on illegal channels they use for sending remittance and will calculate the adjustment ratios to account for the proportion of remittances outside the ITRS. The result of the enterprise survey is ready and BOM is working on identifying the omitted reinvested earnings, dividends in kind, intercompany lending for direct investment. BOM consulted with the Financial Regulatory Commission on measuring the transactions made through foreign exchange bureaus. In recording reserves transactions in BOP we are already excluding holding gains and losses. From the $3^{\text {rd }}$ quarter of 2007 , based on our own separate calculations for each major currency and gold, all these transactions are included without revaluation in the BOP Statistics of Mongolia.

6. Develop annual measures of international investment position. In the meantime, publish already available components on public debt and reserve assets and reserve-related liabilities. Introduce validation checks with the rate of return on various assets and liabilities when international investment position data are developed. Monitor the media and maintain contact with major businesses to identify new developments in the economy so as to be forward-looking in implementing methods to cover these developments in balance of payments statistics at the same time as they emerge.

BOM will introduce such practice.

7. Introduce reconciliation between stocks and flows when international investment position data are developed.

BOM will introduce such practice. 
8. $\quad$ Prepare a standard table comparing data in the latest period with the corresponding data in previous releases and write down explanations. Carry out longer term studies of revisions, if suitable investigatory staff are available.

BOP revisions are done to the previous releases and its explanations are indicated as a footnote in the quarterly and annual BOP reports. We will prepare a standard table for comparing data and will do longer term studies of revisions.

9. Conduct routine checks of balance of payments with overlapping items in government finance statistics and attempt to explain discrepancies.

The BOM contacted the Ministry of Finance and conducting routine checks of BOP with government finance statistics. Data source used in the compilation of BOP is the same.

10. Publish a revisions policy.

The revision policy for BOP Statistics is described as an attachment in the BOP report of the $2^{\text {nd }}$ quarter of 2007 . This quarterly report is already posted on the BOM's website.

11. Publish a catalog of publications and services along with their prices.

The International department will provide more information on its BOP publication in accordance with other department's publication, and it will be indicated with its related charge. 


\section{INTERNATIONAL MONETARY FUND}

MONGOLIA

\section{Report on the Observance of Standards and Codes (ROSC)—Data Module}

\section{Volume III}

\section{Detailed Assessments Using the Data Quality Assessment Framework (DQAF) \\ Prepared by the Statistics Department \\ Approved by Robert W. Edwards and David Burton}

March 27, 2008

This document contains a detailed assessment by dataset of the elements and indicators that underlie the data quality dimensions discussed in Mongolia Report on the Observance of Standards and Codes (ROSC)—Data Module. It also includes as appendices the DQAF generic framework and the results of the users' survey. 


\section{Contents}

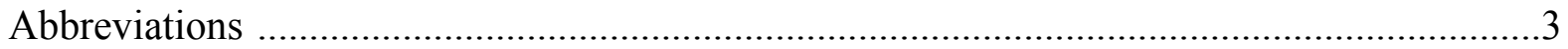

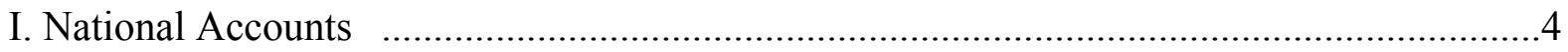

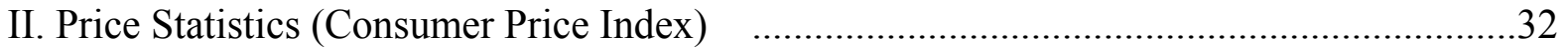

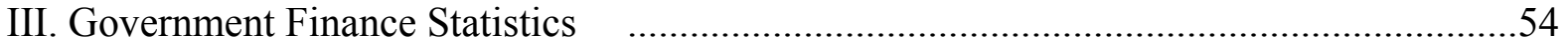

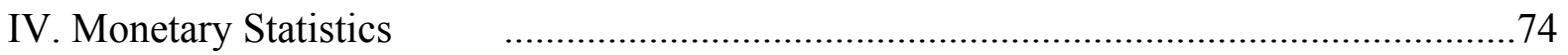

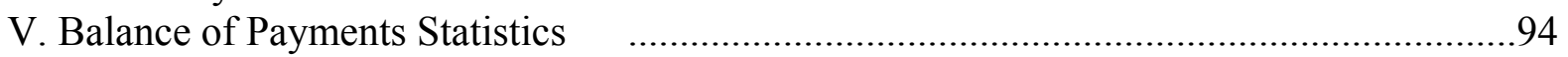

Tables

1. DQAF (July 2003): Summary of Results for National Accounts .....................................30

2. DQAF (July 2003): Summary of Results for Price Statistics (Consumer Price Index).......51

3. DQAF (July 2003): Summary of Results for Government Finance Statistics....................71

4. DQAF (July 2003): Summary of Results for Monetary Statistics ...................................92

5. DQAF (July 2003): Summary of Results for Balance of Payments Statistics..................119

Appendices

I. Summary of the General Data Dissemination System (GDDS) ....................................121

II. Data Quality Assessment Framework-Generic Framework .......................................123

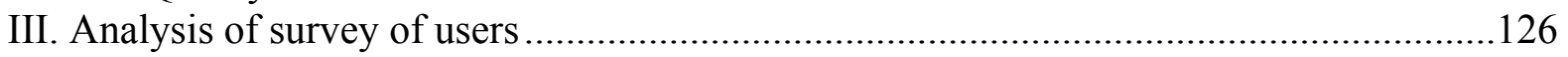

IV. Comments by Users of Macroeconomic Statistics ............................................... 127

Appendix Tables

Appendix Table 1. Mongolia—Results of Users' Survey ..............................................129 
ABbreviations

$\begin{array}{ll}1993 \text { SNA } & \text { System of National Accounts 1993 } \\ \text { BOM } & \text { Bank of Mongolia } \\ \text { BPM5 } & \text { Balance of Payments Manual, fifth edition } \\ \text { BTC } & \text { Bankers Training Centre } \\ \text { c.i.f. } & \text { cost, insurance, and freight } \\ \text { COFOG } & \text { Classification of the Functions of Government } \\ \text { COICOP } & \text { Classification of Individual Consumption by Purpose } \\ \text { CPI } & \text { Consumer Price Index } \\ \text { DMD } & \text { Debt Management Division } \\ \text { DSBB } & \text { Dissemination Standards Bulletin Board } \\ \text { FARD } & \text { Finance, Accounting, and Reporting Division } \\ \text { FIFTA } & \text { Foreign Investment and Foreign Trade Agency } \\ \text { f.o.b. } & \text { free on board } \\ \text { GDDS } & \text { General Data Dissemination System } \\ \text { GFMIS } & \text { Government Financial Management Information System } \\ \text { GFS } & \text { Government Finance Statistics } \\ \text { GFSM 1986 } & \text { A Manual on Government Finance Statistics, 1986 } \\ \text { GFSM 2001 } & \text { Government Finance Statistics Manual 2001 } \\ \text { HIES } & \text { Household Income and Expenditure Survey } \\ \text { IMF } & \text { International Monetary Fund } \\ \text { ISIC } & \text { International Standard Industrial Classification } \\ \text { ISWGNA } & \text { Inter-Secretariat Working Group on National Accounts } \\ \text { ITRS } & \text { International Transactions Reporting System } \\ \text { KFW } & \text { German Development Foundation } \\ \text { MFSM } & \text { Monetary and Financial Statistics Manual } \\ \text { MOF } & \text { Ministry of Finance } \\ \text { NSO } & \text { National Statistical Office } \\ \text { PSMFL } & \text { Public Sector Management and Finance Law } \\ \text { SDDS } & \text { Special Data Dissemination Standard } \\ \text { SPPCD } & \text { Statistics Policy, Planning, and Coordination Department } \\ \text { STA } & \text { IMF Statistics Department } \\ \text { SUT } & \text { Supply and Use Table } \\ \text { TSA } & \text { Treasury Single Accounts } \\ & \end{array}$




\section{National Accounts}

\section{Prerequisites of quality}

\section{$0.1 \quad$ Legal and institutional environment}

\subsubsection{The responsibility for collecting, processing, and disseminating the statistics is clearly specified.}

The central statistical system of Mongolia comprises the National Statistical Office (NSO) and statistical units at the regional level. The NSO is an independent public agency, headed by a chairman who reports directly to the Parliament of Mongolia, the Great Khural.

Chapter 2, Article 5 of the Law on Statistics, passed by the Parliament of Mongolia on June 5, 1997 (revised in 2004) ${ }^{1}$, stipulates that the central statistical system is responsible for collecting, compiling, and disseminating all official statistics. Article 6 of the Law presents a schedule of some of the information that may be considered official statistics. This schedule identifies specifically indicators of gross domestic product (GDP) and the consumer price index (CPI). However, the schedule is considered neither exhaustive nor restrictive; the Law considers as official statistics, all statistics produced by the central statistical system, thus including those not explicitly covered by the schedule. Therefore, the Law adequately supports the NSO's production of national accounts aggregates, beyond GDP, as well as price indices other than the CPI.

Further, Article 12 of the Law provides the NSO with broad authority to determine the responsibilities of respective government agencies with regard to the compilation of official statistics. Thus, this broad authority provided to the NSO would prevent or resolve conflicts or potential conflicts regarding the production of the statistics.

\subsubsection{Data sharing and coordination among data-producing agencies are adequate.}

The Law provides a strong legal basis for the role of the NSO in coordinating statistical activities. Chapter 4, Article 11 of the Law stipulates that the NSO is independently responsible for coordinating all official statistical activities and functions in Mongolia. Further, the NSO's mandate on coordination includes responsibility for the following:

(i) providing the official statistical activities with centralized and overall management and co-ordination;

\footnotetext{
${ }^{1}$ The amendments undertaken in 2004 did not have a material effect on the responsibilities of the NSO that were established in the 1997 version of the Law.
} 
(ii) providing guidelines for the organizations engaged in official statistical activities and respondents for conducting censuses and surveys;

(iii) collecting official statistical information from relevant ministries and other state organizations in a specified time; and

(iv) approving and accepting methodologies and manuals or instructions of various censuses, surveys and official statistics and set up the time of their announcement.

In addition, in order to minimize the duplication of information gathering, the Law stipulates that regional statistical agencies must seek the approval of the NSO on all data gathering activities that they wish to undertake.

The NSO has signed memoranda of understanding on data sharing with the Bank of Mongolia (BOM), the Customs Department, and the Tax Administration Office. The memoranda specify what kinds of data should be shared between the signatories, when the data should be provided, and in what form the data should be transmitted. The NSO also holds regular meetings with these agencies as the need arises.

The NSO has also established a working group on data sharing and coordination with the Ministry of Finance (MOF). The group comprises four representatives from the NSO and two from the MOF. It meets quarterly to discuss the data requirements of both agencies.

\subsubsection{Individual reporters' data are to be kept confidential and used for statistical purposes only.}

Chapter 6, Article 22 of the Law establishes guidelines on confidentiality for both the statistical organizations and respondents. The Law prohibits the staff of official statistical organizations from disseminating information that is being processed or revealing the identity of individuals and establishments. The Law also prohibits the dissemination of raw data from censuses and surveys before the advertised release date.

Chapter 3, Article 9 outlines the rights and responsibilities of respondents regarding the confidentiality of information that they may provide to the NSO. Among these, the respondents have a right to demand that the data they provide to statistical agencies be kept confidential. Thus, the agencies must satisfy respondents that they would take the necessary safeguards to ensure that the data are not disseminated in a form that would allow the identification of the individual units. The data collection instruments clearly outline the confidentiality provisions that underline the data collection process.

Survey results that are transmitted from the regional offices to the NSO are coded and do not contain the identification of the respondents. Thus, the identity of the respondents would not be revealed if the documents are lost during transmission or are accessed by unlawful means. 


\subsubsection{Statistical reporting is ensured through legal mandate and/or measures to encourage response.}

Chapter 3, Article 9 stipulates that respondents have an obligation to provide official statistical information, at their own cost, to the statistical agencies. The NSO, on the other hand, is mandated to collect statistical information from all respondents in a timely manner.

The Law also establishes the responsibilities of the other units of the statistical system to collect decentralized information and to provide such information to the NSO on a timely basis.

The NSO depends heavily on the regional agencies to undertake all the requisite survey fieldwork. Due to the relative unreliability of the postal service, staff of the regional agencies deliver the questionnaires by hand. However, this method is very beneficial as the field staff are able to build good working relationships with the respondents. They therefore make regular follow-up visits to address queries and to assist the respondents in completing the questionnaires. In addition, the NSO employs statistical inspectors who visit nonrespondents and encourage them to respond to the respective surveys.

Although the NSO has the authority to penalize non-respondents, it has seldom resorted to this measure as it considers the other activities to improve response rate as being adequate. The effectiveness of these activities is exemplified by high response rates, (between 80 percent and 90 percent) recorded for the enterprise survey since 2005.

The NSO collects a wide range of data through censuses that are required by the Law and through regular surveys. It is therefore extremely commendable that the agency is able to achieve such high response rates considering the amount of information that it requests, the relatively tight schedule of the data collection process, and the limited resources, both at the regional level and at the central level, available for data collection.

\section{$0.2 \quad$ Resources}

\subsubsection{Staff, facilities, computing resources, and financing are commensurate with statistical programs.}

The NSO employs 82 staff and a further 139 persons work at the 22 regional statistical offices. The staff at the regional offices are primarily engaged in survey data collection to support the work of the NSO. The Statistical Planning and Policy Coordination Department (SPPCD), one of four departments in the NSO, is responsible for compiling the national accounts statistics. The Statistical Integrated Policy Division of the SPPCD employs eight people, and three are engaged in national accounts compilation. The staff have received substantial training in national accounts compilation through attendance at training courses conducted by the International Monetary Fund (IMF) and other international organizations. All the national accounts staff possess university degrees in economics or statistics. Staff 
turnover has been relatively low; thus, the NSO has been able to retain a cadre of trained professionals.

However, the staff complement is not adequate to allow the NSO to undertake the ambitious national accounts compilation program. The NSO recognizes the need to employ additional staff, but it is constrained by the budget allocation received from the central government. The salaries of the NSO staff follow the salary guidelines of the central government, and the wage bill is constrained by the budget allocations.

The staffing levels at the provincial statistical offices are relatively low, considering their workload in conducting surveys for the NSO and in compiling statistics the regional governments. Further, staff turnover is high, due to the low remuneration and expertise needs to be improved. Based on the staffing and expertise of the provincial officers, it is doubtful that they are capable of undertaking the intensive survey follow-up and data crosschecks that are required.

The budget allocation is not sufficient for the NSO to undertake its regular statistical activities, and the agency remains dependent on the grants from international organizations to undertake critical survey work.

The office building provides adequate facilities for the current staff, but office space is very limited. This would therefore preclude the NSO from increasing staffing, even if feasible, without the acquisition of additional space.

The NSO recently upgraded its computing resources. All staff now have adequate access to computing resources through personal computers and a local area network.

\subsubsection{Measures to ensure efficient use of resources are implemented.}

Staff performance is evaluated on a quarterly basis, and the NSO has developed a system of awards to reward good performance. These include nomination of staff for state orders and decorations and increases in benefits.

In planning the statistical program, the NSO also solicits the views of staff on how the work could be improved, areas requiring special attention from management, and whether staff have sufficient time to undertake developmental activities.

\section{Recommendations:}

- Increase staff resources commensurate with the work program; and

- $\quad$ Address the critical shortage of physical facilities since the current facilities will not be able to accommodate additional staff. 


\subsection{Relevance}

\subsubsection{The relevance and practical utility of existing statistics in meeting users' needs are monitored.}

The NSO staff consult regularly with users in the public sector through regular working group meetings and bilateral meetings arranged on the basis on the respective memoranda of understanding.

The NSO has conducted ad hoc seminars with various groups of users in the private sector; however, there is no structured process to obtain regular feedback from users. The management often participates in meetings of regional and international organizations where emerging statistical standards and data requirements are discussed. The NSO frequently makes presentations at these meetings on the statistical compilation process in Mongolia and solicits feedback from other advanced statistical agencies on how the process could be improved.

\section{Recommendation:}

- Implement systematic programs to obtain the views of a wide cross-section of users, especially users in the private sector.

\subsection{Other quality management}

\subsubsection{Processes are in place to focus on quality.}

The NSO's mission is to provide government and public users with reliable and accurate statistics that are immune to political influence, scientifically feasible, and acceptable. The need to improve the quality of the statistics is always at the forefront of the planning process. The NSO has developed a Program for Official Statistics Development, 2006-2010 to improve the statistics in line with the recommendations of the General Data Dissemination System (GDDS). The principal objective of the program is to develop national statistical standards that are based on internationally accepted methodologies to meet the needs of the public and to provide users with high quality statistics.

\subsubsection{Processes are in place to monitor the quality of the statistical program.}

The NSO established a Methodology and Research Department in 2005 to assist the management in monitoring the quality of the agency's output. Among the main objectives of the department are to undertake statistical research to improve the statistical output and to review methodological issues.

In addition, the NSO Board has established a Standing Council on Methodology and Research. The main functions of this council are to improve statistical systems to establish 
reliable and timely statistical systems, and to make recommendations on the statistical framework, concepts, and methodologies.

\subsubsection{Processes are in place to deal with quality considerations in planning the statistical program.}

The NSO prepares an annual work plan twelve months before the start of the year, which outlines the output objectives of each department. The plan identifies the expected cost of the output; however, the expected output is usually constrained by the budget allocation provided by the central government. Thus, the NSO has to consider carefully, the resource implications of the work plan and its attempts to balance the needs for timely data by users, especially those in the public sector, with the need to compile accurate and reliable statistics. The NSO also prepares an annual production schedule that takes account of the need to disseminate the data in a timely manner.

\section{Assurances of integrity}

\subsection{Professionalism}

\subsubsection{Statistics are produced on an impartial basis.}

Chapter I, Article 4 of the Law establishes the independence of official statistics as one of its six key principles. This principle is supported by the institutional arrangements for the appointment, tenure, and functioning of the chairman of the NSO, which provide the necessary guarantees that the agency head would be able to undertake his responsibilities in an impartial manner. The Parliament of Mongolia appoints the chairman for a fixed but renewable six-year term, and the Law outlines the precise conditions under which the tenure of the chairman may be terminated before completion of the six-year term. His services may be terminated involuntarily only if performance is deemed to be unsatisfactory, if he is deemed to be unable to undertake his duties satisfactorily (for health reasons), or if he is convicted for a criminal offense.

The Law provides the chairman with sole authority for approving and adopting decisions relating to the management and organization of official statistics. The chairman has the authority to appoint the heads of regional statistical agencies, based on the recommendations of the regional governors, and maintains direct contact with parliamentary standing committees relating to statistics.

Staff recruitment is governed by the Law of the Public Service. To recruit staff, the NSO must first submit a request to the Public Administration Committee, specifying the requirements for the position. Applicants must take the public service examination and may be interviewed on areas specific to the position. Staff are recruited for a six-month probationary period, during which their performance is assessed. Staff are only appointed to a permanent position if the NSO deems that their performance meets the agency's standards. 


\subsubsection{Choices of sources and statistical techniques, as well as decisions about dissemination, are informed solely by statistical considerations.}

The choices of sources and statistical techniques are influenced solely by statistical considerations. Staff, with the occasional assistance of external experts, decide on the statistical techniques, methodology, and data sources to be employed based solely on the need to implement international recommendations.

\subsubsection{The appropriate statistical entity is entitled to comment on erroneous interpretation and misuse of statistics.}

The NSO, being an independent public agency, is entitled to address the media and comment on the use of the statistics that it produces.

\subsection{Transparency}

\subsubsection{The terms and conditions under which statistics are collected, processed, and} disseminated are available to the public.

The Law on Statistics is available on the website of the NSO in Mongolian. The agency is yet to upload the English version of the Law. In addition, the data collection instruments refer to the Law and advise respondents about their rights and responsibilities under the Law. Copies of the $L a w$ are available at the agencies offices.

\subsubsection{Internal governmental access to statistics prior to their release is publicly identified.}

There is no internal access to the statistics prior to their release.

\subsubsection{Products of statistical agencies/units are clearly identified as such.}

The products of the NSO are clearly identified by name and with the agency's logo. However, the output of individual units within the NSO is not distinguished separately. When the NSO conducts exercises with other government agencies, the NSO is clearly identified as a contributor to the output.

\subsubsection{Advance notice is given of major changes in methodology, source data, and statistical techniques.}

Apart from occasional announcements of the agency's work plans, the NSO provides no advance notice of changes in methodology, source data, and statistical techniques.

The agency released revised estimates of GDP in August 2007 with the volume estimates rebased at 2005 prices. However, it did not provide any indication to users that these revised data were forthcoming. 


\section{Recommendation:}

- Develop and implement a policy to inform users of upcoming changes in the compilation process and the effects on disseminated data. The policy should include guidelines on the timeframe for advance notification and types of media.

\subsection{Ethical standards}

\subsubsection{Guidelines for staff behavior are in place and are well known to the staff.}

Staff are subject to the internal rules of the NSO as well as the rules and regulations of the public service. The NSO's Administration Department provides a copy of the rules and regulations to all new staff upon recruitment. Staff must also take an oath of secrecy before they can have access to any information collected by the NSO. The rules and regulations prohibit staff from using the statistical information for personal gain or from taking part in political activities. Staff may be dismissed for breaching the staff rules.

\section{Methodological soundness}

\subsection{Concepts and definitions}

2.1.1 The overall structure in terms of concepts and definitions follows internationally accepted standards, guidelines, or good practices.

The national accounts statistics are compiled according to the broad guidelines of the 1993 SNA.

\subsection{Scope}

2.2.1 The scope is broadly consistent with internationally accepted standards, guidelines, or good practices.

The accounts and tables in the scope of the national accounts compilation process are limited. The regular national accounts system covers only the following accounts and tables that are considered part of the minimum requirements for implementation of the System of National Accounts, 1993 (1993 SNA) by the Inter-Secretariat Working Group on National Accounts (ISWGNA):

- $\quad$ Value added and GDP by type of economic activity at current and constant prices;

- $\quad$ Value-added components by type of activity; and

- $\quad$ Expenditure components of GDP at current prices. 
These accounts are not sufficient to fulfill the minimum requirements established by the ISWGNA for implementing the 1993 SNA. The other required accounts that are not compiled and disseminated cover the following:

- $\quad$ Expenditure on GDP in constant prices;

- Income and capital accounts with an annual frequency; and

- $\quad$ Annual rest of the world accounts (including net lending).

In addition to the aforementioned accounts, the NSO compiles supply and use tables (SUT) at five yearly intervals; the last SUT was compiled for 2005.

The NSO compiles various other accounts on an experimental basis; however, the compilation process is not complete, and the data are not disseminated. These accounts are as follows:

- Institutional sector for all resident sectors for 2000-2005. The accounts cover the production account, generation of income account, allocation of primary income account, secondary distribution of income account, use of income account, and the capital account;

- $\quad$ Quarterly GDP by type of activity; and

- $\quad$ Expenditure on annual GDP at constant prices is at an advanced stage.

The NSO hopes to complete compilation and disseminate these accounts during 2008.

The NSO has not been able to compile any of the additional accounts and tables that the ISWGNA recommends for implementation of the 1993 SNA.

The delimitation of the constituent units of the economy is in accordance with the 1993 SNA. In particular, the following are considered part of the economic territory of Mongolia:

- Territorial enclaves in the rest of the world; and

- $\quad$ Bonded warehouses.

Mongolian workers who only work part of the year abroad are included in the economic territory of Mongolia. The number of nonresidents working part of the year in Mongolia is considered statistically insignificant. 
The production boundary is in accordance with the 1993 SNA where feasible. In particular, the following items are within the scope of output measurement:

- $\quad$ Own-account production of goods for own final consumption;

- $\quad$ Output of own account fixed capital formation; and

- $\quad$ Mineral exploration.

Research and development on own account, production of computer software, and illegal output is included in the production boundary but measurement remains a major challenge.

The assets boundary includes the following items:

- $\quad$ Tangible assets:

- defense related assets that could be used for civilian purposes;

- valuables; and

- agricultural work-in-progress.

- Intangible assets:

- mineral exploration;

- $\quad$ systems and standard applications computer software and databases;

- entertainment, literary or artistic originals;

- patented entities; and

- leases and other transferable contracts.

It should be noted, however, that the intangible assets, except mineral exploration, are relatively small and are not covered in a systematic manner.

\section{Recommendations:}

- $\quad$ Expedite the dissemination of accounts that are currently being compiled and not disseminated.

- $\quad$ The NSO should also implement a cohesive work program to ensure that these accounts are compiled and disseminated according to regular schedule.

\subsection{Classification/sectorization}

2.3.1 Classification/sectorization systems used are broadly consistent with internationally accepted standards, guidelines, or good practices.

The classifications used are consistent with internationally accepted standards, guidelines, and good practices as follows:

- $\quad$ The 1993 SNA is used to classify institutional units, transactions, and other flows; 
- The International Standard Industrial Classification (ISIC) is used to classify the economic activity of establishments and enterprises;

- The Central Product Classification is used to classify products;

- $\quad$ The Classification of Individual Consumption by Purpose (COICOP) is used to classify consumption; and

- $\quad$ The Classification of the Functions of Government (COFOG) is used to classify government transactions.

\subsection{Basis for recording}

\subsubsection{Market prices are used to value flows and stocks.}

The valuation rules used for recording flows and stocks are consistent with the 1993 SNA, where applicable:

- $\quad$ Market output is valued at producer prices;

- $\quad$ Output for own-use is valued at the prevailing market prices;

- Estimates of imports are adjusted from cost, insurance, and freight (c.i.f.) to free on board (f.o.b.) and exports are valued f.o.b. in line with the balance of payments statistics; and

- $\quad$ Transactions in foreign currency are converted using the mid-point exchange rate prevailing in the market at the time they take place.

\subsubsection{Recording is done on an accrual basis.}

Most transactions and flows are recorded on an accrual basis. Work in progress is recorded in the period that the work takes place. However, government transactions are recorded on a cash basis in line with the reporting procedures of the government finance statistics (GFS). The NSO does not attempt to adjust the estimates from cash to accrual, as this is not considered feasible. Mongolia is currently participating in a project to implement the Government Finance Statistics Manual 2001 (GFSM 2001) which recommends the use of accrual accounting. When implemented, it is expected that the NSO will receive the data in the requisite form.

\subsubsection{Grossing/netting procedures are broadly consistent with internationally accepted standards, guidelines, or good practices.}

Data are collected on an enterprise level; therefore, transactions between establishments of the same enterprise are recorded net. 


\section{Accuracy and reliability}

\subsection{Source data}

\subsubsection{Source data are obtained from comprehensive data collection programs that take into account country-specific conditions.}

The NSO has implemented a comprehensive system of surveys to obtain source data from households and enterprises. This system is supplemented by administrative data sources such as the Tax Administration Office, which provides comprehensive data on registered enterprises, other government agencies, and non-governmental organizations. In addition, the NSO conducted an economic census in 2006, in line with the stipulations of the Law that such censuses be conducted every five years. The source data are adequate for the compilation of the national accounts and are reviewed constantly to ensure that they meet the compilation requirements.

\section{Enterprise Survey}

The enterprise survey is conducted annually and covers all economic activities, with the exception of personal and business services. The survey combines sampling of selected activities (distribution, manufacturing, restaurants, coal mining) and full enumeration of all others. For the sampled activities, all enterprises above a set cut-off mark are included and stratified sampling methods are used to select the sample from remaining enterprises. The precise cut-off criterion depends upon the activity. For 2007, the overall sample was over 14,000 .

The frame for the sample is the business register, which contains about 40,000 listings of active enterprises. The NSO undertook a comprehensive update of the register following the enterprise census that was conducted in 2006. Other regular updates are conducted using the records of the Tax Administration Office, which submits to the NSO, annual reports on new business registrations and closures. The regional statistical offices would review the list to determine the ones that have begun operation. The regional office would then collect basic information on the operation.

\section{Household Income and Expenditure Survey}

The NSO conducts a continuous Household Income and Expenditure Survey (HIES) that covers the complete geographic area of Mongolia. The survey covers 936 households monthly, with a new sample of households being surveyed each month. Thus, 11,432 households are surveyed over a twelve-month coverage period. This represents a two percent sample of domestic households.

A two-stage sampling method is used. At the first stage, the enumeration districts are selected based on a probability proportional to size sampling method. One hundred and four enumeration districts, out of the 11,000 identified in the 2000 population and housing census, 
are sampled every month. At the second stage, households are selected based on simple random sampling methods.

Consumption is recorded at the detailed 6-digit level of the COICOP.

\section{$\underline{\text { Administrative Data }}$}

The NSO has access to a wide range of administrative data from various sources. These include the following:

- $\quad$ Bank of Mongolia-Financial and banking statistics;

- Ministry of Finance-Government finance statistics;

- Tax Administration Office-Returns of enterprises;

- Customs Administration-Foreign trade statistics;

- $\quad$ Financial Regulation Commission-Data on financial corporations;

- $\quad$ Ministry of Internal Justice-nongovernmental organizations;

- $\quad$ Ministry of Health;

- $\quad$ Ministry of Education, Culture, and Science;

- $\quad$ Ministry of Food and Agriculture; and

- $\quad$ Ministry of Construction and Urban Development.

\section{$\underline{\text { Price Statistics }}$}

The available price statistics are currently limited to the CPI and trade unit value indices. The CPI is only used sparingly in deriving constant price estimates when suitable indicators or price indices are not available. The NSO is currently developing a producer price index that it hopes to disseminate from 2008. The agency also plans to develop trade price indices, resources permitting.

\section{Ad hoc Surveys}

The NSO has not conducted many ad hoc surveys due to resource constraints. The most recent was a survey retail trade and transportation services, which was conducted in 2004. The survey was geared to obtaining information on informal sector activity.

\subsubsection{Source data reasonably approximate the definitions, scope, classifications, valuation, and time of recording required.}

The annual enterprise survey was designed specifically to take account of the needs of national accounts compilation and approximates the definitions, scope classifications, valuation, and time of recording required. However, the questionnaires are not activityspecific and may request some information that relevant to the activity being surveyed. 


\subsubsection{Source data are timely.}

The source data are received on a timely basis and allows the NSO to compile early estimates of annual GDP. Data from the enterprise survey, the HIES, and administrative sources are used to compile the first set of preliminary estimates within three months of the end of the reference period. The most challenging data source, in terms of timely execution and completion, is the annual enterprise survey. The survey questionnaires are delivered to respondents about four weeks following the end of the reference year (end-January) and responses are due by mid-March. The data must then be validated and processed in time for the compilation of the first estimates.

\subsection{Assessment of source data}

3.2.1 Source data - including censuses, sample surveys, and administrative records - are routinely assessed, e.g., for coverage, sample error, response error, and nonsampling error; the results of the assessments are monitored and made available to guide statistical processes.

The staff of the regional offices perform preliminary consistency checks on the data and may follow-up with respondents, where necessary. However, a comprehensive assessment of the source data is undertaken by the staff of the NSO. The data entry program contains built-in logical checks to identify errors in the data. In addition, the staff perform manual consistency checks to identify outliers.

The results of the enterprise survey are checked against business accounting data from the Tax Administration Office and the MOF. For large enterprises, the NSO may contact the enterprise directly to determine the accuracy of the data. The staff also conduct checks on the aggregated data for temporal consistency.

Information is available about the sampling error, the non-response, and processing errors of the surveys conducted by the NSO. These are monitored and the information is used to improve the survey process (see also 0.4.2).

However, staff are unable to undertake a comprehensive assessment of the source due to the tight national accounts compilation schedule and adequate follow-up of errors and inconsistencies are not undertaken. Further, there is no incentive to conduct a comprehensive review of the source data following the first round of compilation as the national accounts estimates are only reviewed once-a short period following the initial compilation (see also 4.3.1). 


\subsection{Statistical techniques}

\subsubsection{Data compilation employs sound statistical techniques to deal with data sources.}

The data entry programs for the surveys contain built-in checks, such as range checks, to spot and hence minimize editing and coding errors.

Imputations for nonresponse are minimal because of the relatively high response rates. However, when undertaken they conform to international best practice. Employment-based methods using similar enterprises in the industry are commonly used to estimate the aggregates of the missing enterprises.

3.3.2 Other statistical procedures (e.g., data adjustments and transformations, and statistical analysis) employ sound statistical techniques.

Although there is concern that the output of informal activity may be large, it is not incorporated in the accounts in a systematic manner. The output of self-employed persons and households is not covered by the regular data collection exercise. The NSO has instituted data collection programs to cover these activities and plans to include them in the estimates shortly.

\section{Production Approach Procedures}

The level of detail used to compile estimates of output and intermediate consumption depends on the availability of data and the relative importance of the activity to overall GDP. Estimates of value added for services are derived at the 4-digit level of the ISIC Rev. 3, food and beverage manufacturing is derived at the 3-digit level, and all other activities at the 2-digit level.

\section{$\underline{\text { Specific Issues }}$}

\section{- $\quad$ Owner-occupied dwellings}

The output of owner-occupied dwellings is derived as the estimated rental values that the owner would pay for similar accommodation. This is in line with international practice. The data are derived from the HIES, which collects data on rental values of owner-occupied dwellings.

\section{- Work-in-progress}

Construction projects that span more than one period are treated as work-in-progress. The rearing of livestock for food is also treated as work in progress.

\section{- Inventory valuation adjustment}


Output is not adjusted for holding gains or losses accruing on inventories

\section{- Consumption of fixed capital}

The perpetual inventory method is not used to estimate consumption of fixed capital. Instead, the estimates of depreciation obtained from the enterprise survey are used to approximate consumption of fixed capital.

- $\quad$ Cash versus accrual

The data on government operations, which are on a cash basis, are not converted to accrual (see also 2.4.2).

\section{Issues Relating to Volume Measures of GDP}

The estimation of GDP volumes is based primarily on single indicator methods using the volume indicators listed below. Double deflation is not used due to the unavailability of adequate data to deflate intermediate consumption. However, where price indices are used to derive volume estimates, the value added is deflated directly using the price index. This practice is not in line with international recommendations.

The base year for the volume estimates is 2005 and it was recently updated from 2000 . This is in line with international practice, which recommends that the base year be updated with a minimum frequency of five years.

Volume measures of taxes on products are estimated by direct deflation using the CPI. This is not in line with internationally recommended practice.

The volume of trade margins is estimated by direct deflation using the CPI. 
INDICES USED FOR CONSTANT PRICE ESTIMATION

\begin{tabular}{|c|c|c|}
\hline \multicolumn{2}{|c|}{ CodeEconomic Activity } & \multirow[t]{2}{*}{ Index } \\
\hline $\mathbf{A}$ & Agriculture, hunting, forestry & \\
\hline 011 & growing of crops & Volume index of crops products \\
\hline 012 & farming of animals & Volume index of livestock products \\
\hline 015 & hunting & Volume index of hunted animals \\
\hline 02 & forestry & Volume index of logging trees \\
\hline \multicolumn{3}{|c|}{ C Mining and quarrying } \\
\hline 10 & mining of coal & Volume index of coal \\
\hline 11 & extraction of crude petroleum and natural gas & Volume index of crude petroleum \\
\hline 13 & mining of metal ores & Volume index of metal ores commodities \\
\hline 14 & other mining and quarrying & Volume index of other mining commodities \\
\hline \multicolumn{3}{|c|}{ D Manufacturing } \\
\hline 15 & manufacture of food products and beverages & \\
\hline 151 & $\begin{array}{l}\text { production, processing and preservation of meat, fish, } \\
\text { fruit, vegetables, oils and fats }\end{array}$ & Volume index of meat products \\
\hline \multirow{2}{*}{152} & manufacture of dairy products & Volume index of milk products \\
\hline & manufacture of grain mill products, starches and starch & \\
\hline 153 & products, and prepared animal feeds & Volume index of flour \\
\hline 154 & manufacture of other food products & Volume index of bakery products \\
\hline 155 & manufacture of beverages & Volume index of beverages \\
\hline 17 & manufacture of textiles & Volume index of textile products \\
\hline 18 & $\begin{array}{l}\text { manufacture of wearing apparel, dressing, and dyeing of } \\
\text { fur } \\
\text { tanning, dressing of leather; manufacture of luggage }\end{array}$ & Volume index of cloth goods \\
\hline \multirow{6}{*}{$\begin{array}{l}19 \\
20 \\
21 \\
22 \\
24 \\
25\end{array}$} & handbags, saddlery harness, footwear & Volume index of leather goods \\
\hline & manufacture of wood and wooden products & Volume index of wood products \\
\hline & manufacture of paper and paper products & Volume index of paper products \\
\hline & publishing, printing and reproduction of recorded media & Volume index of printed goods \\
\hline & manufacture of chemicals and chemical products & Volume index of chemical products \\
\hline & manufacture of rubber and plastic products & Volume index of rubber products \\
\hline \multirow{3}{*}{$\begin{array}{l}26 \\
27\end{array}$} & production of other nonmetallic mineral products & Volume index of nonmetallic mineral products \\
\hline & manufacture of basic metals & Volume index of basic metal products \\
\hline & manufacture of fabricated metal product, except machinery & \\
\hline 28 & and equipment & Volume index of fabricated metal products \\
\hline 29 & manufacture of machinery and equipment & Volume index of machinery and equipment \\
\hline 31 & $\begin{array}{l}\text { manufacture of electrical machinery and apparatus } \\
\text { manufacture of radio, television and communication }\end{array}$ & Volume index of electrical apparatus \\
\hline \multirow[t]{2}{*}{32} & equipment & Volume index of TV sets \\
\hline & manufacture of medical precision and optical instruments, & \\
\hline \multirow{7}{*}{$\begin{array}{l}33 \\
34 \\
35 \\
36\end{array}$} & watches and clocks & Volume index of medical products \\
\hline & manufacture of motor vehicles, trailers & \\
\hline & manufacture of other transport equipment & Volume index of other transport equipment \\
\hline & manufacture of furniture, manufacturing n.e.c. & \\
\hline & manufacture of furniture & Volume index of furniture \\
\hline & manufacturing n.e.c & Volume index of other manufactured goods \\
\hline & Recycling & Volume index of recycling \\
\hline
\end{tabular}




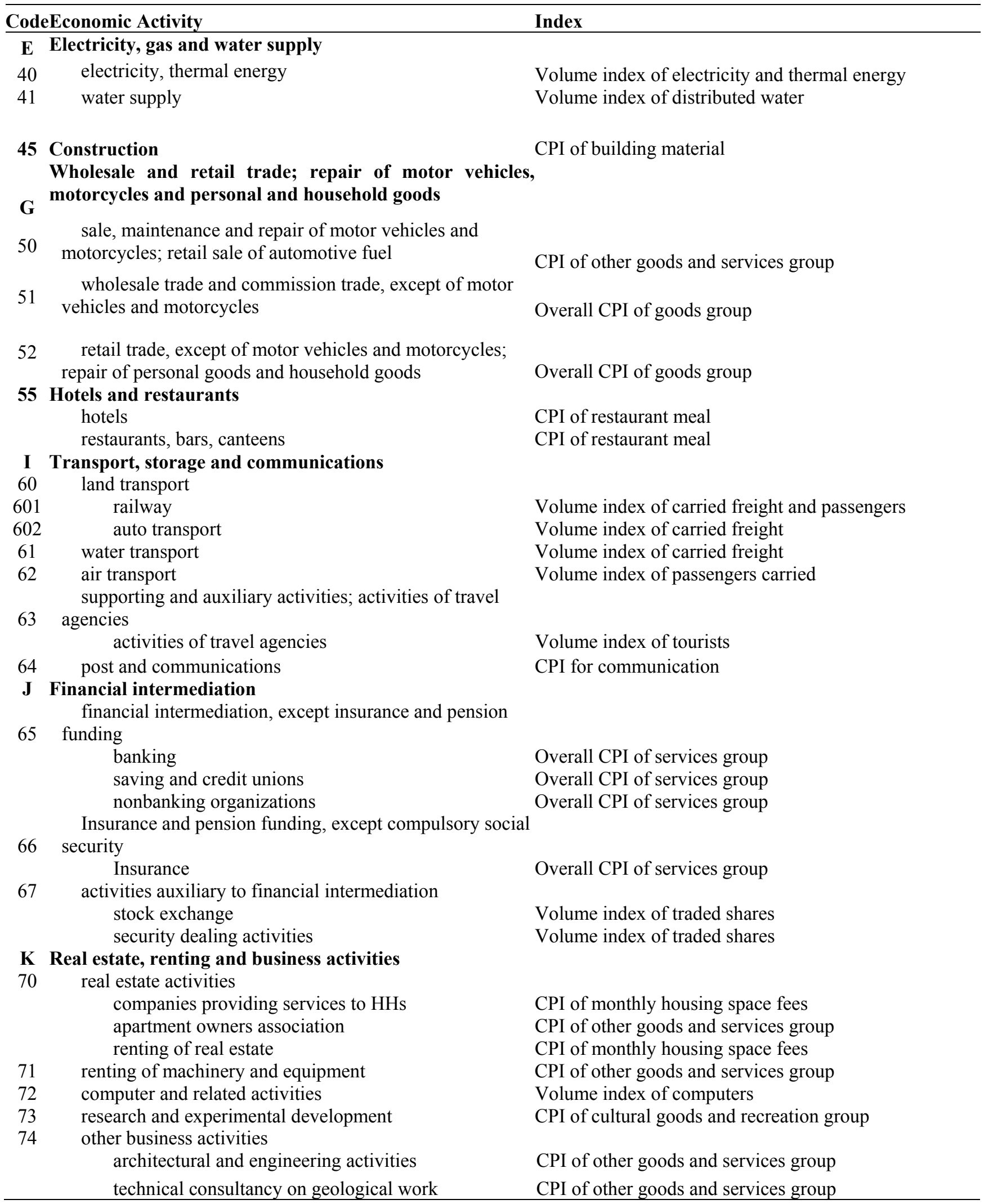




\begin{tabular}{|c|c|c|}
\hline \multirow[t]{4}{*}{ Code } & Economic Activity & Index \\
\hline & security activities & CPI of other goods and services group \\
\hline & photographic activities & $\mathrm{CPI}$ of other goods and services group \\
\hline & other business activities n.e.c. & CPI of other goods and services group \\
\hline & Public administration and defense; compulsory social & \\
\hline $\mathbf{L}$ & security & Volume index of employees \\
\hline \multirow{3}{*}{$\mathbf{M}$} & Education & \\
\hline & Private & CPI of annual tuition fees \\
\hline & Public & Volume index of employees \\
\hline \multirow[t]{4}{*}{$\mathbf{N}$} & Health and social work & \\
\hline & Public & Volume index of employees \\
\hline & Private & CPI of medical care and services group \\
\hline & veterinary activities & CPI of medical care and services group \\
\hline \multirow[t]{15}{*}{$\mathbf{O}$} & Other community, social and personal service activities & \\
\hline & hairdressing and other beauty treatment & CPI of other goods and services group \\
\hline & washing and dry cleaning & CPI of other goods and services group \\
\hline & bath house & CPI of other goods and services group \\
\hline & Other & \\
\hline & civil accomplishment & CPI of other goods and services group \\
\hline & cleaning rubbish & CPI of other goods and services group \\
\hline & sporting and other recreational activities & CPI of other goods and services group \\
\hline & radio \& television activities & CPI of other goods and services group \\
\hline & dramatic arts, music and other art activities & CPI of other goods and services group \\
\hline & other recreational activities & $\mathrm{CPI}$ of other goods and services group \\
\hline & funeral and related activities & CPI of other goods and services group \\
\hline & activities on religious organizations & Overall CPI of services group \\
\hline & $\begin{array}{l}\text { activities of business, employers and professional } \\
\text { organizations \& religious organizations }\end{array}$ & Overall CPI of services groun \\
\hline & FISIM & Overall CPI of services group \\
\hline
\end{tabular}




\section{Expenditure Approach Procedures}

- The major categories of GDP by expenditure are derived independently.

- $\quad$ Household final consumption is estimated using primarily data from the HIES.

The estimates are compiled according to the 6-digit level of the COICOP.

- Gross fixed capital formation is derived by asset groups and type of activity based on data from the annual enterprise survey. The estimates are not adjusted for informal activity; therefore, some gross fixed capital formation undertaken by households may not be included. Further, there is evidence of some double counting and misclassification of items. Durable goods purchased by households are incorrectly classified as gross fixed capital formation, rather than household consumption. The NSO also attempts to reconcile the estimates with the financing of capital investment. However, the definition of capital investment in government and business accounting may not equate with the definition of gross fixed capital formation used in the national accounts.

- The BOM provides estimates on the government holdings of valuables in the form of nonmonetary gold and other valuables. However, the data are not considered comprehensive and may not accurately reflect the economy's acquisitions of valuables.

- Government final consumption expenditure is compiled at the 2-digit level of the COFOG, which is in line with international best practice.

- Data on imports and exports of goods and services are derived from the BOM's balance of payments estimates.

- The reliance on fixed ratios in the estimation process is very limited. The estimates are derived mainly from data that are compiled annually.

Proper techniques are used to address specific items of expenditure on GDP compilation.

- $\quad$ Government final expenditure excludes incidental sales;

- $\quad$ Expenditure of residents abroad is included in estimates of imports; and

- Expenditure of nonresidents in the domestic economy is included in exports.

\section{Recommendations:}

- Review the techniques and data used to derive volume estimates.

- Use single extrapolator methods to derive the volume estimates when using a price index. 
- $\quad$ Value added should never be deflated directly.

- Review the estimation of gross fixed capital formation to eliminate double counting.

- Implement international best practice to derive volume estimates of taxes by applying base-year-tax rates to the volume of transactions subject to a specific tax or by extrapolating the base-year tax using a volume extrapolator of transactions subject to that tax.

- Implement international best practice to derive volume estimates of trade margin by applying the base-year-margin rates to the corresponding volume of sales or by extrapolating the base-year-trade margins using volume extrapolators of sales.

\subsection{Assessment and validation of intermediate data and statistical outputs}

\subsubsection{Intermediate results are validated against other information, where applicable.}

Aggregate data from the annual enterprise survey are validated against data from the Tax Administration Office. Estimates of financial intermediation are validated against information from the Financial Regulatory Commission.

\subsubsection{Statistical discrepancies in intermediate data are assessed and investigated.}

The NSO investigates statistical discrepancies in the intermediate data by assessing the major units. Staff may contact the enterprises, where necessary, to verify the accuracy of the data and to determine the source of the inconsistency. However, this is not undertaken in a systematic manner

\subsubsection{Statistical discrepancies and other potential indicators of problems in statistical outputs are investigated.}

The NSO compiles SUTs every five years. The first SUT was compiled for 2000, and the exercise was repeated for 2005. The results of the 2000 SUT became available in 2004, and the results of the 2005 SUT should become available in 2008.

The NSO, with external technical assistance, has made some initial efforts to use the 2000 SUT to assess the statistical discrepancy. This effort is continuing.

\section{Recommendation:}

- $\quad$ Use the SUT as a benchmark for the GDP estimates. 


\subsection{Revision studies}

3.5.1 Studies and analyses of revisions are carried out routinely and used internally to inform statistical processes (see also 4.3.3).

Studies and analyses of revisions are not undertaken in a systematic manner.

\section{Recommendation:}

- $\quad$ Undertake comprehensive studies and analyses of the revisions of the national accounts estimates. These studies are particularly important when the base year is updated.

\section{Serviceability}

\subsection{Periodicity and timeliness}

\subsubsection{Periodicity follows dissemination standards.}

The GDP estimates are compiled annually in line with the recommendations of the GDDS.

\subsubsection{Timeliness follows dissemination standards.}

The first annual GDP estimates are disseminated three months after the end of the reference period. The timeliness is therefore in line with the recommendations of the GDDS.

\subsection{Consistency}

\subsubsection{Statistics are consistent within the dataset.}

The estimates are internally consistent. The NSO has been able to reduce the statistical discrepancy to about one percent following a comprehensive revision of the estimates that included updating the base year to 2005 and incorporating additional data on unincorporated enterprises from the 2006 Economic Census.

\subsubsection{Statistics are consistent or reconcilable over a reasonable period of time.}

GDP estimates are available from 1980. However, a consistent series of GDP by type of activity at current and constant 2005 prices is only available from 2000 . The NSO revised the estimates of GDP at constant prices from 2000, with the introduction of the 2005 base year. The NSO plans to revise the estimates backwards to 1980 , resources permitting. 


\subsubsection{Statistics are consistent or reconcilable with those obtained through other data sources and/or statistical frameworks.}

The statistics are consistent with the balance of payments from the BOM, the GFS, from the MOF, and the foreign trade statistics from the Customs Administration.

\subsection{Revision policy and practice}

\subsubsection{Revisions follow a regular and transparent schedule.}

The NSO disseminates preliminary GDP estimates three months following the end of the reference year. Revised estimates are disseminated six months after the end of the period.

Although the revision cycle is relatively stable, it is not made known to the public. Further, the reasons underlying the revisions are not normally explained.

The NSO only revises the annual estimates once and this is clearly inadequate. The agency undertakes no further revisions of the estimates after the second publication six months following the end of the reference period, unless it introduces major changes to the methodology. Considering the NSO's tight production schedule and the large volume of data being processed, it is highly likely that further adjustments to the estimates would be warranted. Further, the data from business enterprises would have been revised since the NSO conducted the enterprise survey three months after the end of the period.

\subsubsection{Preliminary and/or revised data are clearly identified.}

The Monthly Bulletin clearly identifies data that are preliminary. However, when the data are revised, no indication is given of such a revision.

\subsubsection{Studies and analyses of revisions are made public (see also 3.5.1).}

Studies and analyses of revisions are not conducted or disseminated.

\section{Recommendations:}

- Increase the number of revisions to the estimates and lengthen the revision cycle. A common practice is to revise the estimates at least twice within the two years following the end of the reference period.

- $\quad$ Identify preliminary and revised data with clear notations. 


\section{Accessibility}

\subsection{Data accessibility}

\subsubsection{Statistics are presented in a way that facilitates proper interpretation and meaningful comparisons (layout and clarity of text, tables, and charts).}

Detailed data are disseminated on the NSO web site, www.nso.mn and in its annual publication, the Statistical Yearbook of Mongolia. The Yearbook presents a five-year series of the data, and the series are introduced with a brief analysis of recent economic developments. Charts highlight major changes in, and the composition of, key aggregates. The monthly bulletins contain less detailed data as these publications are primarily geared at disseminating short-term indicators.

\subsubsection{Dissemination media and format are adequate.}

The NSO conducts a monthly press conference and the national accounts estimate is normally first released at the press conference in the month that it is made available. In addition, the NSO circulates press releases with the data and brief explanations of the economic circumstances underlying the data.

The data are also published in the monthly bulletin and more detailed data are presented in the Statistical Yearbook of Mongolia. The NSO web site reproduces the publications. A dedicated national accounts publication is not produced.

Users may also subscribe to an online service that provides detailed information not available in the regular publications and on the web site. In addition, users may request information on electronic media formats such as compact discs and flash drives.

\subsubsection{Statistics are released on a preannounced schedule.}

The NSO does not disseminate an advance release calendar. However, regular users are aware of the general timing of the release of the estimates, as it has remained relatively stable. Further, the NSO responds to queries from users as to when the data should be expected.

\subsubsection{Statistics are made available to all users at the same time.}

The statistics are only made available to users on the authorization of the NSO Chairman. Following the chairman's authorization, the data are available to all users.

\subsubsection{Statistics not routinely disseminated are made available upon request.}

The NSO makes available to users data that are not routinely published as long as the confidentiality of the respondents is not compromised. 


\section{Recommendation:}

- $\quad$ Develop an advance release calendar and disseminate to the public, preferably via the NSO web site.

\subsection{Metadata accessibility}

5.2.1 Documentation on concepts, scope, classifications, basis of recording, data sources, and statistical techniques is available; and differences from internationally accepted standards, guidelines, or good practices are annotated.

The NSO has compiled a detailed document of the methodology, data sources, and statistical techniques used to compile the estimates. The document is available primarily to staff; however, private users may request copies of the publication or may obtain extracts.

Mongolia became a GDDS participant in August 2000 and detailed national accounts metadata are published on the IMF's GDDS web site. The metadata were last updated in 2006.

The Statistical Yearbook provides a synopsis of the compilation procedures and data sources.

The NSO web site's section on methodology is still under construction.

\subsubsection{Levels of detail are adapted to the needs of the intended audience.}

The Statistical Yearbook contains summary metadata that would be helpful to users who are only interested in the key national accounts aggregates presented in the publication. It provides a brief, simple explanation of some national concepts. Users interested in detailed national accounts methodology and data sources may consult the detailed document referred to in 5.2.1.

\subsection{Assistance to users}

\subsubsection{Contact points for each subject field are publicized.}

The publications and the web site present the contact information for the NSO. The information includes the agency's street address, telephone and facsimile numbers, and email address for enquiries. The NSO has established a separate Dissemination Division to assist users. 
5.3.2 Catalogs of publications, documents, and other services, including information on any charges, are widely available.

The NSO disseminates a catalog of its publications in hardcopy (available from the Dissemination Division) and on the NSO website. The catalog includes the publication's full name, the language of publication, the periodicity, and the price. 
Table 1. Mongolia: Data Quality Assessment Framework (July 2003): Summary of Results for National Accounts

(Compiling Agency: National Statistical Office)

\begin{tabular}{|c|c|c|c|c|c|c|c|}
\hline \multirow{2}{*}{ Element } & \multirow{2}{*}{ NA } & \multicolumn{4}{|c|}{ Assessment } & \multirow{2}{*}{ Comments on Assessment } & \multirow{2}{*}{ Plans for Improvement and Target Dates } \\
\hline & & $\mathrm{O}$ & LO & LNO & $\mathrm{NO}$ & & \\
\hline \multicolumn{8}{|l|}{ 0. Prerequisites of quality } \\
\hline 0.1 Legal and institutional environment & & $\mathrm{X}$ & & & & & \\
\hline 0.2 Resources & & & & $\mathrm{X}$ & & $\begin{array}{l}\text { Staff resources inadequate. Physical } \\
\text { facilities constrain adding staff } \\
\text { resources. }\end{array}$ & $\begin{array}{l}\text { Additional staff to be employed as soon as } \\
\text { the budget allocations permit-Medium } \\
\text { term. }\end{array}$ \\
\hline 0.3 Relevance & & & $\mathrm{X}$ & & & $\begin{array}{l}\text { The views of users in the private sector } \\
\text { not monitored in a systematic manner. }\end{array}$ & $\begin{array}{l}\text { Conduct survey of users in the private } \\
\text { sector-Medium term. }\end{array}$ \\
\hline 0.4 Other quality management & & $\mathrm{X}$ & & & & & \\
\hline \multicolumn{8}{|l|}{ 1. Assurances of integrity } \\
\hline 1.1 Professionalism & & $\mathrm{X}$ & & & & & \\
\hline 1.2 Transparency & & & $\mathrm{X}$ & & & $\begin{array}{l}\text { No advance notice of major changes in } \\
\text { methodology and data sources. }\end{array}$ & $\begin{array}{l}\text { Advise users of upcoming revisions and the } \\
\text { release of new statistics - Short term. }\end{array}$ \\
\hline 1.3 Ethical standards & & $\mathrm{X}$ & & & & & \\
\hline \multicolumn{8}{|l|}{ 2. Methodological soundness } \\
\hline 2.1 Concepts and definitions & & $\mathrm{X}$ & & & & & \\
\hline 2.2 Scope & & & & $\mathrm{X}$ & & $\begin{array}{l}\text { The range of accounts and tables is } \\
\text { limited. }\end{array}$ & $\begin{array}{l}\text { Estimates of quarterly GDP and sequence of } \\
\text { accounts up to the capital account will be } \\
\text { disseminated during } 2008 \text { - Short term. }\end{array}$ \\
\hline 2.3 Classification/sectorization & & $\mathrm{X}$ & & & & & \\
\hline 2.4 Basis for recording & & & $\mathrm{X}$ & & & $\begin{array}{l}\text { Government transactions recorded on a } \\
\text { cash basis. } \\
\text { Transactions between establishments } \\
\text { recorded net. }\end{array}$ & $\begin{array}{l}\text { Additional data on transactions within } \\
\text { enterprises will be collected-Medium term. }\end{array}$ \\
\hline
\end{tabular}


Table 1. Mongolia: Data Quality Assessment Framework (July 2003): Summary of Results for National Accounts (Compiling Agency: National Statistical Office)

\begin{tabular}{|c|c|c|c|c|c|c|c|}
\hline \multicolumn{8}{|c|}{ Key to symbols: NA $=$ Not Applicable; $\mathrm{O}=$ Practice Observed; $\mathrm{LO}=$ Practice Largely Observed; $\mathrm{LNO}=$ Practice Largely Not Observed; NO $=$ Practice Not Observed; SDDS $=$ Complies with SDDS Criteria } \\
\hline \multirow{2}{*}{ Element } & \multirow{2}{*}{ NA } & \multicolumn{4}{|c|}{ Assessment } & \multirow{2}{*}{ Comments on Assessment } & \multirow{2}{*}{ Plans for Improvement and Target Dates } \\
\hline & & $\mathrm{O}$ & LO & LNO & NO & & \\
\hline \multicolumn{8}{|l|}{ 3. Accuracy and reliability } \\
\hline 3.1 Source data & & $\mathrm{X}$ & & & & & \\
\hline 3.2 Assessment of source data & & & $\mathrm{X}$ & & & $\begin{array}{l}\text { Tight compilation schedule precludes a } \\
\text { comprehensive assessment of the source } \\
\text { data. }\end{array}$ & $\begin{array}{l}\text { Additional resources to be allocated to assess } \\
\text { source data-Medium term. }\end{array}$ \\
\hline 3.3 Statistical techniques & & & $\mathrm{X}$ & & & $\begin{array}{l}\text { CPI used to deflate trade margins and } \\
\text { taxes. Some items deflated directly using } \\
\text { CPI. }\end{array}$ & $\begin{array}{l}\text { The deflators to be reviewed. External } \\
\text { technical assistance is available for this } \\
\text { purpose-Short term. }\end{array}$ \\
\hline $\begin{array}{l}\text { 3.4 Assessment and validation of inter- } \\
\text { mediate data and statistical outputs }\end{array}$ & & & $X$ & & & SUT not used as benchmark. & $\begin{array}{l}\text { The SUT to be used as a benchmark for the } \\
\text { revised estimates. Technical assistance is } \\
\text { available-Medium term. }\end{array}$ \\
\hline 3.5 Revision studies & & & & $\mathrm{X}$ & & Revision studies not conducted & $\begin{array}{l}\text { Revision studies to be conducted-Long } \\
\text { term. }\end{array}$ \\
\hline \multicolumn{8}{|l|}{ 4. Serviceability } \\
\hline 4.1 Periodicity and timeliness & & $\mathrm{X}$ & & & & & \\
\hline 4.2 Consistency & & $\mathrm{X}$ & & & & & \\
\hline 4.3 Revision policy and practice & & & & $\mathrm{X}$ & & $\begin{array}{l}\text { Data only revised once, six months after } \\
\text { the end of the period. } \\
\text { Revised data not identified as such. }\end{array}$ & $\begin{array}{l}\text { Revision cycle to be extended-Medium } \\
\text { term. } \\
\text { Revised data to be identified-Short term. }\end{array}$ \\
\hline \multicolumn{8}{|l|}{ 5. Accessibility } \\
\hline 5.1 Data accessibility & & & $\mathrm{X}$ & & & $\begin{array}{l}\text { No preannounced schedule for data } \\
\text { dissemination. }\end{array}$ & $\begin{array}{l}\text { Preannounced schedule to be disseminated- } \\
\text { Medium term. }\end{array}$ \\
\hline 5.2 Metadata accessibility & & $\mathrm{X}$ & & & & & \\
\hline 5.3 Assistance to users & & $\mathrm{X}$ & & & & & \\
\hline
\end{tabular}




\section{Price Statistics (Consumer Price Index)}

\section{Prerequisites of quality}

\section{$0.1 \quad$ Legal and institutional environment}

\subsubsection{The responsibility for collecting, processing, and disseminating the statistics is clearly specified.}

The central statistical system of Mongolia comprises the NSO and statistical units at the regional level. The NSO is an independent public agency, headed by a chairman who reports directly to the Parliament of Mongolia, the Great Khural.

Chapter 2, Article 5 of the Law on Statistics, passed by the Parliament of Mongolia on June 5, 1997 (revised in 2004), ${ }^{2}$ stipulates that the central statistical system is responsible for collecting, compiling, and disseminating all official statistics. Article 6 of the Law presents a schedule of some of the information that may be considered official statistics. This schedule identifies specifically indicators of GDP and CPI. However, the schedule is considered neither exhaustive nor restrictive as the Law considers as official statistics all statistics produced by the central statistical system, thus including those not explicitly covered by the schedule. Therefore, the production of national accounts aggregates, beyond GDP, and other price indices, is adequately supported by the Law.

Further, Article 12 of the Law provides the NSO with broad authority to determine the responsibilities of respective government agencies with regard to the compilation of official statistics. Thus, conflicts or potential conflicts on the production of the statistics are obviated by this broad authority provided to the NSO.

\subsubsection{Data sharing and coordination among data-producing agencies are adequate.}

The Law provides a strong legal basis for the role of the NSO in coordinating statistical activities. Chapter 4, Article 11 of the Law stipulates that the NSO is independently responsible for coordinating all official statistical activities and functions in Mongolia. Further, the NSO's mandate on coordination includes responsibility for the following:

(i) providing the official statistical activities with centralized and overall management and coordination;

(ii) providing guidelines for the organizations engaged in official statistical activities and respondents for conducting censuses and surveys;

\footnotetext{
2 The amendments undertaken in 2004 did not have a material effect on the responsibilities of the NSO that were established in the 1997 version of the Law.
} 
(iii) collecting official statistical information from relevant ministries and other state organizations in a specified time; and

(iv) approving and accepting methodologies and manuals or instructions of various censuses, surveys and official statistics and set up the time of their announcement.

In addition, in order to minimize the duplication of information gathering, the Law stipulates that regional statistical agencies must seek the approval of the NSO on all data gathering activities that they wish to undertake.

The NSO has signed memoranda of understanding on data sharing with the BOM, the Customs Department, and Tax Administration Office. The memoranda specify what kinds of data should be shared between the signatories, when the data should be provided, and in what form the data should be transmitted. The NSO holds regular meetings with these agencies as the need arises.

The NSO has also established a working group on data sharing and coordination with the MOF. The group comprises four representatives from the NSO and two from the MOF. It meets quarterly to discuss the data requirements of both agencies.

\subsubsection{Individual reporters' data are to be kept confidential and used for statistical purposes only.}

Chapter 6, Article 22 of the Law establishes guidelines on confidentiality for both the statistical organizations and respondents. The Law prohibits the staff of official statistical organizations from disseminating information that is being processed or revealing the identity of individuals and establishments. The $L a w$ also prohibits the dissemination of raw data from censuses and surveys before the advertised release date.

Chapter 3, Article 9 outlines the rights and responsibilities of respondents regarding the confidentiality of information that they may provide to the NSO. Among these, the respondents have a right to demand that the data they provide to statistical agencies are kept confidential. Thus, the agencies must satisfy respondents that they would take the necessary safeguards to ensure that the data are not disseminated in a form that would allow the identification of the individual units. The data collection instruments clearly outline the confidentiality provisions that underline the data-collection process.

Survey results that are transmitted from the regional offices to the NSO are coded and do not contain the identification of the respondents. Thus, the identity of the respondents would not be revealed if the documents are lost during transmission or are accessed by unlawful means. Informal working arrangements exist among the inter-departmental units of the NSO.

For instance, the SPPCD, one of four departments in the NSO, is responsible for coordinating the compilation and dissemination of the CPI, the national accounts, and other macroeconomic indicators. 
The SPPCD takes the necessary precautions to ensure the confidentiality of the data it collects. Only indices are disseminated and special aggregation rules are employed to prevent the identification of respondents. All questions regarding the CPI results are forwarded to the director of the SPPCD.

All computers at the NSO and the regional offices are password protected to prevent unauthorized access to individual data.

\subsubsection{Statistical reporting is ensured through legal mandate and/or measures to encourage response.}

Chapter 3, Article 9 stipulates that respondents have an obligation to provide official statistical information, at their own cost, to the statistical agencies. The NSO, on the other hand, is mandated to collect statistical information from all respondents in a timely manner.

The Law also establishes the responsibilities of the other units of the statistical system to collect decentralized information and to provide such information to the NSO on a timely basis.

The NSO depends heavily on the regional agencies to undertake all the requisite survey fieldwork. Due to the relative unreliability of the postal service, staff of the regional agencies deliver the questionnaires by hand. However, this method is very beneficial as the field staff are able to build good working relationships with the respondents. They therefore make regular follow-up visits to respond to queries and to assist the respondents in completing the questionnaires. In addition, the NSO employs statistical inspectors who visit nonrespondents and encourage them to respond to the respective surveys.

Although the NSO has the authority to penalize nonrespondents, it has seldom resorted to this measure as it considers the other activities to improve response rate as being adequate. The effectiveness of these activities is exemplified by high response rates, of between 80 percent and 90 percent, recorded for the enterprise survey since 2005.

The NSO collects a wide range of data through censuses required by the Law and through regular surveys. It is therefore extremely commendable that the agency is able to achieve such high response rates considering the amount of information that it requests, the relative timeliness of the data collection process, and the limited resources available for data collection, both at the regional level and at the level of the NSO.

\section{$0.2 \quad$ Resources}

\subsubsection{Staff, facilities, computing resources, and financing are commensurate with statistical programs.}

The NSO employs 82 staff and a further 139 people work at the 22 regional statistical offices. The staff at the regional offices are primarily engaged in survey data collection to 
support the work of the NSO. The SPPCD is responsible for compiling the CPI. The Statistical Integrated Policy Division of the SPPCD, employs eight people, and two are engaged in the CPI compilation. The staff have received substantive training in the CPI compilation through attendance at training courses conducted the IMF and other international organizations. All CPI staff possess university degrees in economics or statistics. Staff turnover has been relatively low; thus, the NSO has been able to retain a cadre of trained professionals.

However, the staff complement is not adequate to allow the NSO to undertake the ambitious price compilation program. The NSO recognizes the need to employ additional staff, but it is constrained by the budget allocation received from the central government. The salaries of the NSO staff follow the salary guidelines of the central government and are constrained by the budget allocations.

The staffing levels at the provincial statistical offices are relatively low, considering their workload in conducting surveys for the NSO and in compiling statistics for the regional governments. Further, staff turnover is high, due to the low remuneration, and expertise needs to be improved. Based on the staffing and expertise of the provincial officers, it is doubtful that they are capable of undertaking the intensive survey follow-up and data crosschecks that are required.

The government allocation is not sufficient for the NSO to undertake its regular statistical activities, and the agency remains dependent on the grants from international organizations to undertake critical survey work.

The office building provides adequate facilities for the current staff, but office space is very limited. This would therefore preclude the NSO from increasing staffing levels unless the agency acquires additional space.

The NSO recently upgraded the computing resources. Therefore, all staff now have adequate access to computing resources through personal computers and a local area network. Though arduous, the CPI staff use Excel software for compiling and analyzing the CPI statistical series.

There are noteworthy provisions of emergency back-up systems for retrieval of the CPI in the event of natural disasters, accidents, and other unusual events. The Information Technology Division archives three copies of the CPI data on a quarterly basis. A copy is saved on a server at the NSO, at a private commercial bank, and at the National Archive of Ulaanbaatar. However, given the importance of a monthly CPI, the NSO should make efforts to archive the CPI data on a monthly basis. 


\section{Recommendations:}

- Increase the number of staff working on the CPI in the NSO and in the providences.

- $\quad$ Provide travel allowances for price collection.

- $\quad$ Make efforts to back-up and save the CPI data on a monthly basis, and provide more office space.

\subsubsection{Measures to ensure efficient use of resources are implemented.}

Staff performance is evaluated twice per year, and the NSO has developed a system of awards to reward good performance. These include nomination of staff for state orders and decorations and increases in the benefits.

In planning the statistical program, the NSO also solicits the views of staff on how the work could be improved, areas requiring special attention from management, and whether staff have sufficient time to undertake developmental activities.

The agency seeks efficiencies through periodic reviews of the CPI work processes. For example, in order to control for the constant quality of items, the CPI staff took photographs of items and numbered each of these items according to its product classification, for ease of identification for the price collector.

In addition, to the IMF, other international organizations are consulted for assistance to evaluate the CPI methodology and compilation.

\section{$0.3 \quad$ Relevance}

\subsubsection{The relevance and practical utility of existing statistics in meeting users' needs are monitored.}

The NSO staff consult regularly with users in the public sector through regular working group meetings and bilateral meetings arranged on the basis on the respective memoranda of understanding.

The NSO has conducted ad hoc seminars with various groups of users in the private sector; however, there is no structured process to obtain regular feedback from users. The NSO management often participates in meetings of regional and international organizations where emerging statistical standards and data requirements are discussed. The NSO frequently makes presentations at these meetings on the statistical compilation process in Mongolia and solicits feedback from other advanced statistical agencies on how the process could be improved. 


\section{Recommendation:}

- $\quad$ The NSO should develop a structured process to obtain regular feed back from users.

\section{$0.4 \quad$ Other quality management}

\subsubsection{Processes are in place to focus on quality.}

The NSO's mission is to provide government and public users with reliable and accurate statistics that is immune to political influence, scientifically feasible, and acceptable. The need to improve the quality of the statistics is always at the forefront of the planning process. The NSO has developed a Program for Official Statistics Development, 2006-2010 to improve the statistics in line with the recommendations of the GDDS. The principle objective of the program is to develop national statistical standards that are based internationally acceptable methodologies to meet the needs of the public and to provide users with high quality statistics.

\subsubsection{Processes are in place to monitor the quality of the statistical program.}

The NSO established a Methodology and Research Department in 2005 to assist the management in monitoring the quality of the agency's output. Among the main objectives of the department are to undertake statistical research to improve the statistical output and to review methodological issues, not only for the statistical output, but for the data collection and data processing.

In addition, the NSO Board has established a Standing Council on Methodology and Research. The main functions of this council are to improve statistical systems to establish reliable and timely statistical systems, and to make recommendations on statistical concepts, methodologies.

The prices for the main food items are collected every Friday. Data on the other items are collected between the $15^{\text {th }}$ and the $20^{\text {th }}$ of the month in the regions, and between the $22^{\text {nd }}$ and $28^{\text {th }}$ of the month for the city. The CPI data from the regional offices should be received by the NSO by the $21^{\text {st }}$ of the month. This method of price data collection is necessary to ensure that the price indices can be compiled and disseminated one week after the end of referenced month.

\subsubsection{Processes are in place to deal with quality considerations in planning the statistical program.}

The NSO prepares an annual work plan, twelve months before the start of the year, which outlines the output objectives of each department. The plan identifies the expected cost of the output; however, the expected output is usually constrained by the budget allocation provided by the central government. Thus, the NSO considers carefully, the resource implications of the work plan and attempts to balance the needs for timely data by users, especially those in 
the public sector, with the need to compile accurate and reliable statistics. The NSO also prepares an annual production schedule that takes account of the need to disseminate the data in a timely manner.

\section{Assurances of integrity}

\subsection{Professionalism}

\subsubsection{Statistics are produced on an impartial basis.}

Chapter I, Article 4 of the Law establishes the independence of official statistics as one of its six key principles. This principle is supported by the institutional arrangements for the appointment, tenure, and functioning of the chairman of the NSO, which provide the necessary guarantees that the agency head would be able to undertake his responsibilities in an impartial manner. The Parliament of Mongolia appoints the chairman for a fixed but renewable six-year term, and the Law outlines the precise conditions under which the tenure of the chairman may be terminated before the completion of the six-year term. His services may be terminated involuntarily only if his performance is deemed to be unsatisfactory, if he is deemed to be unable to undertake his duties satisfactorily (for health reasons), or if he is convicted for a criminal offence.

The Law provides the chairman with sole authority for approving and adopting decisions relating to the management and organization of official statistics. The chairman has the authority to appoint the heads of regional statistical agencies, based on the recommendations of the regional governors, and maintains direct contact with parliamentary standing committees relating to statistics.

Staff recruitment is governed by the Law of the Public Service. To recruit staff, the NSO must first submit a request to the Public Administration Committee, specifying the requirements of the position. Applicants must first sit the public service examination and may then be interviewed on areas specific to the position. Staff are recruited for a six-month probationary period, during which their performance is assessed. Staff are only appointed to a permanent position if the NSO deems that their performance meets the agency's standards.

\subsubsection{Choices of sources and statistical techniques, as well as decisions about dissemination, are informed solely by statistical considerations.}

The choices of sources and statistical techniques are influenced solely by statistical considerations. Staff, with the occasional assistance of external experts, decide on the statistical techniques, methodology, and data sources to be employed based solely on the need to implement international recommendations. 
1.1.3 The appropriate statistical entity is entitled to comment on erroneous interpretation and misuse of statistics.

The NSO, being an independent public agency, is entitled to address the media and comment on the use of the statistics that it produces.

The CPI publications and news releases, produced by the NSO, provide explanations of the basis for compiling the price indices, and identify the main factors underlying unusual figures and movements, in order to improve user understanding and reduce the likelihood of any misinterpretation. The director of the SPPCD is allowed to respond to public criticism of the price statistics or instances of misuse of statistics.

\subsection{Transparency}

\subsubsection{The terms and conditions under which statistics are collected, processed, and} disseminated are available to the public.

The Law on Statistics is available on the web site of the NSO in Mongolian. The agency is yet to upload the English version of the Law. In addition, the data collection instruments refer to the Law and advise respondents about their rights and responsibilities under the Law.

\subsubsection{Internal governmental access to statistics prior to their release is publicly identified.}

There is no internal access to the statistics prior to its release.

\subsubsection{Products of statistical agencies/units are clearly identified as such.}

The products of the NSO are clearly identified by name and with the agency's logo. However, the outputs of individual units are not distinguished separately. When the NSO conducts exercises with other government agencies, the NSO is clearly identified as a contributor to the output.

\subsubsection{Advance notice is given of major changes in methodology, source data, and statistical techniques.}

Apart from occasional announcements of the agency's work plans, the NSO provides no advance notice of changes in methodology, source data, and statistical techniques.

The CPI weight updates, basket composition, and any methodological changes are announced at the time the CPI data are released. 


\section{Recommendations:}

- Give advance notice of major changes in methodology, source data, and statistical techniques to the public.

- Develop and implement a policy to inform users of upcoming changes in the compilation process and the effects on disseminated data.

- $\quad$ The policy should include guidelines on the timeframe for advance notification and types of media.

\subsection{Ethical standards}

\subsubsection{Guidelines for staff behavior are in place and are well known to the staff.}

The staff of the NSO are subject to the internal rules of the NSO as well as the rules and regulations of the public service. The Administration Department provides a copy of the rules and regulations to all new staff upon recruitment. Staff must also take an oath of secrecy before they can have access to any information collected by the NSO. The rules and regulations prohibit staff from using the statistical information for personal gain or from taking part in political activities. Staff may be dismissed for breaching the staff rules.

\section{Methodological soundness}

\subsection{Concepts and definitions}

2.1.1 The overall structure in terms of concepts and definitions follows internationally accepted standards, guidelines, or good practices.

Concepts and definitions, which have been developed locally, are broadly in line with international standards, guidelines, or good practices. Household expenditure estimates from the HIES are used for the weights of market expenditure on goods and services. The CPI is classified according to the COICOP, which conforms to the guidelines of the $1993 S N A$, the International Labor Organization, and the Consumer Price Index Manual, 2004 (CPI Manual). This CPI was rebased in April 2006 (2005=100), using December 2005 as the price reference period.

The CPI weights include illegal activities and own-produced agriculture products, as well as goods provided by employers as income in kind. However, the level of detail for household residential capital formation expenditure is not sufficient for detailed analysis of price movement. 


\section{$2.2 \quad$ Scope}

2.2.1 The scope is broadly consistent with internationally accepted standards, guidelines, or good practices.

The NSO compiles a monthly consumer price index for the capital and the 21 provinces (aimags). The CPI for the city, Ulaanbaatar, is used as a substitute for the national CPI. The NSO plans to expand the CPI for the entire geographic region. An experimental national CPI has been produced but is not disseminated. Regional (aimag) indexes have been compiled since the beginning of 2005. The geographical region refers to the geographic coverage of expenditures. In Mongolia, price movements in urban and rural areas are different, mainly due to transportation costs. For that reason, a national CPI is necessary.

All resident households, regardless of income, are included in the CPI for Ulaanbaatar and the 21 provinces, which are stratified according to cities, providences, soums, and census sampling units. Informal activity is included in the CPI weights that cover the expenditures of all resident households in the country. In addition, the consumption of nonmonetary goods such own-produced agriculture products and goods provided by employers as income in kind are included.

The CPI does not cover owner-occupied housing in either one of two ways: as consumption of housing services, or as capital formation in (acquisitions less disposals of) housing units. Moreover, even though the HIES collects expenditure estimates on illegal activities and goods and services available in the informal economy, the CPI does not include illegal goods and services that the household willingly buy on the market nor does the index include goods and services provided in the informal economy.

\section{Recommendations:}

- $\quad$ Expand the scope of the CPI to a national CPI.

- $\quad$ Monitor the expenditure estimates on goods and services in the illegal and informal economy, and determine if these goods and services should be represented in the CPI basket.

\subsection{Classification/sectorization}

\subsubsection{Classification/sectorization systems used are broadly consistent with internationally accepted standards, guidelines, or good practices.}

The CPI covers noninstitutionalized Mongolian households that are consistent with the 1993 SNA household sector. The items weights for the CPI are classified using the COICOP that is consistent with international guidelines. 


\subsection{Basis for recording}

\subsubsection{Market prices are used to value flows and stocks.}

The prices reflect those that a consumer would pay on the day of the survey; including value added, excise taxes, trade, and transportation margins. Cash and credit card payments are the basis for the price survey.

Specifically:

- $\quad$ Direct taxes and VAT are included in the price being recorded;

- $\quad$ Sale prices are included if the item will continue to be available after the sale period; and

- In the case of list prices, outlets (such as doctor's offices) are asked to confirm that the prices are actually those being charged to consumers.

All product specifications are carefully designed for the basket items and their varieties with guidance provided by the staff in SPPCD. Price determining characteristics for transactions at market prices generally consider size, color, brand, and quality, etc.

\subsubsection{Recording is done on an accrual basis.}

The prices of goods and services are recorded in the period they are purchased. Discounts and sale prices are recorded in case of temporary reductions.

\subsubsection{Grossing/netting procedures are broadly consistent with internationally accepted standards, guidelines, or good practices.}

Weights are applied to the purchases of existing goods such as used car for which there are secondary markets.

\section{Accuracy and reliability}

\subsection{Source data}

3.1.1 Source data are obtained from comprehensive data collection programs that take into account country-specific conditions.

\section{$\underline{\text { Sources for CPI Prices }}$}

A judgmental list of outlets is compiled by the SPPCD and the regional statistical offices. Price data are collected mainly by personal visits to about ninety shops and other retail 
outlets. Misclassifications and nonresponse tend not to be problem since good relations exist between the price collectors and the retail outlets.

Ad hoc surveys are conducted to identify new products and provide source data for weights and prices. For example, a special survey was conducted for the Population and Social Statistics Division for poverty analysis. In addition, special surveys are conducted for the International Comparison (of prices) Program. New products are introduced into the CPI basket when the CPI is rebased and the results of a new HIES become available.

Very small types of outlets such as kiosks are excluded from price collection. Other large and medium enterprises are represented in the price collection.

The CPI basket comprises of 287 items for twelve main categories. The CPI price information is not derived from any administrative or other available source that can be used to supplement the core compilation. All outlets and enterprises are private.

Although international guidelines recommend the use of probability sampling techniques, Mongolia's use of nonprobability sampling techniques is justified. Due to the geographic nature of the country, it is easier to collect prices near the homes or in the regions of the price collectors. If the NSO had to draw a new sample with each CPI update, then it would become expensive and difficult to retrain the price collectors. Mongolia was able to improve the coverage of the country in terms of the price collectors by having geographically distributed regional offices, working under to auspices of the NSO.

\section{$\underline{\text { Sources for CPI Weights }}$}

The NSO conducts a continuous HIES that covers the complete geographic area of Mongolia. The survey covers 936 households monthly, with a new sample of households being surveyed each month. Thus, 11,432 households are surveyed over the twelve-month coverage period. This represents a two percent sample of domestic households.

A two-stage sampling method is used. At the first stage, the enumeration districts are selected based on probability proportional to size. One hundred and four enumeration districts, out of the 11,000 identified in the 2000 census, are sampled every month. At the second stage, households are selected based on simple random sampling methods.

The HIES excludes all persons from dwellings that were out of scope and coverage, meaning that all institutional dwellings such as army barracks, hospitals, and training colleges were excluded. The NSO does not make adjustment to alcohol and tobacco consumption expenditure. Expenditure on illegal goods and services, own-account production of market goods for own final consumption, and goods and services offered in the informal market are included in the HIES; however, the value of consumption of owner-occupied housing are excluded. 
Even though there is a 90 percent response rate, data from high-income households are difficult to collect. Hence, a substitution ratio of 0.33 is allowed. That is, for every ten highincome households, three high-income households can be selected as substitutes.

The NSO holds meetings with consumer groups and the business community only when there has been a significant change in the CPI results.

\section{Recommendation}

- $\quad$ Include very small types of outlets such as kiosks in the CPI.

3.1.2 Source data reasonably approximate the definitions, scope, classifications, valuation, and time of recording required.

Although weighting information is available from the HIES for the implicit rent of owneroccupants, price information from the rental survey is not considered sufficient to produce a reliable estimate of the average change in free market rental prices for housing units that are similar to the units of owner-occupants.

The CPI group items are collected from outlets over a two-week period. Arithmetic average prices are used in the price relatives. Prices are collected every Friday for twenty main food groups (meat, vegetable, milk, and flour). The prices for the other seventy-two food groups and other items are collected once per month.

Source data are broadly consistent with the definitions, scope, and classification of the CPI estimates.

\section{Recommendation}

- Include the imputation of rents for owner-occupied housing in the CPI by extending the sample of rental units so that they include those equivalent to owner-occupied housing.

\subsubsection{Source data are timely.}

The NSO data are timely to allow for the compilation of the city and the 21 provinces. 


\subsection{Assessment of source data}

3.2.1 Source data-including censuses, sample surveys, and administrative records-are routinely assessed, e.g., for coverage, sample error, response error, and nonsampling error; the results of the assessments are monitored and made available to guide statistical processes.

Whenever there are refusals for the HIES, survey staff attempt to encourage response through follow-up visits. Substitution is allowed for nonresponse.

There are no analyses of the sampling errors nor are there any adjustments made to the HIES for under-reporting of specific products such as alcohol and tobacco using imports data.

Sampling errors for price collection are not available since the sampling of outlets is conducted by judgmental selection. Problems of nonresponse are not common for the outlets sampled due to the established relationships between the interviewers and the enterprises.

\section{Recommendations:}

- $\quad$ Conduct analysis of sampling errors for the HIES.

- $\quad$ Cross-check consumption expenditure on alcohol and tobacco with supply data such as imports and retail trade.

\subsection{Statistical techniques}

\subsubsection{Data compilation employs sound statistical techniques to deal with data sources.}

At the city and regional levels, the prices are first collected and then passed on to the NSO's CPI unit where the price indices are then tabulated. That is, all datasets are combined, weighted, and aggregated into the city and regional indexes.

Prices for temporarily missing and seasonal products for the CPI are estimated by carrying forward or imputing the price. The CPI staff impute price when items permanently disappeared from the market and carry forward the price for temporarily missing items. The CPI index is not seasonally adjusted. Based on the results of the HIES, the basket of fruits and vegetables consists mostly of fruits and vegetables that are permanently available (for themost part imported). Thus there is an implicit price imputation of excluded seasonal products. A permanently unavailable item is replaced with a similar item. However, the agency makes no imputation for quality adjustments.

Comparable replacement method is currently being used to adjust for quality; however, as small changes occur, the CPI index may be biased upward. 
New goods are not introduced into the sample as they gain market share. New goods are only introduced when there is a new HIES.

For the first time, the CPI basket includes mobile telephones. The weights for the mobile telephone were price-updated from the last CPI $2000=100$ series. The communication equipments elementary aggregate was used to adjust the $2005=100$ price series.

\section{Recommendation:}

- $\quad$ Conduct implicit and/or explicit quality adjustment techniques for replacement items that have replaced permanently unavailable product.

\subsubsection{Other statistical procedures (e.g., data adjustments and transformations, and statistical analysis) employ sound statistical techniques.}

At the elementary level, an arithmetic mean or the ratio of average prices is used to calculate the index. Short-term price change is calculated and published based on monthly change, annual average prices of main goods in Ulaanbaatar, and price changes at the end of 2006. Long-term price change is calculated since 1991, and historical chained index with $2000=100$.

The CPI is derived by short-term price relatives. Aggregates for the new index are based on the modified Laspeyres formula. The 2004 weight-based index was linked to the 2000 weight-based index. The overlapping period was December 2005. The price reference period is December 2005, and the prices for the weights have not been updated. The weight reference period is, therefore, 2004, while the price reference period is 2005 . However, even though little time has passed between the price and the weight reference periods, price updating from the weight-reference period to the price-reference period may be necessary since there could have been significant changes in the consumption patterns between the two time periods. The NSO has plans to price update the weights in 2008 when the NSO compiles and disseminates the national CPI. When the CPI was revised backward to 2000, the CPI staff made adjustments at the group level.

According to the CPI staff, prices are not collected from parallel markets or underground economies even though the HIES-derived expenditure estimates. If these expenditure weights are significant, the NSO should consider monitoring prices in the parallel markets.

There are no distinctions in prices if the consumer chooses to pay by credit or by cash. The value recorded for goods and services represent the economic cost to the consumer at the time the good or service is purchased regardless of method for payment.

Goods and services produced for own final consumption is included in the CPI. 


\section{Recommendation:}

- At next rebasing, consider adjusting the weights for price change to align with the price reference period, and adopt the geometric mean for elementary price indices.

\subsection{Assessment and validation of intermediate data and statistical outputs}

\subsubsection{Intermediate results are validated against other information, where applicable.}

The CPI is not regularly compared to other price index series since other price series, such as a producer price index and foreign trade price indices, are not compiled. Nevertheless, the $\mathrm{CPI}$ is assessed and validated against Mongolia's money supply just for comparisons between levels and magnitude.

\subsubsection{Statistical discrepancies in intermediate data are assessed and investigated.}

Any unusual movements such as outliers in item indices are verified and traced back to the reporting outlet, if necessary.

\subsubsection{Statistical discrepancies and other potential indicators of problems in statistical outputs are investigated.}

Discrepancies arising from inconsistent imputation for missing data are routinely assessed. There are ranges of control edits supported by the Excel (conditional statements) computer program that can be used to assess and validate the data.

\subsection{Revision studies}

3.5.1 Studies and analyses of revisions are carried out routinely and used internally to inform statistical processes (see also 4.3.3).

The CPI is considered final when released. The CPI basket and weights are updated when there is a new HIES. However, studies and analyses of the weight revisions are carried out when there is a new HIES, and are used internally to inform of statistical processes.

\section{Serviceability}

\subsection{Periodicity and timeliness}

\subsubsection{Periodicity follows dissemination standards.}

The periodicity of the statistics follows the GDDS requirements. The CPI data is compiled monthly. 


\subsubsection{Timeliness follows dissemination standards.}

The monthly CPI is disseminated within one week after the end of the reference month is published around the $10^{\text {th }}$ of the following month, thus exceeding the GDDS requirements.

\subsection{Consistency}

\subsubsection{Statistics are consistent within the dataset.}

The CPI aggregation structure is consistent from the cell level to the item level, the item level to the group level, and the group level indices to higher levels of expenditure classes and the all-item level. Moreover, city and regional aggregation are consistent.

\subsubsection{Statistics are consistent or reconcilable over a reasonable period of time.}

Time series data are available for at least five years. Aggregated historical time-series data are available back to 1991. When there are revisions, the long-term time-series are carried and revised back to 2000 .

\subsubsection{Statistics are consistent or reconcilable with those obtained through other data sources and/or statistical frameworks.}

The CPI data do not rely on any administrative data source. Nevertheless, the CPI data could be verified with data from administrative sources such as the Ministry of Transportation, the Ministry of Communication, etc. Furthermore, the CPI data could be verified with data from the Chamber of Commerce or other business statistics.

\section{Recommendation:}

- $\quad$ Check to determine if the CPI data are consistent with other data sets from administrative sources, trade associations, or other business statistics.

\subsection{Revision policy and practice}

\subsubsection{Revisions follow a regular and transparent schedule.}

The CPI series are final when first released and are not subject to revisions.

\subsubsection{Preliminary and/or revised data are clearly identified.}

Since the CPI is not normally revised, there is no need to identify preliminary data.

\subsubsection{Studies and analyses of revisions are made public (see also 3.5.1).}

The impact of weight-updating studies is not disseminated in official statistical publications. 


\section{Recommendation:}

- $\quad$ Make available analyses and notes to the public whenever there are changes in the methodology, weights, etc.

\section{Accessibility}

\subsection{Data accessibility}

\subsubsection{Statistics are presented in a way that facilitates proper interpretation and meaningful} comparisons (layout and clarity of text, tables, and charts).

The CPI data are published in a clear manner. In certain publications, charts and tables are also disseminated with the data to facilitate analysis. Datasets are published in consolidated format, by food, nonfood, and services. Data for each category are further broken down by the types of food, nonfood, and services, and by groups and by aimags. In addition, chainlinked historical time series data are disseminated in official publications and on the NSO's web site.

\subsubsection{Dissemination media and format are adequate.}

The CPI data are disseminated in ways that facilitate redissemination in the media through official press releases and internet websites. The data are simultaneously disseminated to all interested parties through a press release prepared by the NSO.

\subsubsection{Statistics are released on a preannounced schedule.}

There is no advance release calendar posted on the NSO's web site: http://www.nso.mn.

\section{Recommendation:}

- Indicate the dates of the CPI data release in an advance release calendar and post this calendar on the NSO's web site.

\subsubsection{Statistics are made available to all users at the same time.}

The CPI is made available to all users at the same time.

\subsubsection{Statistics not routinely disseminated are made available upon request.}

Detailed customized tabulation (detailed breakdowns) of CPI data is available upon request, in addition to the CPI routinely disseminated. For specific purposes, customized tabulation of data that satisfy the NSO's disclosure requirements are also available for a fee.

Data users are aware of the availability of additional statistics and of the procedures for obtaining them. These procedures are explicitly provided in statistical publications. 


\subsection{Metadata accessibility}

5.2.1 Documentation on concepts, scope, classifications, basis of recording, data sources, and statistical techniques is available, and differences from internationally accepted standards, guidelines, or good practices are annotated.

Documentation on concepts, scope, classification, data sources, and methods of the CPI are available on the IMF Data Standards Bulletin Board (DSBB). These metadata were last updated in June 2007. There are, in addition, CPI methodological notes (in Mongolian) on the NSO's web site.

\subsubsection{Levels of detail are adapted to the needs of the intended audience.}

There are no brochures, pamphlets, or newsletters about the CPI. Background papers, working documents, etc., are not available.

\section{Recommendation:}

- $\quad$ Make available to the public brochures, pamphlets, or newsletters about the CPI.

\subsection{Assistance to users}

\subsubsection{Contact points for each subject field are publicized.}

Contact points for the CPI are publicized in official publications.

5.3.2 Catalogs of publications, documents, and other services, including information on any charges, are widely available.

A catalog of publications together with their prices is available on the NSO's web site. 
Table 2. Mongolia: Data Quality Assessment Framework (July 2003): Summary of Results for Price Statistics (Consumer Price Index) (Compiling Agency: National Statistical Office)

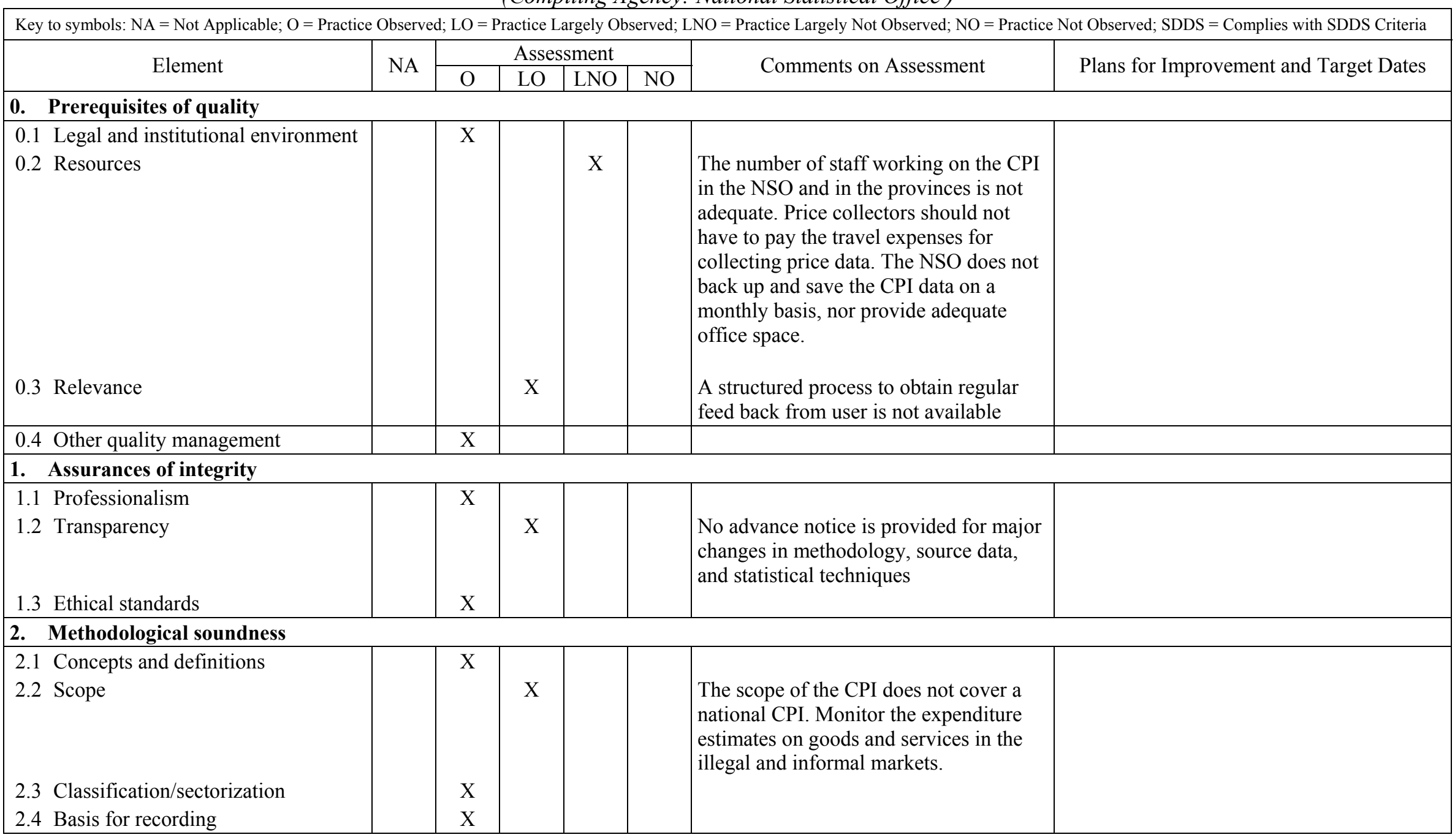


Table 2. Mongolia: Data Quality Assessment Framework (July 2003): Summary of Results for Price Statistics (Consumer Price Index) (Compiling Agency: National Statistical Office)

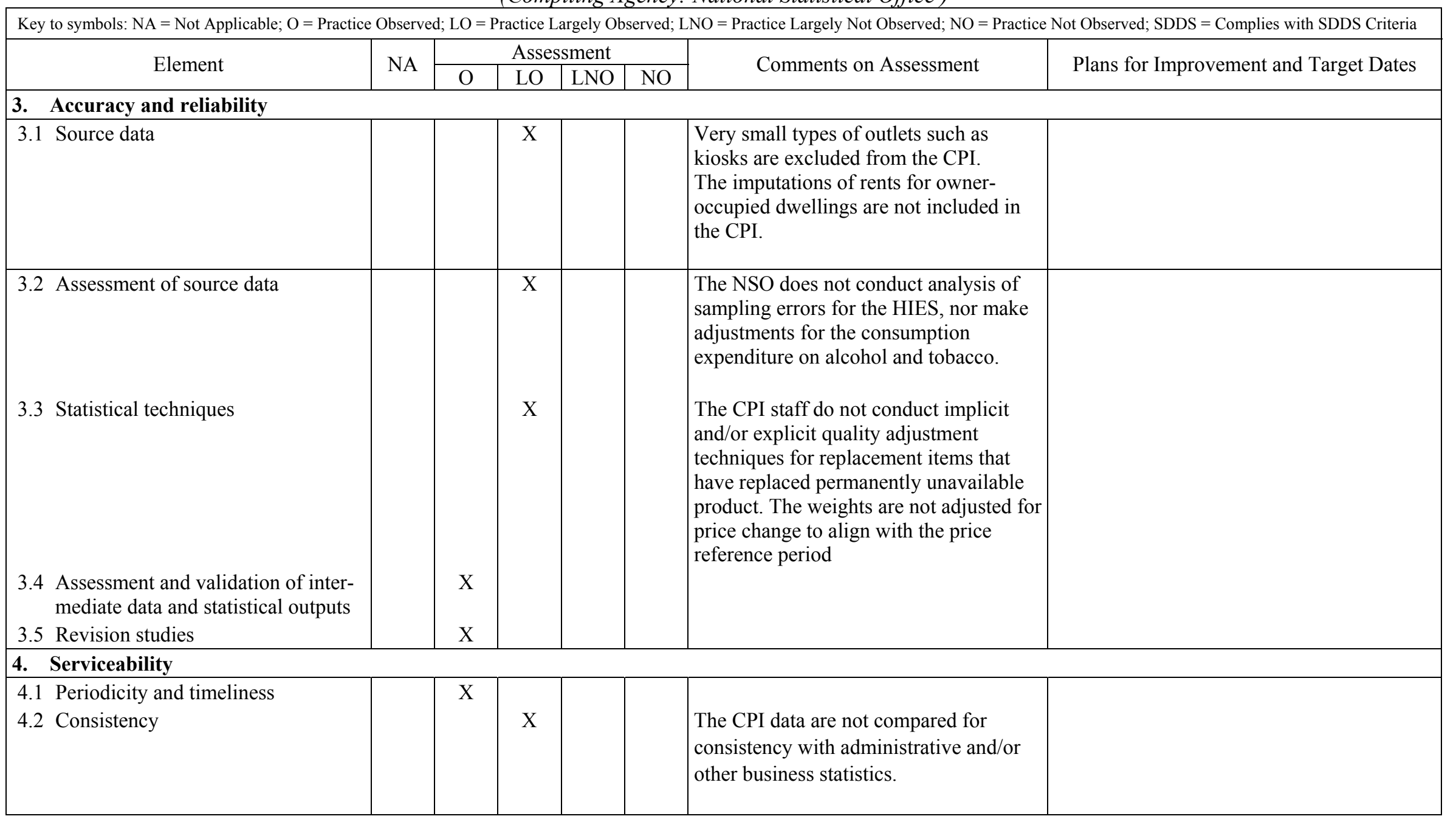


Table 2. Mongolia: Data Quality Assessment Framework (July 2003): Summary of Results for Price Statistics (Consumer Price Index) (Compiling Agency: National Statistical Office)

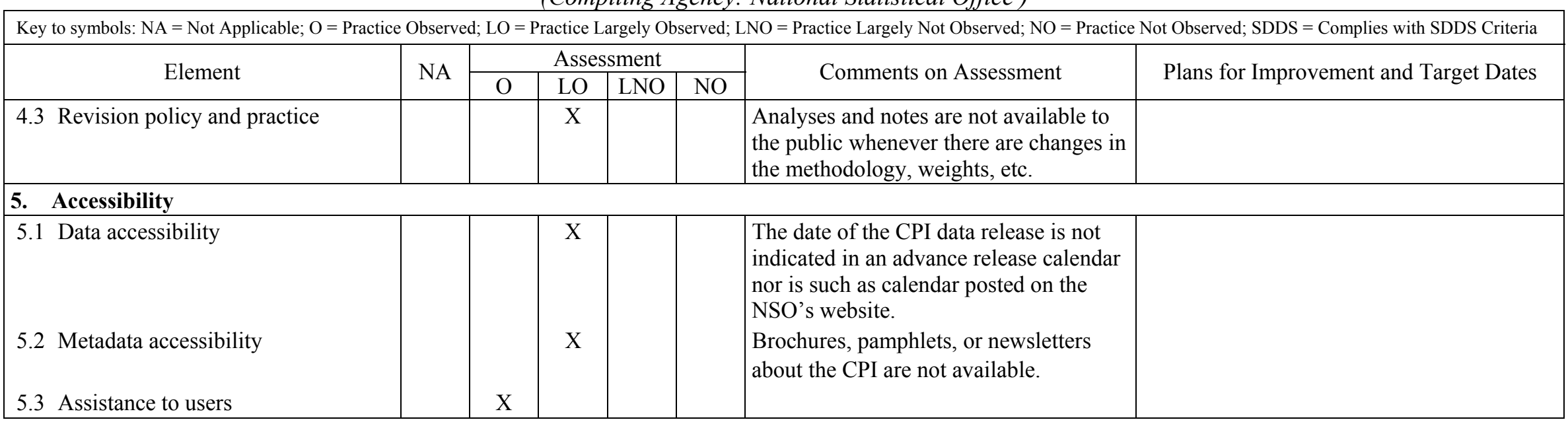




\section{Government Finance Statistics}

\section{Prerequisites of quality}

\subsection{Legal and institutional environment}

\subsubsection{The responsibility for collecting, processing, and disseminating the statistics is clearly specified.}

The responsibility for collecting, processing, and disseminating fiscal statistics is clearly assigned to the MOF by the Budget Law and the Public Sector Management and Finance Law (PSMFL). In particular, Article 9.1 of the PSMFL states that the MOF shall prepare a report on the execution of the budget and the government's annual financial statements in conformity with international accounting standards. Articles 37 and 38 of the PSMFL state that the MOF shall submit these documents to the State Audit Body no later than March 20 of the following year, that this body must issue its opinion within one month, and that the MOF must submit these documents and the audit opinion to Parliament one week later. The MOF is empowered by these laws to issue regulations establishing the formats and timetable for the reporting of data by all budgetary entities.

The Law on Statistics specifies in Article 6 that the official statistical information include state and local budget revenue and expenditure. The law states in Article 4 that one of the principles of statistical activities is that information must be widely disseminated, and in Article 10 that the rights of users of statistical information include being provided with official statistical information. However, it also states in Article 22 that the dissemination of information identified by the appropriate authorities as relating to national interests is illegal. This provision is currently applied to central government debt data under the Law on State Secrets and the Law on the List of State Secrets.

The Financing, Accounting, and Reporting Division (FARD) and the Debt Management Division (DMD) of the MOF's Treasury Department are responsible for compiling the statistics on central and general government operations, and central government debt. Working arrangements are consistent with this assignment of responsibilities.

\section{Recommendation:}

- $\quad$ The decision to consider data on central government debt confidential should be revised, and these data should be disseminated in MOF, BOM, and the NSO publications. Debt data are disseminated by most countries and in any event, Mongolia currently makes them available to international organizations for redissemination. 


\subsubsection{Data sharing and coordination among data-producing agencies are adequate.}

Most of the source data for the compilation of fiscal statistics are generated within the MOF. Clear procedures are in place to ensure effective and timely flow of source data from budgetary agencies. MOF regulations establish the content and timing of the information reported by budgetary agencies.

The MOF is the only data-producing agency for fiscal statistics. It provides the necessary information on public finance to the BOM and the NSO. These two institutions also disseminate fiscal statistics through their publications and websites. The role of the MOF is clear, and therefore there is no duplication of efforts or unnecessary respondent burden concerning fiscal statistics.

\subsubsection{Individual reporters' data are to be kept confidential and used for statistical purposes only.}

The confidentiality of data reported by individual persons and entities is protected by Article 9 of the Law on Statistics, which establishes the right of statistical respondents to confidentiality from legal bodies and individuals. Penalties are applied to individuals who infringe the law. Furthermore, the Civil Service Law sets out the basic principles to guide public servants, including due diligence in the performance of their activities.

The computer systems of the MOF limit access to individual data to authorized officials, and the software programs used to collect and consolidate data are password protected.

\subsubsection{Statistical reporting is ensured through legal mandate and/or measures to encourage response.}

The Budget Law and the PSMFL provide the Minister of Finance with the authority to issue mandatory directives and instructions about budget and financial management, and to require the provision of information necessary to carry-out its functions. The Law on Statistics establishes the obligation of statistical respondents to provide statistical information to official data-producing agencies at their own cost.

The Accounting Department of the MOF provides budgetary agencies templates and instructions on how to fill them, and trains officials from these entities on the procedures for data reporting.

\section{$0.2 \quad$ Resources}

0.2.1 Staff, facilities, computing resources, and financing are commensurate with statistical programs.

Staff levels are generally adequate to perform the tasks associated with compiling fiscal statistics. The FARD and the DMD have nine and seven professional staff, respectively, to 
discharge their responsibilities. However, additional staff would be necessary to improve the quality of the statistics currently compiled or to perform new planned tasks, such as adoption of the methodology of the GFSM 2001.

The qualifications of the staff are adequate, on-the-job training is provided and a mentor assigned to new recruits. All staff in the Treasury Department are rotated every year. This measure aims to motivate staff by broadening their knowledge, but it has an important cost in terms of the loss of experience in the performance of specific tasks. Staff turnover outside the Treasury Department is not a major problem, although in recent years the staff trained in the GFSM 2001 methodology have left their current responsibilities without previously training their replacements. Salary levels in the civil service are considered generally adequate.

Overall, sufficient resources are allocated to computing technology, both for hardware and software. Each staff member has a computer assigned for his personal use, and additional computers are available for other uses (e.g., maintaining databases). Technical support is available and backup systems are in place to protect data.

The MOF office buildings provide comfortable working facilities, though the available space is becoming increasingly insufficient. In this regard, a new bigger building is in the process of being constructed. Office furniture and equipment are adequate to perform the required tasks.

The funding for the identified needs of the units responsible for compiling and disseminating GFS are included in the overall budget of the MOF and is considered secure. However, additional funding would be needed to increase human resources.

\section{Recommendation:}

- $\quad$ Allocate more human resources to the compilation and dissemination of fiscal statistics, and emphasize training in international methodologies.

\subsubsection{Measures to ensure efficient use of resources are implemented.}

A comprehensive performance evaluation system has been introduced for civil servants. It involves the signing of annual contracts with supervisors that establish detailed outputs to be produced. A semiannual review of staff performance is conducted based on these contracts, and good performers are awarded cash bonuses. In addition, the Administration Department of the MOF evaluates on a monthly basis performance at the department level.

The MOF seeks outside expert assistance to improve its statistical methodologies and compilation system on a regular basis. Once a year an effort is made to estimate the cost of generating the output at the division level. 


\subsection{Relevance}

\subsubsection{The relevance and practical utility of existing statistics in meeting users' needs are monitored.}

Current fiscal statistics are mainly geared toward compliance with existing legislation. The needs of senior officials within the MOF, as well as the needs of other government agencies and international organizations, are reasonably met. Additional information requested by these users is provided on demand. The needs of the public do not receive particular attention. No systematic actions to identify future data requirements by the public are undertaken.

The subannual and annual fiscal statistics compiled are an integral part of the budget process, and are used to assess fiscal policy.

\section{Recommendation:}

- $\quad$ Give increased attention to meeting the needs of data users outside the government and international organizations.

\subsection{Other quality management}

\subsubsection{Processes are in place to focus on quality.}

Management recognizes the importance of quality statistics to support fiscal policy. Two major initiatives undertaken with senior management support in recent years to improve the quality of statistics are the introduction in 2002 of the Treasury Single Accounts (TSA) and the introduction in 2005 of the Government Finance Management Information System (GFMIS). In addition, international accounting standards are being increasingly adopted for preparing the government's financial statements.

\subsubsection{Processes are in place to monitor the quality of the statistical program.}

Compliance with the existing accounting and data reporting rules and guidelines is closely monitored. Annual fiscal statistics are audited before publication. However, processes to monitor and improve the quality of fiscal statistics are not fully in place.

\subsubsection{Processes are in place to deal with quality considerations in planning the statistical program.}

The MOF should incorporate international best practice, such as implementation of the GFSM 2001, into its statistical program. Participation in the GDDS represents a significant step in this direction, but a more proactive approach to introducing improvements in the quality of data is required. Timely follow up on the recommendations of recent technical 
assistance missions, as well as the recommendations in this assessment, would strengthen the quality of statistical outputs.

\section{Recommendations:}

- A more explicit and systematic approach to improvements in the quality of data should be taken by the senior MOF management.

- $\quad$ Recommendations of technical assistance missions should be introduced according to an explicit timetable.

\section{Assurances of integrity}

\subsection{Professionalism}

\subsubsection{Statistics are produced on an impartial basis.}

The Law on Statistics states in Article 4 that one of the principles for conducting statistical activities is independence. The chairman of the National Statistical Board is appointed by and reports to Parliament. A culture of professionalism is adhered to, and no outside interference with statistical results is permitted.

Recruitment is conducted through a competitive process based on the qualifications for the position being filled. Candidates for civil service positions must pass competency tests. Promotion is based partly on performance and partly on seniority. Participation in relevant international seminars and courses is supported. However, processes and activities in the workplace that promote a culture of professionalism are limited, and neither research nor analysis is encouraged. However, the MOF does support higher education for the staff.

\subsubsection{Choices of sources and statistical techniques, as well as decisions about dissemination, are informed solely by statistical considerations.}

The choice of source data and statistical techniques is based exclusively on data and processing requirements. Decisions about the timing and other aspects of dissemination are based on statistical considerations and the timetable established by current legislation. However, the dissemination of information deemed by the appropriate authorities as confidential is illegal.

\subsubsection{The appropriate statistical entity is entitled to comment on erroneous interpretation and misuse of statistics.}

The MOF is entitled to comment on misinterpretation or misuse of its statistics, which is usually done by senior officials. A brief explanation of the main developments in budget execution is provided quarterly on radio. The MOF's Public Relations Officer monitors media coverage of the institution's data on a regular basis. 


\subsection{Transparency}

1.2.1 The terms and conditions under which statistics are collected, processed, and disseminated are available to the public.

The legislation referred to in Section 0.1 .1 above is publicly available. The web site of the Ministry of Justice (www.legalinfo.mn) has a legal section where all laws and regulations are posted.

\subsubsection{Internal governmental access to statistics prior to their release is publicly identified.}

Senior officials of the MOF have access to fiscal statistics prior to public release. The prior access by official users is clearly identified in Table C. Data Integrity and Access by the Public of Mongolia's metadata posted on the IMF's DSBB, and on the MOF's web site.

\subsubsection{Products of statistical agencies/units are clearly identified as such.}

The identity of the agency responsible for compiling the data released to the public is clearly identified, and the agency requests attribution when its statistics are used or reproduced. The MOF is the only data producing agency that compiles fiscal statistics, and therefore is the only source of these statistics.

\subsubsection{Advance notice is given of major changes in methodology, source data, and statistical techniques.}

Major changes in methodology and source data are usually contained in legislation or are announced when the changes are introduced.

\subsection{Ethical standards}

\subsubsection{Guidelines for staff behavior are in place and are well known to the staff.}

The Civil Service Law includes provisions on the proper behavior of civil servants. These provisions are incorporated into the contract civil servants sign upon joining the service. In addition, civil servants must take an oath that includes a commitment to faithfully discharge their responsibilities. Staff are not reminded periodically of the ethical standards. 


\section{Methodological soundness}

\subsection{Concepts and definitions}

\subsubsection{The overall structure in terms of concepts and definitions follows internationally} accepted standards, guidelines, or good practices.

The concepts and definitions used to compile fiscal statistics generally follow the guidelines of A Manual on Government Finance Statistics 1986 (GFSM 1986) for the general government sector and its subsectors.

No formal decision has been taken by the authorities on adopting a "migration path" from the GFSM 1986 methodology to the GFSM 2001 methodology. However, it is the intention of the authorities to adopt the new framework for compiling fiscal statistics. In this connection, Mongolia is participating in the pilot study currently being conducted by the IMF's Statistics Department in coordination with the corresponding area departments (Asia Pacific Department in this case), to prepare GFSM 2001-based analytical tables for inclusion in the Article IV consultation report.

\section{Recommendation:}

- A formal decision to adopt the GFSM 2001 methodology should be taken by senior MOF management, and a migration path to this effect developed and implemented.

\subsection{Scope}

2.2.1 The scope is broadly consistent with internationally accepted standards, guidelines, or good practices.

To facilitate understanding of the coverage of fiscal statistics, the institutional structure of Mongolia's general government sector is set out and explained below.

\section{a. Central Government $(1+2+3)$}

1. Budgetary central government. Cabinet Office, Constitutional Council, General Prosecutor's Office, Ministries, Parliament, President's Office, Supreme Court, Government Agencies (except self-financed), Culture and Arts Fund, Construction Department, Employment and Promotion Fund, Environment Fund, Environment Protection Fund, Foreign Citizens and Citizenship Issues Department, Fuel and Energy Authority, Intellectual Rights Department, Oil and Gas Department, Postal and Telecommunications Department, Road, Transportation and Tourism Department, Road Fund, Service of Diplomatic Missions Department, State Center of Standardization and Metrology, State Citizens' Registration and Information Center, State Property Committee, and Tourism Fund. 
2. Extrabudgetary units. Grains Fund, KR-1 Fund, KR-2 Fund, Herd Protection Fund, Assistance of Disabled Citizens Fund, Departments Development Fund, Ministry of Food and Agriculture Fund (USA1), Ministry of Food and Agriculture Fund (USA2), Ministry of Food and Agriculture Fund (Ukraine), and Mongolia Development Fund.

3. Social Security Funds. Health Insurance Fund, Industrial Accidents and Occupational Disease Insurance Fund, Pension Insurance Fund, Social Benefits Insurance Fund, and Unemployment Insurance Fund.

\section{b. Local Governments}

1. City and nine districts of Ulaanbaatar

2. Provinces/aimags (21)

3. Districts/soums (331)

\section{c. General Government Sector $(\mathbf{a}+\mathbf{b})$}

There are two levels of government in Mongolia - central government and local governments. The central government is composed of the budgetary central government, extrabudgetary units, and social security funds. The local governments include the city and districts of Ulaanbaatar, provinces, and districts. In terms of data coverage, subannual and annual fiscal statistics are compiled and disseminated for the general government sector and its subsectors, except extrabudgetary units. Thus, fiscal statistics do not cover the whole central government and general government institutional sector.

The MOF compiles and disseminates a Monthly Report, which includes one table with a breakdown for revenues, expenditures, and financing. The table provides information for central government, local governments, and general government on a cumulative basis, and with a comparison to the similar period for the previous year. It also provides separately information on the Mongolia Development Fund, an extrabudgetary unit. The monthly report for end-of-quarter months also includes a table with a functional classification of expenditure. A brief note explaining the main developments for the period is attached. The monthly report is posted on the MOF's web site (www.MOF.pmis.gov.mn), and a hardcopy version is distributed to thirteen institutions. An Annual Report (Budget Outturn) is also compiled. The summary tables in the report are the same as the monthly report, but a large number of other tables with detailed budget execution information are also included. Text explaining the main developments for the fiscal year is attached. A summary of the text and selected tables are posted on the MOF's website and are printed in hardcopy. Both the monthly report and the annual report are available only in Mongolian. It should be highlighted that central government debt data are compiled, but are not disseminated in either report. 
The MOF is the only data-producing agency for fiscal statistics. However, the BOM and, in particular, the NSO, also disseminate fiscal statistics on their web sites (www.mongolbank.mn and www.nso.mn, respectively) and hardcopy publications. The BOM includes in its Monthly Statistical Bulletin one table with summary data for major fiscal aggregates for central government, local governments, and general government. A time series is provided in the table. The BOM's Annual Report includes a summary table for revenues, expenditures, and financing for general government in its text. In addition, an appendix table of main economic indicators includes a few fiscal aggregates for general government. The data on the BOM's website and its hardcopy publications are available in Mongolian and English.

The NSO's Monthly Bulletin of Statistics includes several tables on fiscal statistics that provide summary and detailed information on revenues, expenditures, and financing for central government, local governments, and general government. The annual Mongolian Statistical Yearbook also includes several tables with similar summary and detailed information for the last four years. The data on the NSO's web site and its hardcopy publications are available in Mongolian and English. Again, it should be highlighted that central government debt are not disseminated in any publications of the BOM and the NSO.

Briefly stated, the institutional scope of the monthly and annual fiscal statistics for the general government sector and its subsectors (except for extrabudgetary units) generally follows international guidelines. However, no data for central government debt are disseminated. This is a major shortcoming of the current dissemination practices.

In terms of transactions coverage, data are generally available to the standard specified in the following GFSM 1986 tables: summary table of major components, government revenue and grants, classification of the functions of government, and economic classification of government expenditure and lending minus repayments. The data for financing is a combination of financing by type of debt instrument and by type of debt holder. Data are available but not disseminated for general government gross debt.

The fiscal statistics compiled for the monthly report are based on essentially complete coverage. If information is missing for a given budgetary unit or institution an estimate is made and later replaced when actual information becomes available. A similar situation applies to the fiscal statistics compiled for the annual report.

\section{Recommendations:}

- Identify data sources for extrabudgetary units and begin compiling fiscal statistics for these units. Incorporate and consolidate these statistics with the statistics for the central government sector and the general government sector.

- $\quad$ Disseminate data for central government debt. 


\subsection{Classification/sectorization}

2.3.1 Classification/sectorization systems used are broadly consistent with internationally accepted standards, guidelines, or good practices.

Institutional sectors are generally defined in accordance with the 1993 SNA (and thereby GFSM 2001), except for the exclusion of extrabudgetary units from the coverage of the central government sector and the general government sector. Monthly fiscal statistics are provided separately for all subsectors (except social security funds) and for consolidated general government. Annual fiscal statistics include separate information on the social security funds.

The classifications used for subannual and annual fiscal statistics on the operations of the general government sector and its subsectors follow broadly the classifications of the GFSM 1986, but with some differences. While revenue and expenditure by economic classification, and expenditure by function are classified in general conformity to international guidelines, the classification of financing follows a national presentation, that combines elements of a classification by type of debt instrument and by type of debt holder. As indicated above, no data for central government debt are disseminated.

There is a major classification issue concerning financing. The item banking system net credit is calculated as a residual, and the change in cash balances for the period is not identified separately. This practice also leads to the inclusion under this item of the statistical discrepancy between revenue minus expenditure and financing. This is not a sound statistical practice and should be discontinued. Information is available for the change in the cash balances in the TSA and should be presented as a separate item, while a separate item denominated statistical discrepancy should be introduced. Of course, if this latter item is significant it should be investigated.

\section{Recommendations:}

- Use the GFSM 1986 classifications for financing.

- $\quad$ Present in the monthly and annual report the information available for the change in the cash balances in the TSA as a separate item, and introduce a separate item denominated statistical discrepancy.

\section{$2.4 \quad$ Basis for recording}

\subsubsection{Market prices are used to value flows and stocks.}

Flows are valued based on the amount of payments in cash. Gross debt is valued at issue price for Treasury bills and nominal value for loans. Flows denominated in foreign currency are converted to national currency using the exchange rate established by the BOM for the 
date the transaction took place. The outstanding external debt is converted to national currency using the BOM for the end of the period.

\subsubsection{Recording is done on an accrual basis.}

Transactions are recorded on a cash basis, as close as possible to the time of payment, consistent with the guidelines of the GFSM 1986.

\subsubsection{Grossing/netting procedures are broadly consistent with internationally accepted} standards, guidelines, or good practices.

All transactions are shown on a gross basis, except for financing transactions and corrective transactions which are shown net.

\section{Accuracy and reliability}

\subsection{Source data}

\subsubsection{Source data are obtained from comprehensive data collection programs that take into account country-specific conditions.}

Data sources are complete to allow the compilation of fiscal statistics for the general government sector and its subsectors (except for extrabudgetary units) on a monthly, quarterly, and annual basis. There is no comprehensive register of individual public sector units. Institutional and geographical coverage is complete. The necessary reports for data collection have been field-tested. Reports are generated automatically from data reported by budgetary units.

\subsubsection{Source data reasonably approximate the definitions, scope, classifications, valuation, and time of recording required.}

Data sources for the general government sector and its subsectors are consistent with international guidelines on definitions, scope, sectorization, classification, time of recording, and valuation of flows and stocks. These sources also permit consolidation with other subsectors.

\subsubsection{Source data are timely.}

Data sources for the general government sector and its subsectors are timely. The monthly report is prepared by the seventh day of the following month. Budgetary agencies must submit their reports by the second day and the provinces/aimags by the fifth day. Reporting units are aware of the deadlines set for reporting, and the timetable is usually met. 


\subsection{Assessment of source data}

3.2.1 Source data-including censuses, sample surveys, and administrative records-are routinely assessed, e.g., for coverage, sample error, response error, and nonsampling error; the results of the assessments are monitored and made available to guide statistical processes.

The monthly reports submitted by budgetary agencies, and the provinces are cross-checked against data in the GFMIS. Data inconsistencies and out-of-trend values are confirmed with reporting units. However, the assessment is conducted based on maintaining the trade-off between accuracy and timeliness.

\subsection{Statistical techniques}

\subsubsection{Data compilation employs sound statistical techniques to deal with data sources.}

Compilation procedures are in place to minimize processing errors. Missing data are estimated by using "plan" data, which are later replaced by actual data when they become available. Monthly data are preliminary when first disseminated, but are not replaced by final data afterwards. Annual data are final when first disseminated. All data are corrected when errors are detected if material. The corrections are made on the cumulative data, not the corresponding month, although monthly data are available on a discrete basis. Compilation procedures are not documented. The discrepancy between subannual and annual data is not removed; however, this discrepancy has been small the last two years.

\section{Recommendations:}

- $\quad$ Replace preliminary monthly data by fiscal (audited) data once the latter become available.

- $\quad$ Present data in tables on a discrete basis instead of a cumulative basis. Correct errors in the corresponding period.

- $\quad$ Document compilation procedures.

- $\quad$ Remove discrepancy between sub-annual and annual data.

3.3.2 Other statistical procedures (e.g., data adjustments and transformations, and statistical analysis) employ sound statistical techniques.

The data collected on a cash basis is cross-checked against data on receivables and payables. Bridge tables have been constructed to transform data in GFSM 1986 format to GFSM 2001 format. 


\subsection{Assessment and validation of intermediate data and statistical outputs}

3.4.1 Intermediate results are validated against other information, where applicable.

Intermediate results are generally not available for fiscal statistics.

\subsubsection{Statistical discrepancies in intermediate data are assessed and investigated.}

Large fluctuations or discrepancies are investigated.

\subsubsection{Statistical discrepancies and other potential indicators of problems in statistical outputs are investigated.}

Statistical outputs are checked horizontally and vertically to reduce discrepancies, and values outside expected ranges are investigated. The sum of components is verified against the total, and the sum of subsectors is verified against the total for the sector. The values for items to be consolidated are compared, and the reason for any differences is investigated. External debt data are compared with creditor information in a regular manner. Fiscal data discrepancies among national compilers on particular items are not regularly reconciled.

\section{Recommendation:}

- $\quad$ Reconcile on a regular (i.e., monthly or quarterly) basis fiscal data discrepancies among national compilers, particularly with monetary data.

\subsection{Revision studies}

3.5.1 Studies and analyses of revisions are carried out routinely and used internally to inform statistical processes (see also 4.3.3).

There are virtually no revisions to fiscal statistics, except for the correction of errors and the replacement of estimates by actual data. Revision studies are not conducted on a routine basis.

\section{Serviceability}

\subsection{Periodicity and timeliness}

\subsubsection{Periodicity follows dissemination standards.}

Statistics for central government budgetary operations are compiled and disseminated monthly, while statistics for central government debt are compiled monthly but are not disseminated. Thus, the periodicity of fiscal statistics meets the GDDS recommendation of quarterly dissemination for central government budgetary operations, but not for central government debt. It should be noted that because the statistics for central government 
budgetary operations are disseminated on a cumulative basis, data for individual months requires subtracting data from consecutive months.

\subsubsection{Timeliness follows dissemination standards.}

Monthly statistics for central government budgetary operations are disseminated on the tenth of the following month, while annual statistics for central government debt are not disseminated. Thus, the timeliness of fiscal statistics meets the GDDS recommendation of dissemination within one quarter for central government budgetary operations, but not for central government debt. It should be noted that information is available to compile and disseminate central government debt within a timeframe that would easily meet the GDDS recommendation.

\subsection{Consistency}

\subsubsection{Statistics are consistent within the dataset.}

The concepts, definitions, and classifications for producing subannual and annual fiscal statistics by the MOF are the same. For both these statistics, the deficit/surplus does not equal the financing, and the discrepancy is incorporated into the item banking system net credit; major aggregates equal the sum of components; functional and economic expenditure are equal; domestic and foreign financing are consistent with changes in debt; transfers paid equal transfers received; and interest in the functional and economic expenditure are equal.

Subannual and annual fiscal statistics have been consistent the last two years, though this was not the case in earlier years. The introduction of the TSA and the GFMIS are the main reasons for this improvement.

\subsubsection{Statistics are consistent or reconcilable over a reasonable period of time.}

Consistent time series for annual fiscal statistics are available for an adequate period. There have been no major changes in source data, methodology, or techniques in recent years. Unusual changes in economic trends are explained in the commentary included in the monthly and annual reports.

\subsubsection{Statistics are consistent or reconcilable with those obtained through other data sources and/or statistical frameworks.}

The MOF is the only data-producing agency that compiles fiscal statistics. As such, all fiscal statistics disseminated by data-producing agencies are fully consistent. MOF data are used for compiling national accounts and balance of payments statistics, thereby ensuring consistency in principle. Nevertheless, published data should be reconciled on a regular basis. There are differences with the financing data from the monetary accounts, which are not reconciled on a regular basis. In the past, these differences have been due to 
misclassifications of accounts by commercial banks and errors in recording specific transactions.

\section{Recommendation:}

- $\quad$ The MOF and the BOM should reconcile bank financing data on a monthly basis.

\subsection{Revision policy and practice}

\subsubsection{Revisions follow a regular and transparent schedule.}

As indicated in 3.5 above, there are virtually no revisions to fiscal statistics, except for the correction of errors and the replacement of estimates by actual data. Thus, there is no formal revision cycle. When revisions to fiscal statistics do occur, they are not made known to the public.

\subsubsection{Preliminary and/or revised data are clearly identified.}

At the time of data dissemination users are not informed whether data are preliminary or final. Only the monthly fiscal statistics for December indicate that the data are preliminary. The monthly statistics for the other months and the annual statistics do not indicate whether the data are preliminary or final.

\section{Recommendation:}

- Data in the monthly reports and the annual report should be clearly identified as being preliminary or final.

\subsubsection{Studies and analyses of revisions are made public (see also 3.5.1).}

Revision studies are not conducted. Thus, there are no studies to be made public.

\section{Accessibility}

\subsection{Data accessibility}

5.1.1 Statistics are presented in a way that facilitates proper interpretation and meaningful comparisons (layout and clarity of text, tables, and charts).

Fiscal statistics are disseminated generally according to the standard recommended by the GFSM 1986 for revenues and expenditures, but not for financing. The monthly report presents the cumulative data for the current year and the corresponding data for the similar period from the previous year. The annual report presents time series for four or five years. The fiscal statistics disseminated in the MOF, BOM, and NSO publications are presented in a clear manner. Nevertheless, the clarity of the presentation could be enhanced by the use of 
more graphs and charts. Commentaries on current period developments are included in the publications.

\subsubsection{Dissemination media and format are adequate.}

Fiscal statistics are disseminated by the MOF, BOM, and NSO on their websites. The MOF also distributes a limited number of reports in hardcopy, while the BOM and NSO distribute their publications more broadly in hardcopy. It should be noted that the most recent versions of the NSO publications could only be accessed on its website for a fee. The NSO publishes in the press monthly commentaries on socioeconomic developments, which include budget developments.

\subsubsection{Statistics are released on a preannounced schedule.}

There is no advance release schedule communicated to the public. However, there is an internal MOF schedule for the release of its reports, which is usually observed. Thus, fiscal statistics are in practice released punctually on a regular schedule, which the public knows.

\section{Recommendation:}

- Introduce an advance release calendar for fiscal statistics.

\subsubsection{Statistics are made available to all users at the same time.}

Fiscal statistics are made available to all users simultaneously and without preferential treatment of selected users, except for the previous access by senior MOF officials discussed under 1.2.2. The public is usually not informed of the statistics being released by the MOF, although the presentation of the quarterly report to the cabinet is attended by the press. The NSO holds a monthly press conference to release its bulletin.

\subsubsection{Statistics not routinely disseminated are made available upon request.}

Fiscal statistics not routinely disseminated are made available upon request to selected users. The availability of additional statistics and the procedures for obtaining them are not made known.

\subsection{Metadata accessibility}

5.2.1 Documentation on concepts, scope, classifications, basis of recording, data sources, and statistical techniques is available, and differences from internationally accepted standards, guidelines, or good practices are annotated.

The MOF publishes on its website the GDDS metadata posted on the IMF's DSBB. The GDDS metadata for the fiscal sector was last updated in August 2003 and remains essentially accurate, but the name of the contact person needs to be updated. 


\section{Recommendation:}

- $\quad$ Update the name of the contact person for the fiscal sector in the GDDS metadata posted on the IMF's DSBB.

\subsubsection{Levels of detail are adapted to the needs of the intended audience.}

The only information available on the sources and methods used to compile fiscal statistics, as indicated above, is the GDDS metadata on the IMF's DSBB and on the MOF's web site. The laws relevant to the budget and financial management are publicly available.

\subsection{Assistance to users}

\subsubsection{Contact points for each subject field are publicized.}

No contact point for fiscal statistics is identified in MOF publications. However, contact persons and contact details for each subject field are publicized in the GDDS metadata on the IMF's DSBB and the MOF's website. In general, limited assistance is provided to general public users of fiscal statistics.

\section{Recommendation:}

- Identify a contact point for fiscal statistics in MOF publications.

5.3.2 Catalogs of publications, documents, and other services, including information on any charges, are widely available.

The MOF does not have a catalog of publications. Its publications are made available free of charge. The NSO provides on its website a list of its publications and their price in electronic and hardcopy format. 
Table 3. Mongolia: Data Quality Assessment Framework (July 2003): Summary of Results for Government Finance Statistics (Compiling Agency: Ministry of Finance)

Key to symbols: $\mathrm{NA}=$ Not Applicable; $\mathrm{O}=$ Practice Observed; $\mathrm{LO}=$ Practice Largely Observed; LNO = Practice Largely Not Observed; NO = Practice Not Observed; SDDS = Complies with SDDS Criteria

Element

\begin{tabular}{|c|c|c|c|c|}
\multirow{2}{*}{ NA } & \multicolumn{4}{|c|}{ Assessment } \\
\cline { 2 - 5 } & $\mathrm{O}$ & LO & LNO & NO \\
\hline
\end{tabular}

Comments on Assessment

Plans for Improvement and Target Dates

\section{Prerequisites of quality}

0.1 Legal and institutional environment

0.2 Resources

\begin{tabular}{|l|l|l|l|l|}
$\mathrm{X}$ & $\mathrm{X}$ & & \\
& & $\mathrm{X}$ & & \\
\hline & & $\mathrm{X}$ & & \\
& & & & \\
\end{tabular}

Staff resources are insufficient to handle new tasks and staff trained in the

GFSM 2001 methodology has moved on

without previously training their

replacements.

0.3 Relevance

0.4 Other quality management

The needs of the general public do not receive adequate attention.

Processes to monitor and improve the

quality of fiscal statistics are not fully in

place. A more proactive approach to

introducing improvements in the quality

of data is required.

\section{Assurances of integrity}

\begin{tabular}{|l|l|l|l|l|l}
\hline 1.1 Professionalism & & $\mathrm{X}$ & & & $\begin{array}{l}\text { Authorities can determine that certain } \\
\text { data are confidential and their } \\
\text { dissemination illegal. } \\
\text { Major changes in methodology and } \\
\text { source data are usually contained in } \\
\text { legislation or are announced when the } \\
\text { changes are introduced. }\end{array}$ \\
\hline
\end{tabular}

1.3 Ethical standards changes are introduced. 
Table 3. Mongolia: Data Quality Assessment Framework (July 2003): Summary of Results for Government Finance Statistics (Compiling Agency: Ministry of Finance)

\begin{tabular}{|c|c|c|c|c|c|c|c|}
\hline \multirow{2}{*}{ Element } & \multirow{2}{*}{ NA } & \multicolumn{4}{|c|}{ Assessment } & \multirow{2}{*}{ Comments on Assessment } & \multirow{2}{*}{ Plans for Improvement and Target Dates } \\
\hline & & $\mathrm{O}$ & $\mathrm{LO}$ & LNO & $\mathrm{NO}$ & & \\
\hline \multicolumn{8}{|l|}{ 2. Methodological soundness } \\
\hline $\begin{array}{l}\text { 2.1 Concepts and definitions } \\
2.2 \text { Scope }\end{array}$ & & & $\mathrm{X}$ & $\mathrm{X}$ & & $\begin{array}{l}\text { No formal decision has been taken by } \\
\text { the authorities on adopting a "migration } \\
\text { path" to the GFSM } 2001 \text { methodology. } \\
\text { No data for central government debt are } \\
\text { disseminated. No fiscal statistics are } \\
\text { compiled for extrabudgetary units. }\end{array}$ & \\
\hline $\begin{array}{l}\text { 2.3 Classification/sectorization } \\
\text { 2.4 Basis for recording }\end{array}$ & & $\mathrm{X}$ & $\mathrm{X}$ & & & $\begin{array}{l}\text { The item banking system net credit is } \\
\text { calculated as a residual and the change } \\
\text { in cash balances for the period is not } \\
\text { identified separately. The classification } \\
\text { of financing does not follow } \\
\text { international standards. }\end{array}$ & \\
\hline \multicolumn{8}{|l|}{ 3. Accuracy and reliability } \\
\hline 3.1 Source data & & & $\mathrm{X}$ & & & $\begin{array}{l}\text { No source data for extrabudgetary units. } \\
\text { No register of individual public sector } \\
\text { units. }\end{array}$ & \\
\hline $\begin{array}{l}\text { 3.2 Assessment of source data } \\
\text { 3.3 Statistical techniques } \\
\text { 3.4 Assessment and validation of inter- } \\
\text { mediate data and statistical outputs } \\
\text { 3.5 Revision studies }\end{array}$ & & $\mathrm{X}$ & $\mathrm{X}$ & $\mathrm{X}$ & & $\begin{array}{l}\text { Monthly preliminary data not replaced } \\
\text { by final data. Compilation procedures } \\
\text { not documented. The discrepancy } \\
\text { between subannual and annual data is } \\
\text { not removed. } \\
\text { Fiscal data discrepancies among national } \\
\text { compilers are not reconciled. } \\
\text { Revisions to fiscal statistics are few. } \\
\text { No revision studies are conducted. }\end{array}$ & \\
\hline
\end{tabular}


Table 3. Mongolia: Data Quality Assessment Framework (July 2003): Summary of Results for Government Finance Statistics (Compiling Agency: Ministry of Finance)

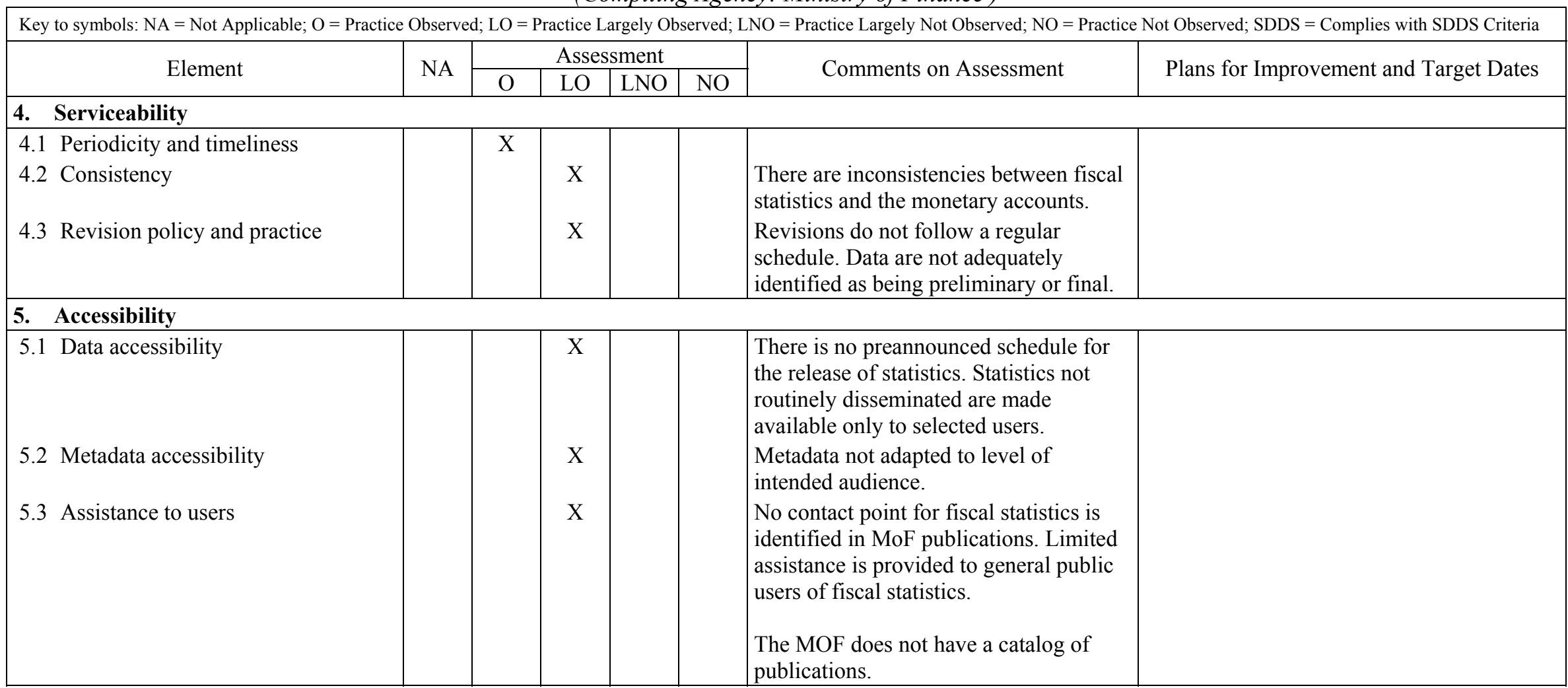




\section{MONETARY STATISTICS}

\section{Prerequisites of quality}

\section{$0.1 \quad$ Legal and institutional environment}

\subsubsection{The responsibility for collecting, processing, and disseminating the statistics is clearly specified.}

The Law of Mongolia on Central Bank (Bank of Mongolia) gives the BOM the mandate for the collection, processing, and dissemination of monetary statistics. Article 34 of the Law stipulates that "(1) The Bank of Mongolia shall publicize information on changes in the implementation and instruments of monetary policy, and on the state of monetary developments and the financial market every quarter; (2) The Bank of Mongolia shall issue a monthly bulletin on monetary statistics; (3) The Bank of Mongolia shall have the right to require information, reports and indices from banks, individual and legal entities in order to compile the information it must provide under paragraphs 1 and 2 of this article; and (4) The Bank of Mongolia may publish statistical information and reports in compliance with the laws." Working arrangements that exist within the various work units of the BOM are consistent with its monetary statistics function. As the monetary statistics are compiled exclusively by the BOM, no conflict exists between the BOM and other data-producing agencies.

\subsubsection{Data sharing and coordination among data-producing agencies are adequate.}

The Research Division of the BOM's Monetary Policy and Research Department compiles monetary statistics by integrating two principal data sources. It takes the central bank's balance sheet data from the BOM's Accounting and Information Technology Department and the other depository corporations' balance sheet data from the commercial banks. The Research Division has established adequate arrangements for coordination with the Accounting and Information Technology Department and the commercial banks to secure these data. In addition, the Research Division coordinates its work with the BOM's International Division (for balance of payments statistics) and with the MOF (for central government statistics).

Cooperation between the Research Division and the Supervision Department takes the form of mutual consultation on the source data. When updates to the chart of accounts for commercial banks are planned, the Supervision Department consults with the Research Division on changes that may affect the monetary statistics. Likewise, when the Research Division notices large movements in the balance sheet items of particular financial institutions, it consults with the Supervision Department. 


\subsubsection{Individual reporters' data are to be kept confidential and used for statistical purposes only.}

The Law of Mongolia on Central Bank (Bank of Mongolia) mandates the confidentiality of data of individual reporters. Article 29 of the Law specifies "disclosing to others official information relating to accounts, account transactions or payments of any bank, legal person or individual, or relating to any agreement or contract on banking activities, unless the law provides otherwise," as one of the activities that BOM employees are prohibited from undertaking. This obligation of employees to safeguard the confidentiality of data continues after the end of their employment at the BOM. As the same article of the Law specifies, "Unless the law provides otherwise, employees of the BOM shall maintain the confidentiality of the documents and information obtained during the course of their duty and for a period of one year after being discharged from duty." Procedures adopted by the BOM complement these legal provisions. Access to individual bank data is restricted to the staff who require those data in the performance of their statistical duties. Moreover, the computer system is protected by the user identification systems and passwords that deny access to these data to all other staff. Finally, only aggregated banking data are allowed to be published, so that there is no disclosure of individual bank data.

\subsubsection{Statistical reporting is ensured through legal mandate and/or measures to encourage response.}

The Banking Law of Mongolia requires individual banks to provide data to the BOM. Its Article 28 stipulates, "A Bank shall issue its financial statement each month and submit it to the Bank of Mongolia. The Bank of Mongolia reserves the right to request any additional clarifying documents related to the financial statement of the bank." The same article specifies what the Law means by "the financial statement" that a bank is obliged to submit ("Financial statements of a bank shall consist of balance sheet, the profit and loss statement, interpretations and clarifications."), and describes what requirements the financial statement should meet ("A financial statement presentation shall conform to the accounting standards set by the Bank of Mongolia in accordance with the international standards, and be signed by Chairman of the Governing Representative Board, Executive Director, and Chief Accountant."). Consequently, Article 49 of the Law gives the BOM authority to impose penalties on banks for not reporting data that have been requested. It stipulates that "For failure in submission of reports, balance sheets and other documents to the Bank of Mongolia in accordance with the relevant rules and for failure in making public the balance sheet according to Article 28 without serious grounds, the bank shall be fined for up to $1,000,000$ togrogs, and bank employees and officers up to 250,000 togrogs." All banks report data to the BOM, as stipulated, and no bank has ever refused data. 


\section{$0.2 \quad$ Resources}

\subsubsection{Staff, facilities, computing resources, and financing are commensurate with statistical programs.}

The monetary statistics team of the Research Division is staffed with only three personnelnamely, one Senior Economist and two Economists. A fourth economist position is currently vacant. Under the present working arrangements, the economists are directly engaged in data compilation, and the senior economist exercises a supervisory oversight over their activities, as well as reviews the final statistical output for accuracy. The senior economist and both economists have participated in the IMF-organized Course on Monetary and Financial Statistics. They have acquired the necessary skills to perform the assigned tasks. Each member of the team is equipped with one personal computer, and the team as a whole shares one printer. Although the present staff size, coupled with the available computer capacity, is adequate for the routine execution of the existing work program - compilation (on a monthly cycle) of a monetary survey with an institutional coverage limited to the commercial banksit is not adequate if the Research Division were to undertake a developmental project, such as incorporating the nonbank depository corporations in the survey. The BOM's salary levels are competitive with public administration conditions in Mongolia.

\section{Recommendation:}

- $\quad$ Allocate additional staff to work on further development of monetary statistics.

\subsubsection{Measures to ensure efficient use of resources are implemented.}

The BOM promotes efficiency through a variety of channels. First, the BOM's managers evaluate the performance of staff members on a quarterly basis, as well as at the end of the year. Second, the BOM conducts periodic reviews of work processes to revise work priorities by eliminating superfluous work and focusing effort on urgent work. Finally, the BOM's Internal Auditing Department audits the Monetary Policy and Research Department on an annual cycle.

\section{$0.3 \quad$ Relevance}

\subsubsection{The relevance and practical utility of existing statistics in meeting users' need are} monitored.

The BOM seeks to monitor the relevance of monetary statistics in meeting user needs. Specifically, it provides a contact list (e-mail addresses), which encourages users to ask questions and provide feedback. Not many questions or feedback on monetary statistics, however, have been received. The Research Division participates in international seminars and meetings. The most recent example of the latter is the Seminar on Implementing the Balance Sheet Approach to Macroeconomic Surveillance held by the BOM in Ulaanbaatar (July 2-5, 2007). 


\subsection{Other quality management}

\subsubsection{Processes are in place to focus on quality.}

The BOM considers it essential to provide reliable monetary statistics and seeks ways to improve the quality of its monetary statistics. Specifically, it provides training for its staff through the Bankers' Training Centre (BTC) in Ulaanbaatar. It also strives to improve statistical accuracy by revising monetary data to correct errors - the most recent example being the revision to monetary data for 2005 related to misreporting of central government deposits by certain commercial banks.

\subsubsection{Processes are in place to monitor the quality of the statistical program.}

The BOM's management conducts a pre-release data check. Also, the Research Division has access to expert guidance on the quality of monetary statistics and on strategies for improving data production. Whenever monetary statistics need revision, the Research Division, if necessary, makes use of services provided by outside consultants - especially technical assistance providers from the IMF Statistics Department.

\subsubsection{Processes are in place to deal with quality considerations in planning the statistical program.}

The BOM takes into account quality issues in planning its statistical program. Consequently, its recent work program for monetary statistics has led to several improvements. These include more detailed sectorization of data, as well as reduction in discrepancy between monetary and fiscal data sets.

\section{Assurances of Integrity}

\subsection{Professionalism}

\subsubsection{Statistics are produced on an impartial basis.}

The Law of Mongolia on Central Bank (Bank of Mongolia) establishes professional independence of the BOM. Article 26 stipulates that the BOM would be headed by the governor appointed, upon the recommendation of its chairman, by the State Ikh Khural (Mongolian Parliament) to which he would report. The First Deputy Governor and the Deputy Governor of the BOM would all be appointed, upon the recommendation of the governor, by the State Ikh Khural. All these officials are appointed for a period of six years, and can be discharged only by the State Ikh Khural and only in circumstances that have been identified in the Law-namely, becoming a shareholder in a commercial bank, acting against the BOM's interest, or committing a criminal offence. Moreover, for one year after their release from the position in the BOM, they are prohibited from occupying a management position in a commercial bank. 
Professionalism is actively promoted and supported within the BOM through a number of channels. First, recruitment and promotion are based, among other factors, on expertise in statistics. Second, as observed in 0.4.1, the BOM provides training to its staff through the BTC. In addition, some of them participate in training seminars on statistics conducted by the IMF. Finally, the BOM provides its staff with the opportunities to participate in meetings of experts - as, for example, in the Seminar on Implementing the Balance Sheet Approach to Macroeconomic Surveillance that was recently held in Ulaanbaatar.

\subsubsection{Choices of sources and statistical techniques as well as decisions about dissemination are informed solely by statistical considerations.}

The BOM chooses data sources and statistical techniques, as well as takes decisions on dissemination, solely by statistical considerations. One of the BOM's policies is that statistics should be disseminated as soon as possible. The BOM's decisions about the timing, media, and other aspects of dissemination are also based solely on statistical considerations.

\subsubsection{The appropriate statistical entity is entitled to comment on erroneous interpretation and misuse of statistics.}

The BOM is entitled to comment on erroneous interpretation and misuse of monetary statistics by the media. Should there be an interpretation of monetary statistics by the media that requires a response from the BOM, the Research Division would prepare a draft and, after the governor has signed off, the Administration Department would send it to the media for publication. No examples of a published response, however, are available.

\section{$1.2 \quad$ Transparency}

\subsubsection{The terms and conditions under which statistics are collected, processed, and disseminated are available to the public.}

The BOM's web site (http://www.mongolbank.mn) posts the Law of Mongolia on Central Bank (Bank of Mongolia) that presents the terms and conditions-such as the BOM's mandate to compile and publish aggregated data, as well as its obligation to safeguard the confidentiality of individual unit data - under which the Research Division compiles monetary statistics.

\subsubsection{Internal governmental access to statistics prior to their release is publicly identified.}

Internal government access to monetary statistics prior to their release does not exist.

\subsubsection{Products of statistical agencies/units are clearly identified as such.}

Monetary statistics are identified as produced by the BOM in the publications of the BOM, as well as in those of the NSO, which reproduces them. 


\subsubsection{Advanced notice is given of major changes in methodology, source data, and statistical techniques.}

The BOM does not give users an advance notice on major changes in methodology, source data, and statistical techniques.

\subsection{Ethical standards}

\subsubsection{Guidelines for staff behavior are in place and are well known to the staff.}

The BOM has set clear guidelines for staff behavior. These guidelines are articulated in the form of The Law of Mongolia on Central Bank (Bank of Mongolia) and a circular on staff rules and regulations. Article 29 of the Law clearly lists a number of activities that a BOM employee is prohibited from undertaking. These activities include representing the interests of any individual or legal entities; procuring advantageous or preferred conditions for himself or his family members, relatives, business counterparts or other acquaintances; and disclosing official information on finances of a commercial bank. The Law is disseminated on the BOM's web site and is easily available and well known to staff. All staff members are given copies of the circular on staff rules and regulations.

\section{Methodological soundness}

\subsection{Concepts and definitions}

\subsubsection{The overall structure in terms of concepts and definitions follows internationally accepted standards, guidelines, or good practices.}

The Monetary and Financial Statistics Manual (MFSM) methodology requires compilation of monetary statistics within the framework of a Depository Corporations Survey. This survey is an analytical presentation of the consolidated accounts of the resident financial corporations and financial quasi-corporations that are mainly engaged in financial intermediation and that issue liabilities included in the national definition of broad money. It presents stock and flow data on those corporations' liabilities to - as well as on those corporations' claims on (i.e., credit to) - other sectors of the economy. It also presents data on the depository corporations' liabilities to and claims on nonresidents. Although the BOM does not compile the Depository Corporations Survey as recommended in the MFSM and, instead, compiles a Monetary Survey that provides consolidated balance sheets of the central bank and the deposit money banks, it broadly follows the concepts and definitions of the MFSM methodology. Wherever there are deviations from the MFSM concepts and definitions (see 2.2.1, 2.3.1, and 2.4.1 below), the Research Division keeps them under review. The BOM however, has not yet rebased monetary data compilation on SRF framework. 


\section{Recommendation:}

Adopt the SRF as a vehicle for reporting monetary data both within the financial system and to the IMF.

\section{$2.2 \quad$ Scope}

2.2.1 The scope is broadly consistent with internationally accepted standards, guidelines, or good practices.

Mongolia has three categories of depository corporations - namely, (i) BOM - the central bank; (ii) 16 operating commercial banks; and (iii) over 970 registered savings and credit unions (of which 128 have been licensed to conduct operations). A Depository Corporations Survey, as recommended in the MFSM, should cover all these categories of depository corporations. The BOM's Monetary Survey, however, covers only the first two of these categories but not the last one, which increasingly competes with commercial banks and whose deposit share is growing rapidly. Consequently, the BOM's monetary aggregates understate Mongolia's money supply by the amount of deposits collected by the savings and credit unions. No firm estimates of the latter have been prepared, but these deposits are believed to be 8 to 10 percent of those collected by commercial banks.

\section{Recommendation:}

- $\quad$ Develop a Depository Corporations Survey by expanding the coverage of the Monetary Survey to include savings and credit unions.

\subsection{Classification/sectorization}

\subsubsection{Classification/sectorization systems used are broadly consistent with the internationally accepted standards, guidelines, or good practices.}

The MFSM methodology requires that claims and liabilities be divided by sectors into which all institutional units with similar characteristics be grouped; that sectorization first distinguish between residents and nonresidents, and then delineate the various domestic sectors and subsectors; and that the resident units of the economy be grouped into the following mutually exclusive sectors:

- $\quad$ Financial corporations (central bank, other depository corporations, other financial corporations);

- Nonfinancial corporations (public nonfinancial corporations, other nonfinancial corporations); 
- $\quad$ General government (central government, state government, local government, social security funds); and

\section{- $\quad$ Other resident sectors.}

The sectorization scheme used by the BOM for its Monetary Survey divides institutional units between resident and nonresident sectors, and subdivides resident sector data by seven subsectors. These are (i) central government; (ii) local government; (iii) other public sector (public nonfinancial corporations); (iv) private sector (other (private) nonfinancial corporations); (v) other financial corporations; (vi) individuals (households); and, finally, (vii) other (nonprofit institutions serving households). With respect to the distinction between resident and nonresident sectors, commercial banks use citizenship rather than the centre of economic activity as a criterion to determine the residency status of their clients.

The MFSM recommends the following classification of financial instruments:

$$
\begin{array}{ll}
\text { - } & \text { Monetary gold and SDRs; } \\
\text { - } & \text { Currency and deposits; } \\
\text { - } & \text { Securities other than shares; } \\
\text { - } & \text { Shares and other equity; } \\
\text { - } & \text { Insurance technical reserves; } \\
\text { - } & \text { Financial derivatives; and } \\
\text { Other accounts receivable/payable. }
\end{array}
$$

The financial instruments classification used for the BOM's Monetary Survey broadly follows the MFSM classification, and the Research Division keeps the deviations from the above MFSM classification under review.

The BOM's classification of accounting data contains some errors. In the central bank's survey, loans provided to the private mining companies are included in unclassified assets rather than identified as claims on other (private) nonfinancial corporations; government lending funds - comprising loan resources from the German Development Foundation (KFW), the Asian Development Bank and United Nations Development Program - are included in unclassified liabilities rather than identified as their own category; and accrued interest on deposits, loans and securities is treated as part of unclassified assets or unclassified liabilities rather than incorporated into the outstanding amount of the financial asset or liability. The last classification error also occurs in the other depository corporations survey.

Consistent with the international standards, the BOM and commercial banks treat repurchase agreements as loans collateralized by central bank bills rather than as instruments for changing the ownership of central bank bills. Thus, when a commercial bank in need of short-period liquidity sells central bank bills to the BOM, the transaction is viewed as giving 
rise to an equivalent amount of credit from the BOM to the commercial bank, with the central bank bills in question continued to be regarded as held by the commercial bank. Likewise, when the BOM sells central bank bills to a commercial bank in order to drain excess bank liquidity, the transaction is viewed as giving rise to an equivalent amount of credit from the commercial bank to the BOM, with the central bank bills in question continued to be regarded as held by the BOM. Similar observations can be made on the treatment of repurchase agreements between one commercial bank that sells central bank bills and another one that provides liquidity as these repurchase agreements are also treated, correctly, as loans collateralized by central bank bills.

\subsection{Basis for recording}

\subsubsection{Market prices are used to value flows and stocks.}

The MFSM methodology recommends the use of market-based prices for valuation of all assets and liabilities other than loans for monetary statistics, as well as the use of the market exchange rate for converting foreign currency positions into domestic currency. In the absence of market-based prices, the use of fair values is recommended.

The BOM follows the principle of market valuation more or less consistently across all positions. First, the BOM revalues monetary gold assets on a daily basis by taking an international market price from Reuters and the mid-point exchange rate. Second, the BOM revalues its foreign securities on a daily basis by taking the mid-point exchange rate- no revaluation is done, however, for the changes in foreign currency-denominated prices of the securities themselves. Likewise, the BOM revalues all of its other foreign currency positions on a daily basis by taking the mid-point exchange rate. Third, the BOM values its issue of central bank bills to commercial banks at the discount price obtained in the interbank auction market.

Commercial banks also follow the principle of market valuation more or less consistently across all positions. First, they revalue all foreign currency positions on a daily basis by taking the mid-point exchange rate. Second, they value their holdings of central bank bills at the discount price obtained in the interbank auction market. To the BOM, they report the value of these holdings at the nominal price, with the data on discount amount separately identified. In the commercial banks' survey, the Research Division uses the discount price data on the banks' holdings of central bank bills. Third, commercial banks value securities that are being held for trading purposes at market prices, but book securities that would be held until maturity for investment purposes at cost value.

Both the BOM and commercial banks record loans at book value. Provisions for expected losses from defaults are shown separately. Shares and other equity on the asset side are valued at market prices, and those on the liability side at book value. 


\subsubsection{Recording is done on an accrual basis.}

Accounting data used for monetary statistics are based on accrual accounting, and interest on financial assets or liabilities is treated as accruing continuously during the accounting period.

\subsubsection{Grossing/netting procedures are broadly consistent with internationally accepted standards, guidelines, or good practices.}

Accounting data used for the BOM's Monetary Survey are collected on a gross basis and, with one exception; claims on a particular transactor or group of transactions are not netted against liabilities to that transactor or group of transactions. The exception relates to the treatment of financial derivatives with the nonresident sector in the central bank's survey. Although gross data on the BOM's foreign assets and foreign liabilities in financial derivatives are available, the Research Division receives only the net data from the Accounting and Information Technology Department, and thus includes the BOM's net foreign position in financial derivatives in the Monetary Survey. This does not conform to the MFSM methodology, which recommends that claims and liabilities with respect to a particular group of transactions be treated on a gross basis.

No such problem, however, exists in the commercial banks' survey. Here financial derivatives are treated differently - and correctly-commercial banks report gross data on both assets and liabilities in financial derivatives to the BOM, and the Research Division includes these assets and liabilities, respectively, in foreign assets and foreign liabilities on a gross basis. This conforms to the MFSM methodology.

Certain statistical aggregates are presented, correctly, on a "net" basis owing to the analytical usefulness of the net concepts involved. The Research Division thus shows Net Foreign Assets, Net Claims on Central Government, and other items (net) in its monetary survey. At the same time, the underlying data are also shown on a gross basis. Credit to various sectors is shown in gross terms, and provisions against bad and doubtful debt are not netted against credit - a practice that conforms to the MFSM methodology.

\section{Accuracy and reliability}

\subsection{Source data}

\subsubsection{Source data are obtained from comprehensive data collection programs that take into account country-specific conditions.}

The BOM maintains a comprehensive and current register of commercial banks. This register is updated to reflect changes arising out of the entry of new banks and liquidation and merger of existing banks. The coverage of the banking sector is complete, and the procedures adopted to maintain the register are adequate, and the source data cover all the banks listed in the register. 
The Research Division uses the following source data sets for its Monetary Survey: (i) the BOM balance sheet data provided by the Accounting and Information Technology Department; and (ii) balance sheet data reported by the commercial banks to the Research Division. The BOM introduced in 2003 a new chart of accounts (currently available in Mongol only) for the banks. This chart of accounts has so far not been adopted by all banks for preparation of their balance sheet data, and some are still using the old chart of accounts. However, all banks have adopted this chart of accounts for reporting their balance sheet data to the Supervision Department, as well as to the Research Division. For the reasons stated in 3.1.2 below, however, this reporting system does not fully deliver the source data that are needed for compiling a Depository Corporations Survey as recommended by the MFSM methodology.

When the BOM determines that there is a need for modifying the report form, it consults with the commercial banks before putting the modifications into effect. The data sources are kept under continuous review to ensure that the data collection system remains comprehensive. In particular, new banks are promptly added to the source data coverage.

\subsubsection{Source data reasonably approximate the definitions, scope, classifications, valuation, and the time of recording required.}

The new chart of accounts delivers much of the source data that are needed for meeting the data requirements of $M F S M$-compliant monetary statistics, and its strengths as a reporting system primarily derive from the following features:

- $\quad$ Loans are divided by the sector or the institution of the borrower (Account group \#160000). The following sector/institutions are identified: commercial banks (resident and nonresident); nonfinancial public corporations; financial corporations (insurance companies, securities companies, other nonbank financial institutions, and savings and credit unions); nonfinancial private corporations; households; and others. Note that there is no government sector in the list, since it does not take loans from commercial banks. Loans are also divided by the currency of denominationdomestic or foreign (as by the degree of risk - past due, substandard, doubtful, and loss), with the same sectorization scheme repeated for each division.

- $\quad$ Deposits are classified by the terms of deposits (current accounts, time and savings deposits, demand deposits, and other deposits), as well as by the sector or the institution of the holder (Account group \#210000 to 220000). These sectors or institutions are identified along the same lines as the loans, with two exceptions: central government and local government are separately identified as these hold deposits with the commercial banks. Deposits are also divided by the currency of denomination-domestic or foreign. 
- Accrued interest receivable on precious metals, securities, loans to various sectors, loans to the BOM, loans to banks and other financial institutions, financial leasing, and others, is recorded, respectively, in Account \#181100, 181200, 181300, 181400, 181500, 181600, and 81700. Likewise, accrued interest payable on loans, current account deposits, time and savings deposits, precious metal deposits, securities, financial leasing, and others, is recorded, respectively, in Account \# 261100, 261200, 261300, 261400, 261500, 261600, and 261700.

- Securities on the asset side are divided by the purpose for which they are heldtrading securities and investment securities - and each group is subdivided into government securities, BOM securities, shares, promissory notes, bills of exchange, foreign securities, securities held under repos, and others.

However, as a reporting system, the new chart of accounts has following information gaps:

- The distinction between resident and nonresident accounts is generally recognized in the chart of accounts on both asset and liability sides. Thus, loans to nonresident corporations are separately identified from those to the resident sector. At the same time, loans to nonresident natural persons are not separately identified. A similar observation can be made for deposits. While deposits of nonresident corporations are separately identified from those of the resident sector, those of nonresident natural persons are not.

- The chart of accounts provides for the recording of accrued interest receivable on loans (Account \#181300) without a breakdown by the sector that has taken the loan, as well as of commercial banks' stocks, bills of exchange, and promissory notes (Account \#151130, 151140, and 151150) without a breakdown by the sector that has issued the instrument.

Commercial banks enter into repurchase agreements with not only the BOM but also one another. Notwithstanding, the chart of accounts provides for only a single account (Account \#151170) on the asset side for recording the banks' assets under the repurchase agreements regardless of whether the claim is being held on the BOM or on another commercial bank, and a single account (Account \# 223800) on the liability side for recording the banks' liabilities under the repurchase agreements regardless of whether the liability is being owed to the BOM or to another commercial bank.

Outside the new chart of accounts, the BOM collects supplementary information from the commercial banks. This information meets the last two gaps mentioned above. The new chart of accounts complemented with supplementary data thus broadly meets the source data needs of MFSM-compliant monetary statistics.

\subsubsection{Source data are timely.}

The BOM collects source data on a timely basis. The Accounting and Information Technology Department compiles the BOM balance sheet data on a daily basis, and the 
balance sheet data for the reference month with a lag of only two to three days. Commercial banks report source data to the BOM within one week from the reference date. To promote timely data reporting by the commercial banks, the BOM employs follow-up procedures, which include imposition of penalties as provided by the law. As most banks' accounting records are accessible in a timely manner, instances of reporting delays have not been significant.

\subsection{Assessment of source data}

3.2.1 Source data-including censuses, sample surveys, and administrative records-are routinely assessed, e.g., for coverage, sample error, response error, and nonsampling error; the results of the assessments are monitored and made available to guide statistical processes.

The BOM assesses the accuracy of the source data from the reporting commercial banks on a routine basis by resorting to the established procedures. It enters all reported data into an automated spreadsheet for cross-checking, and should it identify out-of-trend movements (for example, in comparison with the previous month or year) or high-value transactions, it seeks confirmation from the reporting bank. When similar issues arise with respect to the BOM balance sheet, it seeks necessary confirmation from the Accounting and Information Technology Department.

\subsection{Statistical techniques}

\subsubsection{Data compilation employs sound statistical techniques to deal with data sources.}

The BOM does not use statistical techniques to deal with source data of the monetary survey and, in particular, does not use estimated data to supplement the source data.

\subsubsection{Other statistical procedures (e.g., data adjustments and transformations, and statistical analysis) employ sound statistical techniques.}

The BOM does not use statistical techniques in compilation of monetary survey, which is exclusively based on balance sheet data of the BOM and commercial banks.

\subsection{Assessment and validation of intermediate data and statistical outputs}

\subsubsection{Intermediate results are validated against other information where applicable.}

The BOM uses other information to validate balance sheet data collected from commercial banks. A good example of this is the use of data on issuance of Treasury bills to commercial banks that are available from the MOF to validate data on holdings of Treasury bills that are

available from the commercial banks. The Research Division holds meetings, if necessary, with the Supervision Department to validate financial data that are used for monetary statistics. 


\subsubsection{Statistical discrepancies in intermediate data are assessed and investigated.}

The BOM assesses the behavior of series, wherever such data are available, against related series. For example, as observed in 3.4.1, the data on issuance of Treasury bills to commercial banks that are available from the MOF are used for assessing the data on holdings of Treasury bills that are available from the commercial banks. As no financial transactions data are reported, no reconciliation is attempted with changes in the corresponding stock data collected through balance sheets.

\subsubsection{Statistical discrepancies and other potential indicators of problems in statistical outputs are investigated.}

The BOM investigates classification/sectorization errors or omissions as a possible source of fluctuations or discrepancies in monetary statistics, especially by calling the reporting commercial banks for explanation. For example, about two years ago, when a commercial bank misreported discounted loans taken from the BOM that had already been repaid, the Research Division called the commercial bank, which confirmed its reporting error and corrected the misreported data. No attempt is made to reconcile the implied flows in monetary statistics with the flows in the government budget data and balance of payments statistics (see 4.2.3 below).

\subsection{Revision studies}

3.5.1 Studies and analyses of revisions are carried out routinely and used internally to inform statistical processes (see also 4.3.3).

The BOM does not prepare studies on revisions made to its monetary statistics as revisions are primarily caused by the need to correct errors whenever the latter are found.

\section{Serviceability}

\subsection{Periodicity and timeliness}

\subsubsection{Periodicity follows dissemination standards.}

Data on the central bank's survey, as well as those on the other depository corporations' survey, are disseminated once every month, in conformity with the monthly periodicity recommended under the GDDS.

\subsubsection{Timeliness follows dissemination standards.}

Data on the central bank's survey, as well as those on the other depository corporations' survey, are simultaneously disseminated within three weeks after the end of the reference period. This time-lag is significantly shorter than that of one to two months allowed for the 
central bank's survey under the GDDS, or two to three months allowed for the other depository corporations' survey.

\subsection{Consistency}

\subsubsection{Statistics are consistent within the dataset.}

Discrepancies exist (i) between the BOM's data on its credit to commercial banks and the latter's data on their borrowing from the BOM; (ii) between the BOM's and commercial banks' data on their deposits with the BOM; and (iii) between the BOM's data on issuance of central bank bills to commercial banks and the latter's data on the holdings of central bank bills. These discrepancies arose because of the different times at which transactions have been recorded, as well as different exchange rates used by the parties for converting foreign currency components into domestic currency. As observed in 3.4.2 above, no reconciliation is attempted with changes in the corresponding stock data collected through balance sheets, since no financial transactions data are reported.

\section{Recommendation:}

- $\quad$ Harmonize interbank positions within monetary statistics.

\subsubsection{Statistics are consistent or reconcilable over a reasonable period of time.}

When changes in the source data, methodology, or techniques are introduced, the BOM reconstructs the historical series as far back as reasonably possible. Thus, when in 2006 the sectorization scheme used for monetary statistics was revised, the BOM revised the monetary data series beginning January 2004. In the event of a discontinuity in data, the BOM identifies and explains the main breaks in the component time series, their causes and adjustments made to maintain consistency over time. Moreover, if a change in the statistical system were identified as a cause of the discontinuity, the BOM provides adjusted data on its website.

\subsubsection{Statistics are consistent or reconcilable with those obtained through other data sources and/or statistical frameworks.}

Monetary statistics have not been fully consistent with government budget data as the numbers on bank credit to the central government have differed between these data sets by moderate amounts in most recent years. A large discrepancy, however, developed between these datasets for 2005 when the monetary data on bank financing amounted to only about half of the comparable fiscal data, implying a discrepancy equivalent to 3.4 percent of GDP. This discrepancy was primarily due to (i) an unspent cash appropriation that had been misclassified by the MOF as negative bank financing; and (ii) government deposits that had been misclassified by commercial banks. Subsequently, although the authorities implemented measures to resolve this problem, monetary statistics and government budget data continued 
to show large discrepancies. Monetary and balance of payments statistics are consistent as these datasets use the same source data. At the same time, since the monetary statistics use end-period exchange rates for converting foreign exchange-denominated positions into domestic currency, while the balance of payments statistics uses average period exchange rates for converting foreign exchange-denominated transactions into domestic currency, net foreign assets differ between them. These differences, however, are reconcilable.

\subsection{Revision policy and practice}

\subsubsection{Revisions follow a regular and transparent schedule.}

As noted in 3.5.1, the BOM revises its monetary statistics primarily to correct errors. As errors are random events, revisions are done on a random basis, with no regular cycle.

\subsubsection{Preliminary and/or revised data are clearly identified.}

At the time of data dissemination, users are informed of the preliminary nature, as well as of the revised nature, of the monetary data. Thus, when the BOM revised recent monetary data to correct misreporting of central government deposits by commercial banks, the revised data were published with a footnote: "Data are revised according to the changes in budget fund recording (December 2005-August 2006)."

\subsubsection{Studies and analyses of revisions are made public (see also 3.5.1).}

As noted in 3.5.1, the BOM does not prepare revision studies for monetary statistics.

\section{Accessibility}

\subsection{Data accessibility}

\subsubsection{Statistics are presented in a way that facilitates proper interpretation and meaningful comparisons (layout and clarity of text, tables, and charts).}

The BOM makes its presentation of the monetary data commensurate with users' needs in various ways. First, it disseminates monetary statistics in the form of tables that are clearly laid out, which enables construction of time-series data. Second, it disseminates monetary statistics and key components to meet a range of users' needs with various levels of detail. For example, data on loans are disseminated by the borrowing sector, by the quality of loan (performing versus nonperforming), and by commercial bank. Data on deposits are disseminated by the holding sector, by maturity (current account versus term deposits), and by the currency of denomination. Finally, BOM's dissemination of monetary data is frequently accompanied by a summary on recent economic and financial developments. 


\subsubsection{Dissemination media and format are adequate.}

The BOM disseminates monetary statistics in formats that satisfies users' needs - for example, by posting the monetary data and monthly report on its website (http://www.mongolbank.mn). This form of dissemination facilitates redissemination in the media. The BOM also disseminates monetary statistics in its publications, especially Monthly Statistical Bulletin.

\subsubsection{Statistics are released on a preannounced schedule.}

The BOM has recently posted on its website (http://www.mongolbank.mn) a preannounced schedule for releasing monetary data.

\subsubsection{Statistics are made available to all users at the same time.}

The BOM makes monetary statistics available to all users simultaneously. This is achieved by posting monetary statistics on its website (http://www.mongolbank.mn). It does not brief the press in advance, and the press receives monetary statistics simultaneously with other users.

\subsubsection{Statistics not routinely disseminated are made available upon request.}

The BOM makes available upon request those aspects of monetary statistics that are not routinely disseminated. For example, the BOM recently received a request from a private individual for data on the real value of commercial bank deposits, and the Research Division responded positively to the request. Customized tabulations to meet specific requests can be provided without fee, although so far no such requests have been received.

\subsection{Metadata accessibility}

5.2.1 Documentation on concepts, scope, classifications, basis of recording, data sources, and statistical techniques is available, and differences from internationally accepted standards, guidelines, or good practices are annotated.

The IMF website established for disseminating GDDS metadata, the DSBB, provides a comprehensive sources and methods document on the BOM's monetary statistics. The website of the NSO, which is Mongolia's coordinator for the GDDS, provides a link to the GDDS metadata. The GDDS metadata on monetary statistics are reviewed and updated on a regular basis - the most recent update was posted in May 2007.

\subsubsection{Levels of detail are adapted to the needs of the intended audience.}

The metadata mentioned in 5.2.1 above are the only ones that are disseminated as there are no alternative metadata with levels of detail adapted to the needs of the audience. 


\subsection{Assistance to users}

\subsubsection{Contact points for each subject field are publicized.}

The BOM's publications and its website (http://www.mongolbank.mn) provide contact points for monetary statistics.

5.3.2 Catalogs of publications, documents, and other services, including information on any charges, are widely available.

No such catalog is available from the BOM. 
Table 4. Mongolia: Data Quality Assessment Framework (July 2003): Summary of Results for Monetary Statistics (Compiling Agency: Bank of Mongolia)

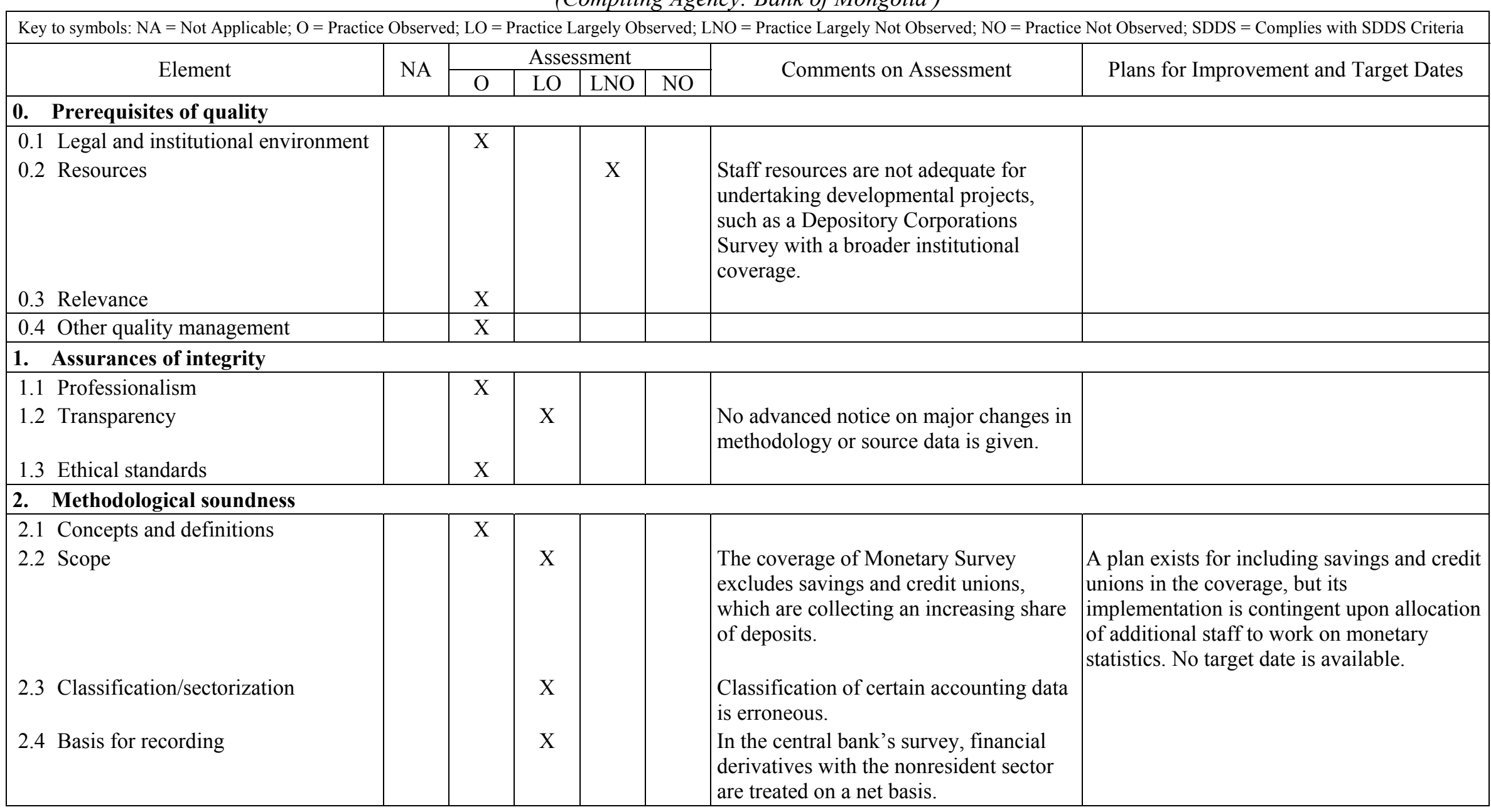


Table 4. Mongolia: Data Quality Assessment Framework (July 2003): Summary of Results for Monetary Statistics (Compiling Agency: Bank of Mongolia)

\begin{tabular}{|c|c|c|c|c|c|c|c|}
\hline \multirow{2}{*}{ Element } & \multirow{2}{*}{ NA } & \multicolumn{4}{|c|}{ Assessment } & \multirow{2}{*}{ Comments on Assessment } & \multirow{2}{*}{ Plans for Improvement and Target Dates } \\
\hline & & $\mathrm{O}$ & $\mathrm{LO}$ & LNO & $\mathrm{NO}$ & & \\
\hline \multicolumn{8}{|l|}{ 3. Accuracy and reliability } \\
\hline 3.1 Source data & & $\mathrm{X}$ & & & & & \\
\hline $\begin{array}{ll}\text { 3.2 } & \text { Assessment of source data } \\
3.3 & \text { Statistical techniques }\end{array}$ & & $\begin{array}{l}X \\
X\end{array}$ & & & & & \\
\hline $\begin{array}{l}\text { 3.4 Assessment and validation of inter- } \\
\text { mediate data and statistical outputs } \\
\text { 3.5 Revision studies }\end{array}$ & & $\mathrm{X}$ & & $\mathrm{X}$ & & No revision studies are prepared. & \\
\hline \multicolumn{8}{|l|}{ 4. Serviceability } \\
\hline $\begin{array}{l}\text { 4.1 Periodicity and timeliness } \\
\text { 4.2 Consistency } \\
4.3 \text { Revision policy and practice }\end{array}$ & & $\mathrm{X}$ & X & & & $\begin{array}{l}\text { Within monetary statistics, interbank } \\
\text { positions between the central bank and } \\
\text { other depository corporations show } \\
\text { discrepancies. Large discrepancies exist } \\
\text { between monetary statistics and } \\
\text { government budget data on bank } \\
\text { financing to the government sector. } \\
\text { Revisions do not follow a regular and } \\
\text { transparent cycle. }\end{array}$ & \\
\hline \multicolumn{8}{|l|}{ 5. $\quad$ Accessibility } \\
\hline $\begin{array}{l}\text { 5.1 Data accessibility } \\
\text { 5.2 Metadata accessibility } \\
\text { 5.3 Assistance to users }\end{array}$ & & $\mathrm{X}$ & $\mathrm{X}$ & & & $\begin{array}{l}\text { There are no alternative metadata with } \\
\text { levels of detail adapted to needs of } \\
\text { audience. } \\
\text { There is no catalog of the BOM's } \\
\text { publications and other services to users. }\end{array}$ & \\
\hline
\end{tabular}




\section{Balance of Payments Statistics}

\section{Prerequisites of quality}

\subsection{Legal and institutional environment}

0.1.1 The responsibility for collecting, processing, and disseminating the statistics is clearly specified.

The responsibility for compiling balance of payments statistics is assigned to the Balance of Payments and Research Unit of the International Department of the BOM.

The Law of Mongolia on Central Bank (Bank of Mongolia) Article 28(2) (available in Mongolian and English at http://www.mongolbank.mn/web/guest/about the bank/law) authorizes the BOM to collect statistics for its operational purposes. An agreement dated March 12, 1996 and signed by the Minister of Finance, Minister of Trade, and Governor of BOM assigned responsibility for compilation of balance of payments statistics to BOM, while responsibility for balance of payments forecasting was assigned to the Ministry of Finance.

\subsubsection{Data sharing and coordination among data-producing agencies are adequate.}

Data sharing and coordination among data-producing agencies are reasonably adequate. There is cooperation through a working group and other less formal channels.

The Working Group on Trade Statistics was established in October 2002. It met three times and concluded most of its work by July 2003. The Ministry of Industry and Trade was the Chair and Secretariat, with other members being BOM, the MOF, and the NSO. The working group prepared a draft resolution for continuing work on the insurance and freight components included in the values of merchandise imports.

The Working Group on Balance of Payments Statistics was re-established in 2005. Its objectives are to improve data quality of the balance of payments statistics of Mongolia, extend their scope, follow international standards, and cooperate on conducting related surveys. Members of the working group are BOM; MOF; the Ministry of Industry and Trade; NSO; the Customs General Administration; the Foreign Investment and Foreign Trade Agency (FIFTA); the Ministry of Road, Transport and Tourism; the Civil Aviation Authority of Mongolia; the General Authority for Border Protection; and representatives of selected large corporations. The working group meets annually, although it has also fostered more frequent informal contact.

Data are shared within the BOM concerning monetary and balance of payments statistics in order to ensure consistency. 
Under the Law on Statistics, BOM is required to obtain comment and approval from the NSO for questionnaires for its surveys. This procedure is considered to be useful and has not caused delays. Informal communication with NSO is also effective.

\subsubsection{Individual reporters' data are to be kept confidential and used for statistical purposes only.}

The Law on Statistics covers data confidentiality, stipulates penalties for divulging of individual enterprise data by compilers, and gives authority to other institutions to obtain information, provided the NSO has approved the surveys.

The Law of Mongolia on Central Bank (Bank of Mongolia), Article 29, Paragraph 1.3 states that the employees of BOM are prohibited from disclosing official information supplied by banks, legal persons, and individuals except in the cases stated in the relevant legislation. When they join the organization, staff are required to sign a statement obliging them to maintain the confidentiality of information obtained at BOM.

Data collected by the BOM International Department for the compilation of the balance of payments are used exclusively for statistical purposes. When the BOM requests data from other agencies and institutions, it states that data will be used only for compiling balance of payments statistics and the BOM will keep these data confidential. While published data cells may sometimes relate to a single entity, BOM staff will not divulge this fact or the name of the entity.

Completed questionnaires are kept in locked cupboards in the BOM building with limited access to ensure security. Confidential data on computers are protected by password requirements for access.

\subsubsection{Statistical reporting is ensured through legal mandate and/or measures to encourage response.}

The legal mandate to collect external statistics is derived from the Law of Mongolia on Central Bank (Bank of Mongolia), 1996; the Banking Law of Mongolia (as revised in 2003); the Foreign Investment Law of Mongolia 1991 (as revised in 2002); and the Law on Statistics 1997-98 (as revised in 2004). The BOM has used the first and last Acts mentioned above as the legal basis for bank reporting and surveys.

The legislation includes penalties in cases of failure to report the required information. Since 2002, bank customers have been required to provide information on the purpose of their transactions.

The Working Group on Balance of Payments Statistics assists in contacts with datasupplying ministries, agencies, and major economic operators. The group provides input on data collection procedures. The BOM International Department maintains close working 
relationships with the principal agencies that produce source data, and has used membership of the working group to make them aware of the importance of this task.

Assistance with completion of questionnaires is provided in the enterprise survey. There is also some follow-up for nonreporters, but it appears that more intensive follow-up will be required to boost response rates, which are lower for the BOM than for the NSO enterprise survey.

\section{$0.2 \quad$ Resources}

\subsubsection{Staff, facilities, computing resources, and financing are commensurate with statistical programs.}

There are seven positions in the Balance of Payments and Research Unit of the International Department of the BOM. However, only four staff are currently working on balance of payments statistics. The other three positions are vacant with recruitment efforts under way.

Particular staff members are responsible for each of the current account, the capital and financial account, and the international investment position, respectively. All staff also work on conducting the surveys. The staff also have some other responsibilities, such as statistics on public debt, exchange rates, and the trade price and volume indices.

While salaries and benefits offered by BOM are considered acceptable, staff turnover among balance of payments staff has been extremely high. Two of the current staff have had one year of balance of payments experience, while the other two have had even less. Former staff have been promoted to other jobs in BOM or recruited by other employers. Staff turnover has caused a loss of institutional memory and a continuing high training burden.

Because of the staffing situation, BOM has been largely confined to generating statistics according to existing methods and limited work in the areas identified for improvement, such as development of international investment position data and incorporation of the results of the enterprise survey. Nevertheless, some progress has been made since the most recent IMF technical assistance mission on balance of payments statistics (conducted in 2004), such as new surveys on travel and remittances. As the Mongolian economy becomes more open, new business projects are undertaken, and the financial sector innovates, the number and variety of international transactions is increasing substantially, putting new demands on staff. For example, purchases by nonresidents on the Mongolian stock exchange, free trade zones, new bond issues, financial derivatives, and the shadow economy are all emerging issues that would benefit from investigation by BOM staff to make sure they are properly recorded in balance of payments statistics.

Besides having on-the-job training, some of the staff have received training in balance of payments statistics at the Singapore Training Institute and the IMF Institute in Washington, D.C. All staff either have a Bachelor's or Master's degrees in banking, finance, or economics. Recruitment processes mean that vacancies take many months to fill. Because 
standards for economist recruitment are high, it may also be worth considering the creation of positions that would be specialized in data collection and processing and that would do not require such high qualifications (and who may stay longer in the job).

All staff have a personal computer. All compilation is currently done in Excel, which is not ideal for large-scale data collection. Specialized statistical database software is more suitable for functions such as maintaining business registers, calculation of response rates, signaling enterprises for follow-up, checking data, comparing data with previous periods, estimation of missing items, and transferring data between different uses. (However, Excel may still be suitable for overall tabulations and analysis.)

In addition, BOM staff see scope for substantial future improvement in the speed and efficiency of data collection through on-line reporting by respondents. However, such a system would also need specialized information technology support.

\section{Recommendations:}

- $\quad$ Fill vacant staff positions. Consider creating one or two statistical officer grade positions to specialize in surveys and data processing. Link future improvements in balance of payments statistics to the provision of additional staff.

- $\quad$ Provide specialized computer support suitable for use in large-scale statistical collection systems, such as on-line reporting and a data processing system built on a database.

\subsubsection{Measures to ensure efficient use of resources are implemented.}

A working plan for the BOM International Department is adopted as part of the annual working plan of BOM and is updated every year. It is discussed and approved by the Governor of BOM and disseminated to all directors of the BOM, who in turn advise their staff of its contents. The plan sets out operational targets and deadlines for achieving them, as well as responsibility for each project. The plan makes it possible to monitor achievement of objectives and serves as a useful tool for ensuring the efficient use of resources. There are also quarterly and annual staff evaluations.

The BOM International Department has introduced collection of data from banks and enterprises through e-mail, to improve efficiency. Data are collected simultaneously in hard copies that are signed and stamped to give them official status.

In transmitting and processing data, the BOM International Department is putting more emphasis on computerization and plans to replace existing methods by electronic data collection. 


\subsection{Relevance}

\subsubsection{The relevance and practical utility of existing statistics in meeting users' needs are monitored.}

The BOM seeks to monitor the relevance of balance of payments statistics in meeting user needs in a variety of ways. First, the International Department provides explanations on the various aspects of its balance of payments statistics by making appropriate materials available on the BOM's website at $h t t p: / / w w w . m o n g o l b a n k . m n$.

Second, BOM provides a contact list (including e-mail addresses, telephone numbers, and fax numbers) which encourages users to ask questions and provide a feedback on balance of payments statistics. Users' needs are considered in response to their specific requests. The frequent requests submitted to the BOM International Department demonstrate keen interest by the specialized users in balance of payments data. The BOM takes account these queries in drafting its publications, for example, the notes were amended in the most recent issue to explain the methodology for data on direct investment. In addition, some members of the Working Group on Balance of Payments Statistics are data users, so they are able to provide a user perspective.

Finally, the staff members participate in international seminars and meetings, such as those held by the IMF, and contact other sections of the BOM that engage in financial and economic research in order to identify new and emerging data requirements. The most recent example of an international seminar in which staff participated is the Seminar on Implementing the Balance Sheet Approach to Macroeconomic Surveillance held by the BOM in Ulaanbaatar (July 2-5, 2007).

\subsection{Other quality management}

\subsubsection{Processes are in place to focus on quality.}

The importance of data quality is clearly recognized by the BOM International Department. The BOM provides training for its staff through the Bankers' Training Centre in Ulaanbaatar. As well, the budgetary allocation for statistical programs provides an infrastructure for quality by recognizing trade-offs, economies of scale, and interrelations between datasets.

Priority is placed on procedures to ensure quality. Documentation of internal procedures is extensive in working notes and annotations on spreadsheets, so that staff can follow procedures in the future and understand the background to them. Documentation of definitions is provided to data suppliers (Balance of Payments Sources and Methods Manual and Manual on the International Transactions Reporting System). As well, training and feedback to data suppliers focus on quality in the statistical process. The BOM strives to improve quality by revising balance of payments data to correct errors and shortcomings that have been found. 


\subsubsection{Processes are in place to monitor the quality of the statistical program.}

In order to improve data quality obtained from banks through the international transactions reporting system (ITRS), at least once a year, the BOM International Department organizes a course for commercial bank staff who prepare ITRS reports, to give them a better understanding of the ITRS and its methodology. In addition to that course, BOM staff keep close relationships with commercial banks, including answering telephone calls and e-mails from ITRS reporters on definitions and classifications, while BOM staff also contact reporters to clarify and check data submitted.

The BOM's management conducts a pre-release data check.

When balance of payments statistics methodologies are revised, the BOM makes use of guidance from outside experts, including technical assistance from the IMF Statistics Department and consultation with compilers in other countries.

\subsubsection{Processes are in place to deal with quality considerations in planning the statistical program.}

The BOM considers quality issues (including implicit and explicit trade-offs among the dimensions of quality) in planning its statistical program. Prior to major revision to the methodology, the BOM takes into consideration opinions from experts from other countries and the IMF.

The BOM International Department is aware of the trade-offs that must be made between the various dimensions of data quality, particularly between timeliness and accuracy/reliability. The balance of payments statistics publications take account of these factors, indicating that the data are preliminary and will be revised.

The work program of the BOM International Department in the annual working plan of the BOM includes efforts to maintain and improve the quality of balance of payments statistics in terms of timeliness, methodological soundness, and accessibility.

\section{Assurances of integrity}

\subsection{Professionalism}

\subsubsection{Statistics are produced on an impartial basis.}

The Law of Mongolia on Central Bank (Bank of Mongolia) mandates the professional independence of the BOM. Thus, Article 26 stipulates that the BOM is headed by the governor appointed by the State Ikh Khural (Mongolian Parliament), upon the recommendation of its chairman, to which he or she would report. The First Deputy Governor and the Deputy Governor of the BOM are both appointed, upon the recommendation of the governor, by the State Ikh Khural. All these officials are appointed 
for a period of six years, and can be discharged only by the State Ikh Khural and only in circumstances that have been identified in the Law-namely, becoming a shareholder in a commercial bank, acting against the BOM's interest, or committing a criminal offence. Moreover, for one year after their release from the position in the BOM, they are prohibited from occupying a management position in a commercial bank.

Professionalism is actively promoted and supported within the BOM through a number of channels. First, professional competence plays a key role in recruitment and promotion policies. Recruitment and promotion are based, among other factors, on expertise in statistics. Second, BOM maintains the Bankers' Training Centre for providing training to staff. In addition, some of them participate in training seminars on statistics conducted by the IMF. Finally, the BOM provides its staff with the opportunities to participate in meetings of experts - for example, the Seminar on Implementing the Balance Sheet Approach to Macroeconomic Surveillance that was recently held in Ulaanbaatar.

The Law of Mongolia on Central Bank (Bank of Mongolia), Article 26 provides protection of the professional independence of the BOM. The BOM carries out the compilation of balance of payments statistics with professionalism and complete independence. For example, some recent revisions in methods had a negative effect on the current account balance, but there was no interference with this change.

\subsubsection{Choices of sources and statistical techniques, as well as decisions about dissemination, are informed solely by statistical considerations.}

The choice of sources and techniques as well as decisions on dissemination are guided by statistical considerations and conform to international standards.

The BOM chooses data sources and statistical techniques, as well as takes decisions on dissemination, solely by statistical considerations. One of the BOM's policies is that the statistics should be disseminated as soon as possible. The BOM's decisions about the timing, media, and other aspects of dissemination are also based solely on statistical considerations.

\subsubsection{The appropriate statistical entity is entitled to comment on erroneous interpretation and misuse of statistics.}

The BOM is entitled to comment on erroneous interpretation and misuse of balance of payments statistics by the media. There are no recent examples of press releases on misinterpretation of data, although procedures have been developed to do so. The explanatory notes to publications are revised to take into account misunderstandings by commentators. For example, a description of the types of services included in other services was recently added in response to the finding that users did not fully understand the coverage of this item. 


\subsection{Transparency}

1.2.1 The terms and conditions under which statistics are collected, processed, and disseminated are available to the public.

The BOM's web site (http://www.mongolbank.mn) posts the Law of Mongolia on Central Bank (Bank of Mongolia) in Mongolian and English. The law presents the terms and conditions under which the International Division compiles balance of payments statistics. The provisions include the BOM's mandate to compile and publish aggregated data for carrying out its functions, as well as its obligation to safeguard the confidentiality of individual unit data.

\subsubsection{Internal governmental access to statistics prior to their release is publicly identified.}

There is no internal government access to balance of payments statistics prior to their release.

\subsubsection{Products of statistical agencies/units are clearly identified as such.}

Balance of payments data are published in reports that cite the BOM International Department as the producer of the data. When the data are reproduced in other publications or through another means of communication, the BOM International Department insists that the source be quoted. When the NSO republishes balance of payments statistics in its bulletin, it cites BOM as the source of the data.

1.2.4 Advance notice is given of major changes in methodology, source data, and statistical techniques.

Changes in methodology and statistical techniques are notified to users after their adoption. When the data are published, publications contain details on the methodology used for compiling the data, and any modification to it. For instance, the 2006 publication offers an explanation of updated method for the valuation of imports.

\section{Recommendation:}

- $\quad$ Adopt a policy of advance notification of major changes in methods (either by notification in a regular quarterly publication or by ad hoc release).

\subsection{Ethical standards}

\subsubsection{Guidelines for staff behavior are in place and are well known to the staff.}

The BOM guidelines for staff behavior are articulated in the Law of Mongolia on Central Bank (Bank of Mongolia) and a circular on staff rules and regulations. Article 29 of the Law lists a number of activities that BOM employees are prohibited from undertaking. These activities include: representing the interests of any individual and legal entities; procuring 
advantageous or preferred conditions for themselves or their family members, relatives, business counterparts or other acquaintances; and disclosing official information on finances of a bank, legal person, or individual. The $L a w$ is disseminated on the BOM's website, and is easily available and well known to staff. All staff members are given copies of the circular on staff rules and regulations. Respect for these rules is part of the agency's culture. The ethical practices are communicated to new recruits during their internal training.

\section{Methodological soundness}

\subsection{Concepts and definitions}

2.1.1 The overall structure in terms of concepts and definitions follows internationally accepted standards, guidelines, or good practices.

The BOM strictly follows the concepts and methods in the Balance of Payments ManuaI, fifth edition (BPM5).

The presentation of the balance of payments shows goods, services, income, transfers, the capital account, and the financial account. The double-entry accounting system is used. Definitions of residence and economic territory follow international standards.

\section{$2.2 \quad$ Scope}

2.2.1 The scope is broadly consistent with internationally accepted standards, guidelines, or good practices.

In compiling the balance of payments, in principle, the BOM International Department attempts to capture all transactions between residents and nonresidents in accord with BPM5. Transactions are included whether in cash or in kind. Treatments of goods for processing, repairs on goods, nonmonetary gold, reinvested earnings, intercompany lending, portfolio investment of private sector, and trade credit follow international standards, although, as noted in 3.1 below, there are some variations from the ideal due to limitations of data sources.

\subsection{Classification/sectorization}

\subsubsection{Classification/sectorization systems used are broadly consistent with internationally accepted standards, guidelines, or good practices.}

Transactions between residents and nonresidents are classified in accordance with the standard components of BPM5. The classification system covers the current account, including goods, services, income and current transfers; the capital account and the financial account, including direct investment; portfolio investment; other investment; and reserve assets. 
Four institutional sectors are identified, consistent with BPM5, specifically monetary authorities, general government, banks, and other sectors.

\subsection{Basis for recording}

\subsubsection{Market prices are used to value flows and stocks.}

Generally speaking, transactions are recorded on a settlement basis, which for most transactions is considered as satisfying the market-price valuation principle. Transactions that are not valued, such as aid and barter, use market-equivalent valuations.

Balance of payments data are recorded in United States dollars. Source data expressed in togrog and other currencies are converted to dollars at the daily mid-point exchange rate (for transactions recorded with the date available, such as from the ITRS) or by the quarterly average exchange rate (in other cases).

\subsubsection{Recording is done on an accrual basis.}

In principle, BOM seeks to record data on an accrual basis. However, in practice, major data sources use different bases (in particular, a customs clearance basis is used for goods, and a payments basis is used in the ITRS). No investigations are carried out on the impact of these variations and no adjustments are made for large transactions, however BOM staff consider that the differences in practice are generally minor. The value of net errors and omissions fluctuates between negative and positive, indicating timing inconsistencies in the data.

\section{Recommendation:}

- $\quad$ Seek to identify any variations in timing for major transactions (such as major sales or purchases of equipment) and make adjustments where necessary.

\subsubsection{Grossing/netting procedures are broadly consistent with internationally accepted standards, guidelines, or good practices.}

For the current account, transactions are recorded on a gross basis, according to BPM5 guidelines. For financial transactions, transactions are recorded net (acquisitions less disposals for assets; incurrence less repayment for liabilities). Financial transactions are available separately for assets or liabilities. In the published table, some items are shown on a net basis, however gross data are available on request. Gross data are also supplied to the IMF for publication in International Financial Statistics and Balance of Payments Statistics Yearbook. 


\section{Accuracy and reliability}

\subsection{Source data}

\subsubsection{Source data are obtained from comprehensive data collection programs that take into account country-specific conditions.}

The main data sources for the balance of payments are

Trade statistics from the Customs General Administration. Data on exports and imports of goods are available monthly, with commodity detail, and splits by funding (hard currency, barter, aid, loan, direct investor, goods for processing).

- International transactions reporting system (ITRS). Data on cross-border transactions are reported by the banks and some major nonbank financial institutions on a monthly basis. The data are reported to BOM transaction-by-transaction. The records show a code for type of transaction, the date, country of counterpart, as well as a description and name of parties.

- Government agencies. The General Authority for Border Protection ( arrival and departure numbers from border posts); the Tourism Agency in the Ministry of Road, Transport, and Tourism (travel expenditure patterns), MOF (official aid, government debt, budget report, report on the expenditures of the embassies of Mongolia in foreign countries); and FIFTA (direct investment commitments).

- Direct reporting from major enterprises. Eight large enterprises report data directly to BOM for balance of payments statistics purposes. These eight enterprises include telecoms companies, MIAT, the railway company, and some commodity exporters.

- $\quad$ Enterprise survey. An enterprise survey has been conducted for several years since 2000 , most recently for 2006). It covers 460 enterprises. The questionnaire covers a wide range of data, including direct investment flows, bank accounts abroad, and international investment position. To date, the results have not been incorporated in balance of payments statistics, because of disappointing response rates, lack of resources to make necessary improvements to the survey results (such as updating the business register, intensive follow-up of nonreporters, and make estimates for missing enterprises), and lack of staff time to modify the balance of payments compilation procedures. Two aspects of particular concern are:

- The business register is not updated continuously. The business register (that is, the population frame for the survey), needs to include new businesses and existing businesses that commence international transactions as the economy grows and opens up. Otherwise, new and growing businesses are omitted, which causes a downward bias in the results. 
- Adjustments are not made for nonresponse. With some enterprises not responding to the survey, data have a downward bias and variation in response rates from year to year can lead to spurious movements in the time series. The preferred method to deal with nonresponse is more follow-up. Follow-up should be the most intensive for larger enterprises. If necessary, partial data or estimates by company staff should be accepted. If no data can be obtained, data should be estimated based on other available indicators. (Options could include ITRS data for that enterprise, company annual reports, or FIFTA data on commitments in conjunction with ratios obtained from the reporting enterprises. It is important that nonresponse enterprises with non-zero values are distinguished from enterprises with zero values, i.e., where the enterprise has ceased operations or has no international transactions or positions, which should correctly be included in the survey as zero values.)

- Specific purpose surveys. Surveys include workers' remittances, tourism, and the border survey on education and medical treatment.

\section{Recommendations:}

- $\quad$ Update the register for the enterprise survey on an annual basis.

- $\quad$ Conduct intensive follow-up of nonresponse and develop estimation procedures for nonresponse for the enterprise survey.

3.1.2 Source data reasonably approximate the definitions, scope, classifications, valuation, and time of recording required.

The major components of the balance of payments, the sources used, and deviations from the definitions, scope, classifications, valuation, and time of recording required by international standards are as follows:

- $\quad$ Exports and imports of goods: Data are obtained from the Customs General Administration. The data differ from balance of payment requirements in a number of ways. In the case of cost, insurance, and freight (c.i.f.) valuation, goods procured in port by carriers, nonmonetary gold, repairs on goods, and purchases from abroad by duty-free stores, adjustments are made by BOM to the basic customs data. In the cases of possible undervaluation or overvaluation, smuggling, shuttle trade, and gifts for Mongolian relatives, adjustments are not made. The timing of exports and imports within the year is not completely correct, because quarterly data are derived from cumulative data, although the effect is considered to be minor. (For example, the fourth quarter is derived as the difference between the previously published JanuarySeptember figure and the final calendar year figure. As a result, later data and revisions relating to January-September may be wrongly attributed to the fourth quarter.) Processing fees on gold sent for processing are included in services. 
The coverage arrangements for free trade zones, which are just starting operations, have not yet been established.

- $\quad$ Transportation services: Source data are from the ITRS and direct reporting by three large transport operators (namely, MIAT, Mongolian Railways, and the airport authority). Transactions in cash by smaller operators may be omitted.

- $\quad$ Travel: Estimates are based on numbers of inward and outward visitors and length of stay obtained from the General Authority for Border Protection and the BOM's survey. The numbers of travelers are multiplied by an average daily expenditure obtained from a survey conducted by Tourism Agency of the Ministry of Road, Transport, and Tourism. The method takes account of the different expenditure patterns of visitors from different countries. The daily expenditure estimates are currently from the 2005 survey and it is planned to collect revised data for 2007. However, data are not adjusted for changes in prices between surveys, and so could cause a discontinuity when new survey results are incorporated..

- $\quad$ Other services: These data are based on ITRS results, direct reporting by large service-providing enterprises (telecommunication), and the expenditure and revenue of Mongolian embassies abroad. There is no survey of embassy and international organization purchases in Mongolia, but it is considered that a large proportion of their transactions is captured in the ITRS.

- $\quad$ Compensation of employees: There are no credits reported and only a small value of debits identified from the ITRS. However, there appears to be an increasingly large number of short-term Chinese workers in the construction industry, often without official status, which receive compensation of employees but are not currently covered, probably because payment is outside the ITRS.

- Direct investment income: The data source for dividend debits is tax submissions for major enterprises. In addition, reinvested earnings are estimated, but on a case-bycase basis, not comprehensively. No interest is currently recorded under direct investment. Direct investment dividends in the form of goods or through bank accounts held abroad are omitted from the ITRS, but are identified for the major enterprises covered by direct reporting.

- Other investment income: Data are obtained from the ITRS, the accounts of the $\mathrm{BOM}$ and MOF, and direct reporting by the banks and major enterprises. Portfolio investment income is shown as zero, although purchases by nonresidents on the stock exchange and the issue of Mongolian bonds means that income should be identified in future. Interest is recorded on a payments basis, which may differ from an accrual basis for securities in some cases, such as where there are annual coupon payments and deep-discount bonds. 
- Workers' remittances. Data are obtained from the ITRS: The ITRS covers the banks as well as two major money transfer companies commonly used for remittances (Western Union and Moneygram). Remittances made in the form of banknotes, goods, ATM withdrawals, and transactions through foreign exchange bureaus are omitted. The BOM ran a survey of remittance income and related consumption in March 2007. The survey was conducted through bank customers, who reported that about 60 percent of remittances were received through banks and other formal channels, which indicates that cash remittances received would add around another two-thirds to the currently recorded values. BOM would like to run the survey again to confirm the results and assess the stability of the behavior before adjusting the official balance of payments statistics.

- $\quad$ Other current and capital transfers: Data on transfers in cash are obtained from the ITRS. Data on official grants in kind are derived from customs statistics and data on foreign grants in cash are provided by the MOF, State Standing Emergency Commission, Mongolian Red Cross Society, and other selected nongovernment organizations. The data on technical assistance are based on information obtained from the MOF's Project Coordination Unit and international organizations. Data on transfers provided directly to nongovernment organizations are estimated as the difference between the customs figure on transfers in kind and the official grants received in kind recorded on the budget. Credits from sale of hunters' licenses to visitors are supplied by the Ministry of the Environment. The split between current and capital transfers is not available, so all transfers are shown as current except for debt forgiveness, which is shown as capital transfers.

- Direct investment: Direct investment abroad has been insignificant so far. Data on direct investment in Mongolia are obtained from direct reporting by a few large enterprises, the ITRS, and trade statistics (for direct investment supplied in the form of equipment and other goods, rather than funds). Direct investment in the form of loans is included under other investment in direct reporting forms, but separately in the ITRS codes.

- $\quad$ Portfolio investment: As noted for portfolio investment income above, transactions are not currently reported.

- $\quad$ Loans and deposits: The MOF reports data for all public debt. In addition, there is direct reporting from the banks and major enterprises. Loans and deposits of other enterprises are obtained from the ITRS.

- $\quad$ Trade credit: Data are based on direct reporting by the eight major enterprises and agencies. They cover advance payments associated with oil imports, prepayments for imports under grant aid, copper producers, and cashmere exporters. Other trade credit, such as for general importers, is not taken into account, which may be a factor in the volatility of net errors and omissions. 
- $\quad$ Financial derivatives: These instruments are not recorded at present. The possible use of derivatives (e.g., by banks, oil importers, or commodity exporters) should be monitored. The use of derivatives has already been identified in banking statistics.

- $\quad$ Reserve assets: These data are based on direct reporting by the Accounting and Information Technology Department of BOM. The data follow international standards in terms of scope and valuation. However, transactions data are estimated from the change in the balance sheet values between the beginning and end of the period and accordingly include the effect of holding gains and losses as well as transactions. (For example: an increase in reserve assets in US dollar terms due to the appreciation of reserve assets denominated in euros does not arise from a transaction, so will have no counterpart credit entry; misattributing this increase as a transaction will contribute to an imbalance in the data.)

Since the coding and identification of economy of residence for the ITRS are undertaken by bank clerks, there may be departures from definitions (for example, BOM staff have sometimes identified implausibly large values for particular items.) BOM staff seek to ensure proper coding by annual or more frequent courses for staff in the commercial banks who report for the ITRS. In addition, BOM provides detailed documentation, responds to numerous queries from commercial banks, and goes back to banks for explanation or correction of unclear or anomalous individual transactions. The ITRS is limited to domestic banks, so transactions by Mongolian enterprises through accounts held abroad are omitted, except for the eight major enterprises involved in direct reporting.

The timing used in the ITRS is according to time of payment, rather than on an accrual basis. No adjustments are made to an accrual basis, although BOM staff consider that payments generally approximate change of ownership reasonably closely. The pattern of net errors and omissions in Mongolia shows large quarterly fluctuations between positive and negative, which tends to suggest that some entries are recorded with timing that is inconsistent with the corresponding financial flows.

The transactions of foreign exchange bureaus are not recorded. Potentially significant values of informal trade, remittances, and possibly other items, are conducted through these dealers, and so are omitted from the ITRS. The net purchases of foreign exchange or togrog by foreign exchange bureaus from the banks are not monitored. Foreign exchange bureaus are under the control of the Financial Regulatory Commission, rather than BOM. The Commission is in the process of developing data collection from bureaus, so it is important that BOM International Department staff be involved in this process so that balance of payments statistical requirements are taken into account in these decisions. It would also be useful to identify the net transactions of foreign exchange bureaus with the banks to see whether they are major buyers or sellers of foreign currency. 


\section{Recommendations:}

- $\quad$ Review gaps and problems on a continuing basis to see if they become more significant.

- $\quad$ Monitor new economic developments, such as free trade zones and commercial bond issues, to see if they require additional sources of data to be developed.

- $\quad$ Conduct a further survey of remittance recipients on channels used for sending remittances, and incorporate adjustment ratios to account for the proportion of remittances outside the ITRS.

- Use the enterprise survey to identify the scope of omitted reinvested earnings, dividends in kind, and intercompany lending for direct investment in Mongolia.

- $\quad$ Consult with the Financial Regulatory Commission to collect data on international transactions made through foreign exchange bureaus to meet the needs of balance of payments statistics.

- $\quad$ Attempt to exclude holding gains and losses from reserve assets transactions, by direct reporting from the BOM Accounting and Information Technology Department or making calculations separately for each major currency and gold.

\subsubsection{Source data are timely.}

Trade data are provided monthly within two weeks of the end of the month. ITRS data are also provided monthly by each of the banks within a few days of the end of the month. Direct reporters also provide data on a timely basis.

BOM staff contact all the data providers in advance to ensure that they are aware of BOM needs, that any problems are identified in advance, and that information is received on time.

\subsection{Assessment of source data}

\subsubsection{Source data-including censuses, sample surveys, and administrative records-are} routinely assessed, e.g., for coverage, sample error, response error, and nonsampling error; the results of the assessments are monitored and made available to guide statistical processes.

The BOM International Department checks the quality of ITRS data through various checking mechanisms. ITRS records are supplied separately for each bank transaction involving nonresidents, of which there are usually several thousand per month. Techniques used include drop-down software menus to validate coding, visual inspection of large amounts, following up vague descriptions and descriptions not matching the transaction 
code, and querying uncategorized data. When problems are detected, the relevant bank is called, and the transaction is rechecked, corrected, and resubmitted by the commercial bank to BOM. Large-value transactions are regularly confirmed with the banks or with the operators themselves.

Direct investment transactions are checked against direct investment commitments identified by FIFTA, so that all new direct investment projects are included. Some cases of exports to parent companies that are not paid for in full were identified and treated as implied dividends.

Response rates from surveys are monitored. Data are compared over time to identify anomalous movements. Some possible checks are not routinely done, because the staff consider them inconclusive. For example: the value of inwards goods for processing are not compared with outward goods; trade data derived from customs are not compared with the corresponding ITRS entries.

Special attention is given to check the transactions of the eight major enterprises included by direct reporting. Because there is a small number of large corporations with a large impact on the economy, BOM takes special efforts to ensure their correct inclusion in the statistics, through these companies' membership of the working group, other contact with the companies, and cross-checking against what is reported for these companies in the ITRS.

\subsection{Statistical techniques}

\subsubsection{Data compilation employs sound statistical techniques to deal with data sources.}

The BOM International Department receives the source data in hard (paper) and soft (electronic) formats. Processing of data is done by BOM staff using Excel. Questionable values are identified and queried, with adjustments made when reporting mistakes are confirmed by the data supplier. The BOM has a longer-term objective of developing an integrated database that would facilitate comparison with previous periods and other datasets (such as bank reporting for monetary statistics) and automated validation checks.

Enterprise survey data are checked in relation to previous data and for internal consistency. However, there are no procedures for adjusting for nonresponse. Absence of such adjustments brings a downward bias to numbers and can distort year-to-year comparisons if response rates vary.

\section{Recommendation:}

- Develop procedures to estimate nonresponse in the enterprise survey. 


\subsubsection{Other statistical procedures (e.g., data adjustments and transformations, and statistical analysis) employ sound statistical techniques.}

In compiling the balance of payments, the BOM International Department makes a number of adjustments to respect the methodological principles set forth in BPM5.

Differences in the practices used for foreign trade data and balance of payments statistics are taken into consideration. Trade statistics from customs are compiled on a c.i.f. basis, while data are required on a free on board (f.o.b.) basis for balance of payments statistics, so as to exclude insurance and freight services from the price of the good. A ratio derived from customs declarations is used to make the adjustment, which is a single ratio for aggregate imports. The ratio is updated every one or two years to take into account changes in the composition of imports, changes in freight charges, etc.

Adjustments are made to ITRS data for travel (where many transactions occur outside the banking system) and services provided by the eight major enterprises that use direct reporting (for example, netting of inward and outward telecommunications services in bank payments is avoided by direct reporting).

No seasonal adjustment is undertaken, although seasonal patterns are recognized in goods, transportation, and travel.

\subsection{Assessment and validation of intermediate data and statistical outputs}

\subsubsection{Intermediate results are validated against other information, where applicable.}

Data from the ITRS are verified by crosschecking with information reported by other agencies, for example, in the case of the public foreign debt, data on drawings and repayments are compared with those from the MOF on public debt management or with public enterprises and institutions. Data provided by FIFTA on direct investment commitments and high value projects reported in the press are compared with the corresponding direct investment data to make sure all direct investment relationships are covered. However, data on dividends and reinvested earnings are not checked against the exports of direct investment enterprises. (The increase in export values should be offset to some extent by increased profits of foreign-owned commodity exports.)

Balance of payments information from the banking system is also cross-checked with data on external assets and liabilities of banks obtained from monetary statistics. Although partial information exists to compile an international investment position, the investment income data are not compared with the corresponding assets and liabilities to check that the rates of return are meaningful.

The staff monitor economic developments reported in the press, but they are not always fully taken into account by the adoption of new methods. As the Mongolian economy becomes more open and complex, the balance of payments system needs to be updated simultaneously 
or in advance of such changes, rather than lagging. For example, no procedures have yet been developed as to how the free trade zones will be recorded, and publicity on share market trading and bond issues, but there have been no investigations as to how these items will be incorporated in balance of payments statistics.

\section{Recommendations:}

- Develop annual measures of international investment position. In the meantime, publish already available components on public debt and reserve assets and reserverelated liabilities.

- Introduce validation checks with the rate of return on various assets and liabilities when international investment position data are developed.

- $\quad$ Monitor the media and maintain contact with major businesses to identify new developments in the economy to be forward-looking in implementing methods to cover these developments in balance of payments statistics at the same time as they emerge.

\subsubsection{Statistical discrepancies in intermediate data are assessed and investigated.}

Statistical discrepancies in intermediate data are subjected to analysis when they occur. In this regard, crosschecks are carried out regularly between the information provided by banks and that collected from the principal economic operators. However, the total values of transactions reported for the ITRS for each bank are not reconciled with the opening and closing balance sheets of the banks. There is no systematic reconciliation of the balance of payments financial account with the corresponding opening and closing stock data from the partial international investment position data.

\section{Recommendation:}

- Introduce reconciliation between stocks and flows when international investment position data are developed.

\subsubsection{Statistical discrepancies and other potential indicators of problems in statistical outputs are investigated.}

The "net errors and omissions" item is monitored closely for each quarterly and annual compilation of the balance of payments. For example, investigations are undertaken for large changes in the value of net errors and omissions. In ongoing work there is regular crosschecking between the different categories of data in order to identify possible sources of statistical discrepancy. 
Bilateral reconciliations of trade flows are not undertaken. However, because of transshipment trade through Russia and China of goods sourced from third countries, these efforts are considered to be of limited value.

\subsection{Revision studies}

\subsubsection{Studies and analyses of revisions are carried out routinely and used internally to inform statistical processes (see also 4.3.3).}

The balance of payments statistics compilers maintain records on revisions made each quarter, by comparing old and new values for each item. Where significant, they provide comments and footnotes in the relevant text and tables, however there is no regularly published overview table to show revisions.

There are no long-term studies of revision patterns. By comparing a value initially published with the value published for it some years later, it may sometimes be possible to identify indicators of systematic bias. For example, missing reports in early data may lead to systematic upward revisions over time.

\section{Recommendations:}

- $\quad$ Prepare a standard table comparing data in the latest period with the corresponding data in previous releases and provide written explanations.

- $\quad$ Carry out longer term studies of revisions, if suitable investigatory staff are available.

\section{Serviceability}

\subsection{Periodicity and timeliness}

\subsubsection{Periodicity follows dissemination standards.}

Balance of payments statistics are published on a quarterly and annual basis.

The periodicity satisfies the GDDS guideline for annual data with quarterly data encouraged. It also satisfies the SDDS requirement for quarterly data. SDDS requirements for external sector statistics are satisfied for balance of payments as well as merchandise trade, reserves, and exchange rates; however, data on external debt and international investment position are not published.

\subsubsection{Timeliness follows dissemination standards.}

Quarterly balance of payments statistics are generally published within six weeks of the end of the reference quarter. (The data for the second quarter of 2007 will be released later than usual, because of other priority work.) 
The timeliness satisfies the GDDS guideline for data to be published within six months of the end of the period. It also satisfies the SDDS requirement for quarterly data within one quarter of the end of the period.

\subsection{Consistency}

\subsubsection{Statistics are consistent within the dataset.}

Quarterly and annual data are consistent. The balance of payments credit and debit entries are balanced, with the difference shown as net errors and omissions, which are monitored closely.

\subsubsection{Statistics are consistent or reconcilable over a reasonable period of time.}

Long-term time series from 1989 to the first quarter of 2007 are available on the web site of the BOM. Some methodological changes are flagged and explained to users in the notes accompanying the publication and the web site.

Revised methods are carried back to earlier periods where possible. In some cases, backdating is not practical, as for example with the recent identification of reinvested earnings. Where such breaks in the series occur, they are noted in the accompanying text.

\subsubsection{Statistics are consistent or reconcilable with those obtained through other data sources and/or statistical frameworks.}

Balance of payments data are consistent with exports and imports of goods and services in the national accounts, although they differ in presentation due to conversion of data to togrogs in the national accounts.

Balance of payments statistics are consistent with monetary statistics, with both datasets based on direct reporting by the banks of their foreign assets and liabilities. The balance of payments and monetary statistics compilation staff also consult each other to develop consistent treatments on topics such as residence and classification. Differences may occur in practice because of different vintages of data, with monetary statistics compiled monthly. Comparison should take into account that the monetary data are stocks in togrogs, while balance of payments data are transactions in US dollars.

The balance of payments differ from government finance statistics on external financing, because of independent sources, and there is no process of comparison and reconciliation.

\section{Recommendation:}

- $\quad$ Conduct routine checks of balance of payments with overlapping items as published in monetary and government finance statistics and attempt to explain discrepancies. 


\subsection{Revision policy and practice}

\subsubsection{Revisions follow a regular and transparent schedule.}

The quarterly data are compiled initially on a provisional basis and revisions are made on each quarter's statistics when the final annual figures are established. Given the publication schedule for the data, revisions are made for the final annual balance of payments reports. There is no published statement of revisions policy.

\section{Recommendation:}

- $\quad$ Publish a revisions policy on the BOM website and refer to it in the balance of payments publication.

\subsubsection{Preliminary and/or revised data are clearly identified.}

The preliminary data (quarterly and annual) are published clearly identifying them as preliminary. For example, this is stated in the current quarterly publication for relevant components.

\subsubsection{Studies and analyses of revisions are made public (see also 3.5.1).}

Where there are significant methodological changes, the reasons are noted in the quarterly and annual publications. For example, the first quarter 2007 publication states that revisions were "made revisions to the preliminary data due to changes in net income account" and "increase in reinvested earnings caused the decrease in the net income account." The longterm tables have footnotes on two major changes in methods (concerning gold and imports valuation) that caused breaks in the series.

\section{Accessibility}

\subsection{Data accessibility}

\subsubsection{Statistics are presented in a way that facilitates proper interpretation and meaningful comparisons (layout and clarity of text, tables, and charts).}

The balance of payments statistics are published in general accordance with the standard components of the BPM5. However, data are more aggregated than the BPM5 standard components, so the table covers just more than a page. It may also be useful to use classifications that would allow the appraisal of mining sector-related external transactions.

The quarterly and annual publications also contain additional tables and graphs that trace the behavior of the principal components. The reports also contain detailed analyses of the economic and trade situation during the period under review. The commentary and additional 
material covered 14 pages in the 2006 publication and 11 pages in the publication for the first quarter of 2007.

Each time a balance of payments publication is released, a press release is issued by the public relations specialist in the BOM Administration Department. The press release shows the main highlights in a simplified form designed for use by the media.

\subsubsection{Dissemination media and format are adequate.}

Balance of payments statistics are published in dedicated publications (hard copy) and are posted on the BOM website (http:/www.mongolbank.mn/web/guest/statistics) in pdf format.

In addition to the regular quarterly and annual publications, which show only very short time series, another tabulation containing long time series is provided on the BOM web site.

Balance of payments data are also included in the BOM Annual Report and the NSO Monthly Bulletin.

\subsubsection{Statistics are released on a preannounced schedule.}

The BOM International Department announces a data publication schedule in advance to its principal users and on the web site in Mongolian and English (available at http://www.mongolbank.mn/web/guest/cal ).

\subsubsection{Statistics are made available to all users at the same time.}

The BOM International Department posts the balance of payments annual and quarterly publications on BOM's web site. As a result, all users are able to access the information at the same time. As a longer-term objective, a fixed time of publication (such as 9:00 a.m. on the release day) would further assure that all users would know the exact time of release.

\subsubsection{Statistics not routinely disseminated are made available upon request.}

Unpublished subsets of data are provided to users upon request, in hardcopy or electronically, provided there are no confidentiality concerns. The availability of additional statistics and the contact information for obtaining them are made known to the public by being stated in the publication. 


\subsection{Metadata accessibility}

5.2.1 Documentation on concepts, scope, classifications, basis of recording, data sources, and statistical techniques is available, and differences from internationally accepted standards, guidelines, or good practices are annotated.

Some methodological issues of interest are included briefly in the commentary on the quarterly and annual reports of the balance of payments. They indicate the concepts, the scope, the coverage, the classifications, and data sources.

The GDDS web site (http://dsbb.imf.org; linked to from the NSO web site) provides more complete metadata produced by the BOM on Mongolia's balance of payments statistics, including information on concepts, definitions, classifications, data sources, compilation methods, and other relevant methodological aspects and procedures, as well as deviations from international standards. Furthermore, more detailed information is supplied by the BOM and published in the IMF's Balance of Payments Statistics Yearbook, Part 3.

The Balance of Payments Sources and Methods Manual and Manual on the ITRS are two sets of documentation of the balance of payments compilation system. The former has 42 pages, the latter 10 pages. Both are available in Mongolian. They are designed primarily for BOM compilation staff and for data suppliers, and are supplied to members of the Working Group on Balance of Payments Statistics, which includes users. They are also made available to interested users who seek more detailed information on the balance of payments compilation system. The BOM publications would be improved by providing a listing of available metadata and giving links.

\subsubsection{Levels of detail are adapted to the needs of the intended audience.}

The levels of detail in the different methodological notes discussed in 5.2.1 above provide a range of levels of detail. Based on feedback from users, these notes are considered by BOM to be suitable for meeting users' needs.

\subsection{Assistance to users}

\subsubsection{Contact points for each subject field are publicized.}

The quarterly and annual balance of payments publications indicate the names, positions, functions, e-mail addresses, telephone number, and fax number of contact persons. The BOM staff respond to users' requests or direct them to the appropriate contact point.

\subsubsection{Catalogs of publications, documents, and other services, including information on} any charges, are widely available.

The BOM web site lists BOM publications available in Mongolian and English (see www.mongolbank.mn/web/guest/statistics and 
www.mongolbank.mn/web/guest/pubications). There are no charges for these publications. However, the listing is not in the form of a catalog with information on services and prices.

\section{Recommendation:}

- $\quad$ Publish a catalog of publications and services along with their prices. 
Table 5. Mongolia: Data Quality Assessment Framework (July 2003): Summary of Results for Balance of Payments Statistics (Compiling Agency: Bank of Mongolia)

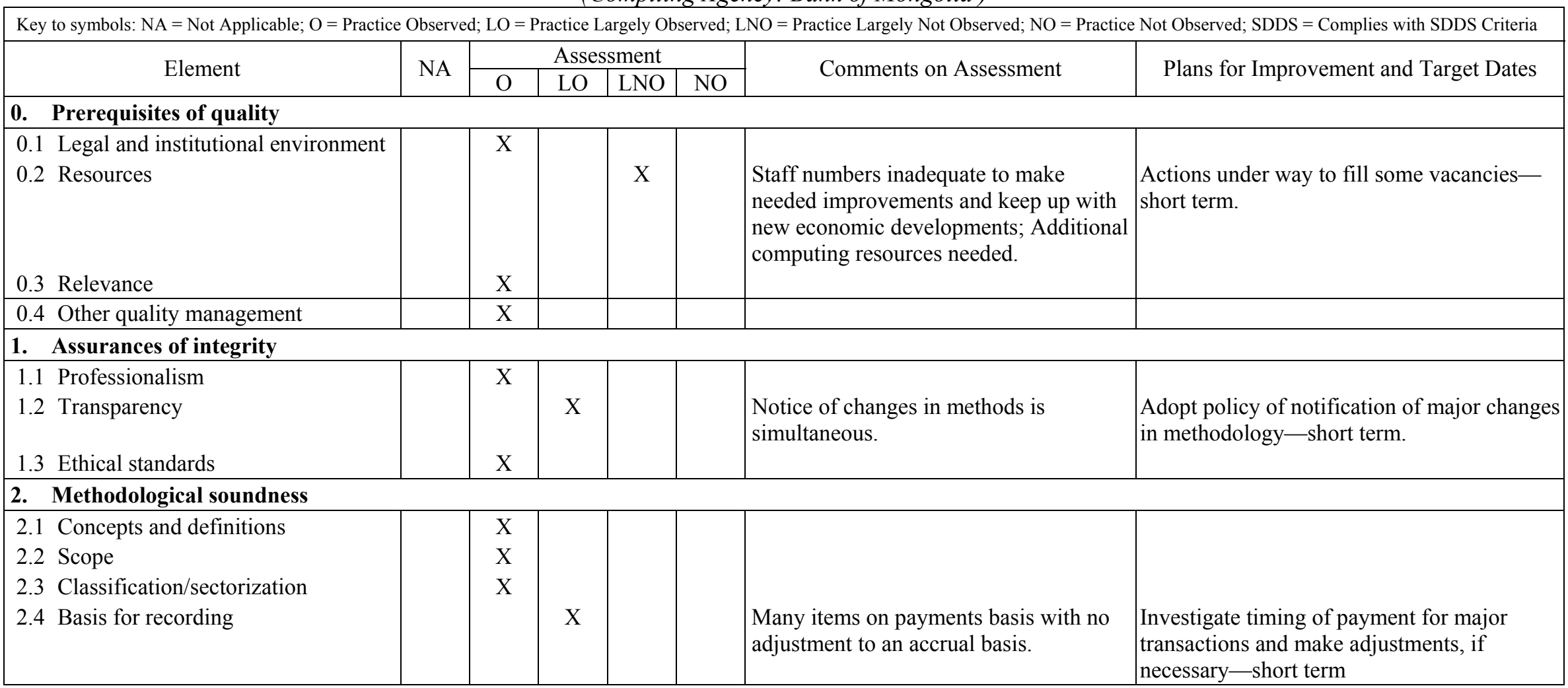

\section{Accuracy and reliability}

\begin{tabular}{|c|c|c|c|c|}
\hline 3.1 Source data & & $\mathrm{X}$ & $\begin{array}{l}\text { Measures lacking for some areas, } \\
\text { including informal trade, cash } \\
\text { remittances, transactions of foreign } \\
\text { exchange bureaus, some trade credit. }\end{array}$ & $\begin{array}{l}\text { Undertake measures to improve measurement } \\
\text { of selected components-long term. }\end{array}$ \\
\hline $\begin{array}{l}\text { 3.2 Assessment of source data } \\
\text { 3.3 Statistical techniques }\end{array}$ & $\mathrm{X}$ & $\mathrm{X}$ & $\begin{array}{l}\text { No estimation for missing data in } \\
\text { enterprise survey. }\end{array}$ & $\begin{array}{l}\text { Develop procedures for missing } \\
\text { enterprises-short term. }\end{array}$ \\
\hline
\end{tabular}


Table 5. Mongolia: Data Quality Assessment Framework (July 2003): Summary of Results for Balance of Payments Statistics (Compiling Agency: Bank of Mongolia)

\begin{tabular}{|c|c|c|c|c|c|c|c|}
\hline \multicolumn{8}{|c|}{ Key to symbols: NA = Not Applicable; $\mathrm{O}=$ Practice Observed; $\mathrm{LO}=$ Practice Largely Observed; $\mathrm{LNO}=$ Practice Largely Not Observed; NO $=$ Practice Not Observed; SDDS $=$ Complies with SDDS Criteria } \\
\hline \multirow{2}{*}{ Element } & \multirow{2}{*}{ NA } & \multicolumn{4}{|c|}{ Assessment } & \multirow{2}{*}{ Comments on Assessment } & \multirow{2}{*}{ Plans for Improvement and Target Dates } \\
\hline & & $\mathrm{O}$ & LO & LNO & $\mathrm{NO}$ & & \\
\hline $\begin{array}{l}\text { 3.4 Assessment and validation of inter- } \\
\text { mediate data and statistical outputs }\end{array}$ & & & $\mathrm{X}$ & & & No checking with position data. & $\begin{array}{l}\text { Do checks with partial position data-short } \\
\text { term. Publish international investment } \\
\text { position-long term. }\end{array}$ \\
\hline 3.5 Revision studies & & & $\mathrm{X}$ & & & No long-term analysis of revisions. & Do further analysis of revisions-long term. \\
\hline \multicolumn{8}{|l|}{ 4. Serviceability } \\
\hline 4.1 Periodicity and timeliness & & $\mathrm{X}$ & & & & & \\
\hline 4.2 Consistency & & & $\mathrm{X}$ & & & $\begin{array}{l}\text { Differences with government finance } \\
\text { statistics not reconciled. }\end{array}$ & $\begin{array}{l}\text { Investigate causes of discrepancies with } \\
\text { government finance statistics-medium term }\end{array}$ \\
\hline 4.3 Revision policy and practice & & & $\mathrm{X}$ & & & Revision policy not published. & Publish revisions policy_-short term \\
\hline \multicolumn{8}{|l|}{ 5. Accessibility } \\
\hline 5.1 Data accessibility & & $\mathrm{X}$ & & & & & \\
\hline 5.2 Metadata accessibility & & $\mathrm{X}$ & & & & & \\
\hline 5.3 Assistance to users & & & $\mathrm{X}$ & & & No published catalog & Publish catalog-short term \\
\hline
\end{tabular}




\section{Appendix I. Summary of the General Data Dissemination System (GDDS)}

\section{Data coverage, periodicity, and timeliness}

Dissemination of reliable, comprehensive, and timely economic, financial, and sociodemographic data is essential to the transparency of macroeconomic performance and policy. The GDDS contains specific recommendations concerning coverage, periodicity, and timeliness for comprehensive frameworks as well as for data categories and indicators.

\section{Quality}

Data quality must have a high priority. Data users must be provided with information to assess quality and quality improvements. The GDDS recommends:

- dissemination of documentation on methodology and sources used in preparing statistics; and

- $\quad$ dissemination of component detail, reconciliations with related data, and statistical frameworks that support statistical cross-checks and provide assurance of reasonableness.

\section{Integrity}

To fulfill the purpose of providing the public with information, official statistics must have the confidence of their users. In turn, confidence in the statistics ultimately becomes a matter of confidence in the objectivity and professionalism of the agency producing the statistics. Transparency of practices and procedures is a key factor in creating this confidence. The GDDS, therefore, recommends:

- dissemination of the terms and conditions under which official statistics are produced, including those relating to the confidentiality of individually identifiable information;

- $\quad$ identification of internal government access to data before release;

- identification of ministerial commentary on the occasion of statistical releases; and

- $\quad$ provision of information about revision and advance notice of major changes in methodology. 


\section{Access to the public}

Dissemination of official statistics is an essential feature of statistics as a public good. Ready and equal access by the public are principal requirements. The GDDS recommends:

- $\quad$ dissemination of advance release calendars; and

- $\quad$ simultaneous release to all interested parties.

\section{Plans for improvement}

The GDDS recommends that plans for improvement be developed for all areas in which shortcomings exist and that these plans be disseminated.

The GDDS also recommends that any needs for assistance be identified in the metadata. This may also be helpful for donors and technical assistance providers to prioritize their activities.

For each participating member country, the GDDS metadata provide descriptions of the dimensions listed above, together with plans for improvement and needs for assistance. This information is posted on the DSBB; participating countries are encouraged to also post the metadata on their national websites.

Source: Guide to the GDDS, March 2002: http://dsbb.imf.org 


\section{Appendix II. Data Quality Assessment Framework-Generic Framework (July 2003 Framework)}

\begin{tabular}{|c|c|c|}
\hline Quality Dimensions & Elements & Indicators \\
\hline \multirow[t]{4}{*}{$\begin{array}{l}\text { 0. Prerequisites of } \\
\text { quality }\end{array}$} & $\begin{array}{l}\text { 0.1 Legal and institutional } \\
\text { environment-The environment } \\
\text { is supportive of statistics }\end{array}$ & $\begin{array}{l}\text { 0.1.1 The responsibility for collecting, processing, } \\
\text { and disseminating the statistics is clearly specified. } \\
\text { 0.1.2 Data sharing and coordination among data- } \\
\text { producing agencies are adequate. } \\
\text { 0.1.3 Individual reporters' data are to be kept } \\
\text { confidential and used for statistical purposes only. } \\
\text { 0.1.4 Statistical reporting is ensured through legal } \\
\text { mandate and/or measures to encourage response. }\end{array}$ \\
\hline & $\begin{array}{l}\text { 0.2 Resources-Resources are } \\
\text { commensurate with needs of } \\
\text { statistical programs. }\end{array}$ & $\begin{array}{l}\text { 0.2.1 Staff, facilities, computing resources, and } \\
\text { financing are commensurate with statistical } \\
\text { programs. } \\
0.2 .2 \text { Measures to ensure efficient use of resources } \\
\text { are implemented. }\end{array}$ \\
\hline & $\begin{array}{l}\mathbf{0 . 3} \text { Relevance-Statistics cover } \\
\text { relevant information on the } \\
\text { subject field. }\end{array}$ & $\begin{array}{l}\text { 0.3.1 The relevance and practical utility of existing } \\
\text { statistics in meeting users' needs are monitored. }\end{array}$ \\
\hline & $\begin{array}{l}\text { 0.4 Other quality } \\
\text { management-Quality is a } \\
\text { cornerstone of statistical work. }\end{array}$ & $\begin{array}{l}\text { 0.4.1 Processes are in place to focus on quality. } \\
\text { 0.4.2 Processes are in place to monitor the quality of } \\
\text { the statistical program. } \\
\text { 0.4.3 Processes are in place to deal with quality } \\
\text { considerations in planning the statistical program. }\end{array}$ \\
\hline \multirow{3}{*}{$\begin{array}{l}\text { 1. Assurances of } \\
\text { integrity } \\
\text { The principle of } \\
\text { objectivity in the } \\
\text { collection, } \\
\text { processing, and } \\
\text { dissemination of } \\
\text { statistics is firmly } \\
\text { adhered to. }\end{array}$} & $\begin{array}{l}\text { 1.1 Professionalism-Statistical } \\
\text { policies and practices are } \\
\text { guided by professional } \\
\text { principles. }\end{array}$ & $\begin{array}{l}\text { 1.1.1 Statistics are produced on an impartial basis. } \\
\text { 1.1.2 Choices of sources and statistical techniques } \\
\text { as well as decisions about dissemination are } \\
\text { informed solely by statistical considerations. } \\
\text { 1.1.3 The appropriate statistical entity is entitled to } \\
\text { comment on erroneous interpretation and misuse of } \\
\text { statistics. }\end{array}$ \\
\hline & $\begin{array}{l}1.2 \text { Transparency_Statistical } \\
\text { policies and practices are } \\
\text { transparent. }\end{array}$ & $\begin{array}{l}\text { 1.2.1 The terms and conditions under which } \\
\text { statistics are collected, processed, and disseminated } \\
\text { are available to the public. } \\
\text { 1.2.2 Internal governmental access to statistics prior } \\
\text { to their release is publicly identified. } \\
\text { 1.2.3 Products of statistical agencies/units are } \\
\text { clearly identified as such. } \\
\text { 1.2.4 Advance notice is given of major changes in } \\
\text { methodology, source data, and statistical techniques. }\end{array}$ \\
\hline & $\begin{array}{l}\text { 1.3 Ethical standards-Policies } \\
\text { and practices are guided by } \\
\text { ethical standards. }\end{array}$ & $\begin{array}{l}\text { 1.3.1 Guidelines for staff behavior are in place and } \\
\text { are well known to the staff. }\end{array}$ \\
\hline
\end{tabular}




\begin{tabular}{|c|c|c|}
\hline Quality Dimensions & Elements & Indicators \\
\hline $\begin{array}{l}\text { 2. Methodological } \\
\text { soundness } \\
\text { The methodological } \\
\text { basis for the } \\
\text { statistics follows } \\
\text { internationally } \\
\text { accepted standards, } \\
\text { guidelines, or good } \\
\text { practices. }\end{array}$ & $\begin{array}{l}\text { 2.1 Concepts and definitions-- } \\
\text { Concepts and definitions used } \\
\text { are in accord with } \\
\text { internationally accepted } \\
\text { statistical frameworks. } \\
\mathbf{2 . 2} \text { Scope-The scope is in } \\
\text { accord with internationally } \\
\text { accepted standards, guidelines, } \\
\text { or good practices. } \\
\mathbf{2 . 3} \text { Classification/ } \\
\text { sectorization-Classification } \\
\text { and sectorization systems are in } \\
\text { accord with internationally } \\
\text { accepted standards, guidelines, } \\
\text { or good practices. } \\
\mathbf{2 . 4} \text { Basis for recording-Flows } \\
\text { and stocks are valued and } \\
\text { recorded according to } \\
\text { internationally accepted } \\
\text { standards, guidelines, or good } \\
\text { practices }\end{array}$ & $\begin{array}{l}\text { 2.2.1 The scope is broadly consistent with } \\
\text { internationally accepted standards, guidelines, or } \\
\text { good practices. } \\
\text { 2.3.1 Classification/sectorization systems used are } \\
\text { broadly consistent with internationally accepted } \\
\text { standards, guidelines, or good practices. }\end{array}$ \\
\hline $\begin{array}{l}\text { 3. Accuracy and } \\
\text { reliability } \\
\text { Source data and } \\
\text { statistical techniques } \\
\text { are sound and } \\
\text { statistical outputs } \\
\text { sufficiently portray } \\
\text { reality }\end{array}$ & $\begin{array}{l}\text { 3.3 Statistical techniques-- } \\
\text { Statistical techniques employed } \\
\text { conform to sound statistical } \\
\text { procedures } \\
\text { 3.4 Assessment and validation } \\
\text { of intermediate data and } \\
\text { statistical outputs- } \\
\text { Intermediate results and } \\
\text { statistical outputs are regularly } \\
\text { assessed and validated. } \\
\text { 3.5 Revision studies- } \\
\text { Revisions, as a gauge of } \\
\text { reliability, are tracked and } \\
\text { mined for the information they } \\
\text { may provide. }\end{array}$ & $\begin{array}{l}\text { 3.1.1 Source data are obtained from comprehensive } \\
\text { data collection programs that take into account } \\
\text { country-specific conditions. } \\
\text { 3.1.2 Source data reasonably approximate the } \\
\text { definitions, scope, classifications, valuation, and } \\
\text { time of recording required. } \\
\text { 3.1.3 Source data are timely. } \\
\text { 3.2.1 Source data-including censuses, sample } \\
\text { surveys, and administrative records - are routinely } \\
\text { assessed, e.g., for coverage, sample error, response } \\
\text { error, and nonsampling error; the results of the } \\
\text { assessments are monitored and made available to } \\
\text { guide statistical processes. } \\
\text { 3.3.1 Data compilation employs sound statistical } \\
\text { techniques to deal with data sources. } \\
\text { 3.3.2 Other statistical procedures (e.g., data } \\
\text { adjustments and transformations, and statistical } \\
\text { analysis) employ sound statistical techniques. } \\
\text { 3.4.1 Intermediate results are validated against other } \\
\text { information where applicable. } \\
\text { 3.4.2 Statistical discrepancies in intermediate data } \\
\text { are assessed and investigated. } \\
\text { 3.4.3 Statistical discrepancies and other potential } \\
\text { indicators or problems in statistical outputs are } \\
\text { investigated. } \\
\text { 3.5.1 Studies and analyses of revisions are carried } \\
\text { out routinely and used internally to inform statistical } \\
\text { processes (see also } 4.3 .3 \text { ). }\end{array}$ \\
\hline
\end{tabular}




\begin{tabular}{|c|c|c|}
\hline Quality Dimensions & Elements & Indicators \\
\hline $\begin{array}{l}\text { 4. Serviceability } \\
\text { Statistics, with } \\
\text { adequate periodicity } \\
\text { and timeliness, are } \\
\text { consistent and } \\
\text { follow a predictable } \\
\text { revisions policy. }\end{array}$ & $\begin{array}{l}\text { 4.1 Periodicity and } \\
\text { timeliness_Periodicity and } \\
\text { timeliness follow internationally } \\
\text { accepted dissemination } \\
\text { standards. } \\
\text { 4.2 Consistency — Statistics are } \\
\text { consistent within the dataset, } \\
\text { over time, and with major } \\
\text { datasets. } \\
\text { 4.3 Revision policy and } \\
\text { practice-Data revisions follow } \\
\text { a regular and publicized } \\
\text { procedure. }\end{array}$ & $\begin{array}{l}\text { 4.2.1 Statistics are consistent within the dataset. } \\
\text { 4.2.2 Statistics are consistent or reconcilable over a } \\
\text { reasonable period of time. } \\
\text { 4.2.3 Statistics are consistent or reconcilable with } \\
\text { those obtained through other data sources and/or } \\
\text { statistical frameworks. } \\
\text { 4.3.1 Revisions follow a regular and transparent } \\
\text { schedule. } \\
\text { 4.3.2 Preliminary and/or revised data are clearly } \\
\text { identified. } \\
\text { 4.3.3 Studies and analyses of revisions are made } \\
\text { public (see also 3.5.1). }\end{array}$ \\
\hline $\begin{array}{l}\text { 5. Accessibility } \\
\text { Data and metadata } \\
\text { are easily available } \\
\text { and assistance to } \\
\text { users is adequate. }\end{array}$ & $\begin{array}{l}\text { 5.1 Data accessibility- } \\
\text { Statistics are presented in a } \\
\text { clear and understandable } \\
\text { manner, forms of dissemination } \\
\text { are adequate, and statistics are } \\
\text { made available on an impartial } \\
\text { basis. } \\
\text { 5.2 Metadata accessibility- } \\
\text { Up-to-date and pertinent } \\
\text { metadata are made available. } \\
\text { 5.3 Assistance to users- } \\
\text { Prompt and knowledgeable } \\
\text { support service is available. }\end{array}$ & $\begin{array}{l}\text { 5.1.1 Statistics are presented in a way that facilitates } \\
\text { proper interpretation and meaningful comparisons } \\
\text { (layout and clarity of text, tables, and charts). } \\
\text { 5.1.2 Dissemination media and format are adequate. } \\
\text { 5.1.3 Statistics are released on a preannounced } \\
\text { schedule. } \\
\text { 5.1.4 Statistics are made available to all users at the } \\
\text { same time. } \\
\text { 5.1.5 Statistics not routinely disseminated are made } \\
\text { available upon request. } \\
\text { 5.2.1 Documentation on concepts, scope, } \\
\text { classifications, basis of recording, data sources, and } \\
\text { statistical techniques is available, and differences } \\
\text { from internationally accepted standards, guidelines, } \\
\text { or good practices are annotated. } \\
\text { 5.2.2 Levels of detail are adapted to the needs of the } \\
\text { intended audience. } \\
\text { 5.3.1 Contact points for each subject field are } \\
\text { publicized. } \\
\text { 5.3.2 Catalogs of publications, documents, and other } \\
\text { services, including information on any charges, are } \\
\text { widely available. }\end{array}$ \\
\hline
\end{tabular}




\section{Appendix III. Mongolia-Analysis of survey of users}

The ROSC mission conducted a survey of users of the macroeconomic statistics disseminated by the NSO, the BOM, and the MOF to obtain the views of users on the quality of the statistics and to determine the extent to which the data are being used. Thus, the survey covered the national accounts, price statistics, government finance statistics, monetary statistics, and balance of payments statistics. The survey was designed to complement the mission's own assessment of the quality of the statistics and covered users in the public sector, commercial banks, other private commercial enterprises, international organizations, and academia.

The response to the survey was satisfactory with 36 users returning completed questionnaires. Users rated the quality of the statistics as average with the individual datasets receiving overall ratings of between 2.9 and 3.6. ${ }^{3}$ Only 45 percent of respondents rated the quality of the statistics as being as good as, or better than that of other countries in the region.

Users expressed general satisfaction with the coverage of the statistics although this satisfaction varied widely amongst the datasets. Whereas 80 percent of the users of the monetary statistics were satisfied with the coverage, only 50 percent of the users of the national accounts expressed similar satisfaction. On the other hand, users were less satisfied with the level of detail; a majority of the users of the national accounts statistics expressed dissatisfaction with the level of detail of the disseminated national accounts data.

Although all the agencies disseminate data on their websites, users accessed the majority of the data through hardcopy publications, official press releases, or specific requests to the agencies. Only 29 percent of the data were accessed through the agencies' official websites. In general, two-thirds of respondents noted that they could easily access the official statistics but the views on the ease of access varied widely amongst the datasets. Eighty-six (86) percent of users of monetary statistics noted that they could easily access the statistics compared with 57 percent of the users of the national accounts.

A large majority of users (67 percent) expressed general difficulty in accessing the metadata on the respective datasets. Further, 70 percent noted that the metadata lacked sufficient clarity and level of detail to be useful.

The comments from the survey are summarized below. The comments are categorized according to the DQAF dimensions of quality.

\footnotetext{
${ }^{3}$ Users were asked to use a scale of one to five, with five being the highest rating.
} 


\section{Appendix IV. Mongolia-Comments by Users of Macroeconomic Statistics ${ }^{4}$}

\section{Legal and Institutional Environment}

- $\quad$ National Statistical Office should improve its staff capacity and skills.

- $\quad$ The NSO needs to have enough funding, in particular budget allocated each year to be able to fulfill its obligation and meet the needs of different stakeholders.

- Look at the current Statistics Law. Usually we can't receive the useful information from NSO. If they don't provide the information for ministries, government agencies, policy making organizations, why did they collect the information.

\section{Accuracy and Reliability}

- The sources of information and data should be improved since there are a few agencies.

- The quality of data and their methodology should be improved.

- $\quad$ There is the issue of accuracy. For example, the CPI basket should be reviewed to reflect the current consumption data; PPI needs to be published; GFS needs to be consolidated on a monthly basis.

- $\quad$ The main statistics should be estimated in line with international requirements/definitions. And those institutions who issue the official statistics should have efficient cooperation.

- $\quad$ More work needs to be done to improve the GFS which is useful for future work in improving public finance and make the government accountable and transparent. It is difficult to gather needed data on government finance.

\section{Serviceability}

- In other countries, we can see monthly data for national accounts and production indexes, but for Mongolia, it is not available.

- It is confusing to see differences in methodology between official statistics and the IMF statistics (eg. CPI and monthly inflation figures).

\footnotetext{
${ }^{4}$ The comments are reproduced verbatim.
} 
- $\quad$ The main area for improvement are levels of detailed breakdown of official statistics in order to use for social research and quality of data in terms of completeness and timeliness.

- $\quad$ Improve the frequency of release.

- $\quad$ Expand and improve the range of data disseminated to the public.

- $\quad$ Factor analysis on price indexes reflecting the main reasons of increases and decreases of prices is needed.

- $\quad$ More analytical work needs to be done on balance of payments.

- $\quad$ More detailed disaggregation is needed.

- $\quad$ Such information as utilization of the budget is usually missing.

\section{Accessibility}

- Data should be accessible through internet.

- $\quad$ More specific survey data should be made available to the public (with removal of personal identification of responses).

- It is important that the official statistical data and analysis are open to the public.

- $\quad$ State and government institutions ought to be open to the public, serve the public needs, and do not charge for providing information.

Accessibility and availability needs to be improved, particularly raw data. 
Appendix Table 1. Mongolia-Results of Users' Survey

\begin{tabular}{|c|c|c|}
\hline \multicolumn{3}{|c|}{ General Information about Uses of Official Macroeconomic Statistics of } \\
\hline & & $\begin{array}{l}\text { Number of } \\
\text { Responses }\end{array}$ \\
\hline \multirow[t]{2}{*}{1.} & Which official statistics do you use regularly? & \\
\hline & $\begin{array}{l}\text { a. National accounts (NA) } \\
\text { b. Prices } \\
\text { c. Government finance statistics (GFS) } \\
\text { d. Monetary statistics (Monetary) } \\
\text { e. Balance of payments (BOP) } \\
\text { f. Other: } \\
\text { - Production indices } \\
\text { - Labor market } \\
\text { - Merchandise trade } \\
\text { - International reserves and foreign currency liquidity } \\
\text { - External debt } \\
\text { - International investment position }\end{array}$ & $\begin{array}{l}25 \\
25 \\
26 \\
27 \\
21 \\
16 \\
13 \\
13 \\
14 \\
19 \\
15 \\
4\end{array}$ \\
\hline \multirow[t]{2}{*}{2.} & Where do you obtain the national official statistics? & \\
\hline & $\begin{array}{l}\text { a. Official press releases and publications on macroeconomic statistics } \\
\text { b. Private sector summaries and analyses } \\
\text { c. Official policy papers } \\
\text { d. Publications from international organizations about the country } \\
\text { e. Other sources }\end{array}$ & $\begin{array}{c}27 \\
6 \\
20 \\
23 \\
10 \\
\end{array}$ \\
\hline \multicolumn{3}{|c|}{$\begin{array}{l}\text { 3. Do you refer to official descriptions of the sources and methods that were used to compile the } \\
\text { official statistics? }\end{array}$} \\
\hline & $\begin{array}{ll}- & \text { Yes } \\
- & \text { No }\end{array}$ & $\begin{array}{c}23 \\
5\end{array}$ \\
\hline \multirow[t]{2}{*}{4.} & For what purposes do you use official statistics? & \\
\hline & $\begin{array}{ll}\text { f. } & \text { Analysis of current developments for short-term decision making } \\
\text { g. } & \text { Analysis of trends for longer-term policy formulation? } \\
\text { h. } & \text { Econometric model building and forecasting } \\
\text { i. } & \text { Economic research } \\
\text { j. } & \text { Comparison with economic developments in other countries } \\
\text { k. } & \text { General economic background } \\
\text { l. } & \text { Other }\end{array}$ & $\begin{array}{l}21 \\
21 \\
9 \\
24 \\
14 \\
24\end{array}$ \\
\hline
\end{tabular}




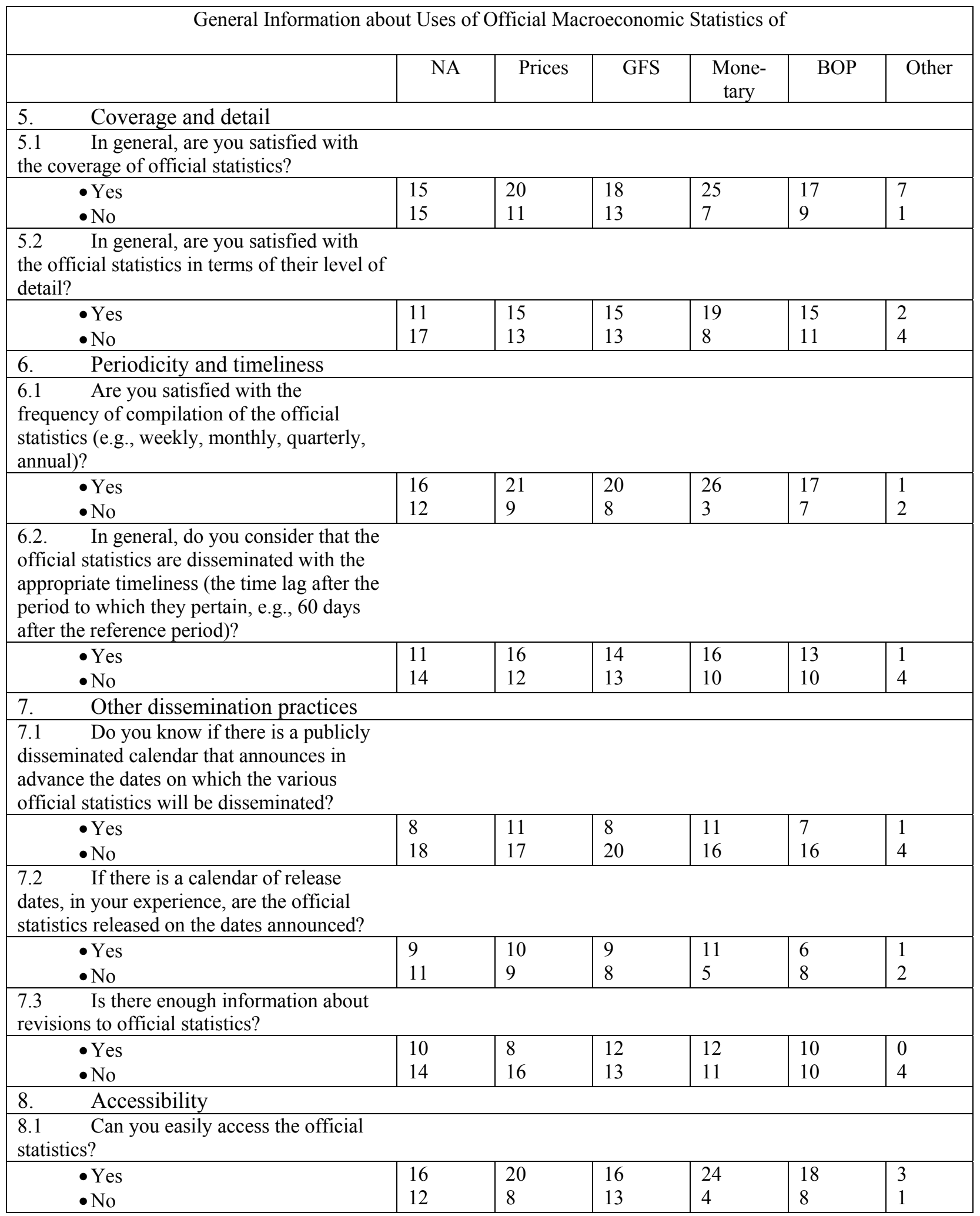




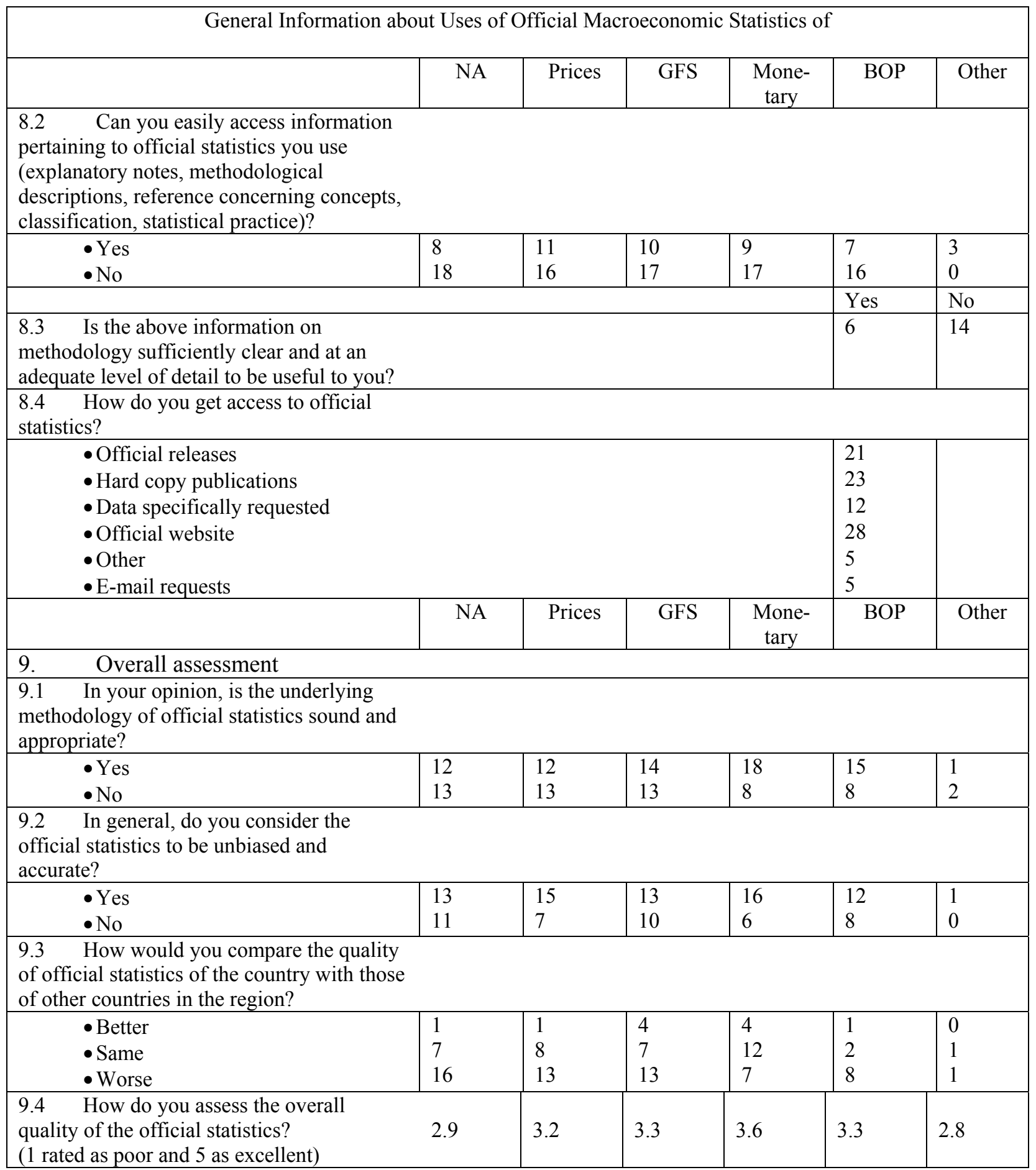

NA = National Accounts; Prices refers to: CPI (Consumer Price Index) and PPI (Producer Price Index); GFS $=$ Government Finance Statistics; Monetary $=$ Monetary Statistics; and BOP $=$ Balance of Payments Statistics 